BABELAO 1 (2012), p. 25-76

(C) ABELAO (Belgium)

\title{
Un nouveau témoin de l'Histoire des Sept Dormants d'Ephèse \\ Le manuscrit Cambridge Syr. Add. 2020. Texte et traduction
}

Par

Naïma Afif

Université de Louvain, Louvain-la-Neuve

L

'Histoire des Sept Dormants d'Ephèse a connu une large diffusion au sein de la chrétienté orientale : il en existe des versions syriaque, grecque ${ }^{1}$, copte, éthiopienne, arabe et arménienne ${ }^{2}$. Sous la persécution de Dèce (249-251), de jeunes chrétiens de noble famille (sept ou huit, selon les versions) refusent d'honorer le culte officiel. Ils se réfugient dans une caverne où condamnés à être emmurés, ils s'endorment paisiblement. Ils se réveillent alors sous le règne de Théodose (408-450) pour témoigner de la résurrection des corps et de leur incorruptibilité. Ce thème fait écho à l'aphtartodocétisme, controverse christologique qui est au centre du débat monophysite dès la seconde moitié du $5^{\mathrm{e}}$ siècle. C'est durant cette période que le texte syriaque semble

\footnotetext{
${ }^{1}$ BHG, p. 223-255.

2 Pour les références de certaines de ces versions, cf. $B H O$, p. 223 . Au-delà du christianisme oriental, on trouve une évocation des Dormants dans la sourate 18 du Coran intitulée « La caverne ».
} 
s'être développé. L'existence d'un lieu de pèlerinage consacré aux Dormants $^{3}$ a par la suite certainement contribué à la circulation du récit en Orient et en Occident ${ }^{4}$.

Dans la littérature syriaque, la tradition des Dormants nous est parvenue à travers une homélie métrique de Jacques de Saroug (m. 521) $)^{5}$ et un texte hagiographique. Ce dernier est inclus dans des manuscrits regroupant des Vies de saints ainsi que dans certaines sources historiques. Les plus importantes sont L'bistoire ecclésiastique de Zacharie le Rhéteur (m. 550) qui couvre les périodes de 450 à 491, et La Chronique de Pseudo-Denys de Tellmahré ${ }^{6}$, chronique universelle qui commence à la création du monde et se termine en 775-776.

Les acquis de la recherche sur la tradition syriaque des Dormants ont été exposés et développés par A. Allgeier ${ }^{7}$ (1915/1918), puis complétés par M. van Esbroek ${ }^{8}$ (1994). Ces recherches basées sur dix manuscrits dont la majeure partie a fait l'objet d'une édition, ont permis de mettre en évidence cinq familles de textes (cf. p. 68). La présente publication consacrée à l'édition du manuscrit Cambridge Syr. Add. 2020 (fol. 121 ${ }^{\mathrm{a}}-131^{\mathrm{a}}$ ) vient apporter un éclairage supplémentaire à ce vaste corpus. L'édition est accompagnée d'une première traduction française du texte, pour lequel on disposait principalement de traductions en allemand, en latin et en italien. Dans la deuxième partie de l'article, une étude des variantes majeures situe le témoin dans l'ensemble de la tradition manuscrite syriaque : elle laisse supposer que le manuscrit de Cambridge Syr. Add. 2020 représente une tradition distincte de l'histoire des Dormants.

${ }^{3}$ Par souci de commodité, nous dirons les Dormants pour désigner le texte généralement plus connu sous l'appellation de «Sept Dormants d'Ephèse ».

${ }^{4} \mathrm{Il}$ en existe une version latine de Grégoire de Tours ( $6^{\mathrm{e}}$ siècle).

${ }^{5}$ Nous ne l'étudierons pas dans le cadre de cette publication, consacrée essentiellement au récit sous sa forme hagiographique. Pour une édition de l'homélie, cf. I. GuIDI, "Testi orientali inediti sopra i Sette Dormienti di Efeso ", Atti della Reale Accademia dei Lincei, série 3, 12, Roma, 1884, p. 358-363. Même édition, vocalisée, dans E. GISMONDI, Linguae Syriacae grammatica et chrestomathia, Rome, 1900, p. 45-53. Pour la traduction française cf. F. JOURDAN, La tradition des Sept dormants: une rencontre entre chrétiens et musulmans, Paris, Maisonneuve, 1983, p. 59-68.

${ }^{6}$ Il s'agit de la Chronique de Zuqnin, cf. étude exhaustive de W. WiTAKOWSKI, The Syriac Chronicle of Pseudo-Dionysius of Tel-Mahre. A Study in the History of Historiography, (Acta Universitatis Upsaliensis. Studia Semitica Upsialensa 9), Uppsala, 1987.

7 A. ALLGEIER, «Untersuchungen zur syrischen Überlieferung der Siebenschläferlegende », OC 4 (1915), p. 279-297; 5 (1915), p. 10-59 et 263-271. ID., «Die älteste Gestalt de Siebenschläferlegende », OC 6 (1916), p. 1-43; 7/8 (1918), p. 33-87.

${ }^{8}$ M. VAn Esbroeck, «La légende des Sept Dormants d'Ephèse selon le codex syriaque N.S.4 de Saint-Pétersbourg ", dans R. LAVENANT (éd.), VI. Symposium Syriacum 1992 (University of Cambridge 30 August-2 September 1992), Rome, 1994, p. 189-200 (OCA 247). 


\section{Description du manuscrit Cambridge Syr. Add. 2020}

\section{L'ensemble du manuscrit}

Le manuscrit Cambridge Syr. Add. 2020 (désigné par le sigle J) a été décrit par Wright'. Il s'agit d'un manuscrit sur papier de 12 pouces sur $8(30,48 \times 20,32 \mathrm{~cm})$ composé de 190 folios dont la plupart sont sales et mutilés, particulièrement le fol. 158. Le fol. 190 est vierge. Les cahiers étaient originellement au nombre de 20 , mais les deux premiers et une partie du troisième ont été perdus et remplacés par un ajout moderne (folio 1 à 5). Les cahiers restants contiennent 10 folios exceptés les cahiers 8,22 et 5 . Il y a une lacune après le fol. 184. L'écriture syro-orientale est vocalisée avec des points voyelles chaldéens. Le texte est disposé en une colonne d'écriture de 27 à 30 lignes par page.

Le manuscrit possède un colophon (fol. $188^{\mathrm{b}}-189^{\mathrm{a}}$ ) nous indiquant que la copie en a été achevée à Alqoš ${ }^{10}$ en l'année $2009^{11}$ c'est-à-dire en 1697 de l'ère chrétienne, pour l'église de Mār Miles à Tell-Haš ou Tell-Heš. Il s'agit actuellement du village de Tell Hišaf à $6 \mathrm{~km}$ d'Alqoš $^{12}$. Le copiste est un prêtre dénommé Hormizd bar Hadhbešabā bar Israël d'Alqoš. Les dépenses et moyens d'exécution de la copie ont été assurés par un prêtre du nom de Yāldā et une femme du nom de Zìzè.

Le manuscrit contient essentiellement des vies de saints, des passions, des proverbes, et des matières théologiques. Parmi les martyrs et les saints cités, on compte d'éminents personnages locaux : Rabban Hormidz, fondateur du couvent du même nom au nord de l'Iraq près d'Alqoš, l'évêque de Miles et Mār Daniel. Le premier était fêté le troisième jour après le vendredi de la résurrection; on a ensuite un exposé sur la résurrection des morts. Le dernier texte concerne l'histoire de Marie, mais nous ignorons s'il y est question de la Dormition et donc d'un thème proche de notre récit:

1. Histoire de Mār Hormizd, l'anachorète persan, fol. $1^{\mathrm{b}}-41^{\mathrm{b}}$.

2. Sur la résurrection des morts et les événements du Jour Dernier, fol. $42^{\mathrm{b}}-52^{\mathrm{b}}$.

3. L'histoire de Yohanan bar Malkē ou Jean de Rome, fol.

\footnotetext{
${ }^{9} \mathrm{~W}$. WRIGHT, A Catalogue of the Syriac Manuscripts preserved in the Library of the University of Cambridge, vol. 2, Cambridge, 1901, p. 583-589.

${ }^{10}$ Important village au nord de la plaine de Mossoul, voisin du couvent de Rabban Hormizd, longtemps résidence des patriarches syro-orientaux, cf. J.-M. FIEY, Pour un Oriens Christianus novus : répertoire des diocèses syriaques orientaux et occidentaux (Beiruter Texte und Studien 49), Stuttgart, 1993, p. 49.

${ }^{11}$ Selon le calendrier des Séleucides ou ère d'Alexandre qui débute le $1^{\text {er }}$ octobre (du calendrier julien) 312 A.C., cf. V. GRUMEL, Traité d'études byzantines. 1, La chronologie (Bibliothèque byzantine), Paris, 1958, p. 210.

${ }^{12} \mathrm{~J}$.-M. FIEY, Assyrie chrétienne. Contribution à l'étude de l'histoire et de la géographie ecclésiastiques et monastiques du nord de l'Iraq, vol. 2, Beyrouth, 1965, p. 324.
} 
$52^{\mathrm{b}}-61^{\mathrm{a}}$.

4. Le martyre de l'évêque Miles, du prêtre Abōrsām et du diacre Sinnai, fol. $61^{a}-66^{a}$.

5. Les proverbes ou l'histoire d'Ahîkar le sage, fol. $66^{\mathrm{a}}-78^{\mathrm{a}}$.

6. Un bref extrait des Proverbes de Salomon, fol. $78^{\mathrm{a}}$.

7. Fables du sage Esope, fol. $78^{a}-82^{a}$.

8. L'histoire de Mār Yāreth d'Alexandrie, fol. 82 $2^{\mathrm{a}}-97^{\mathrm{a}}$.

9. Le martyre de George et Antonine et de la reine Alexandra, fol. $97^{\mathrm{a}}-105^{\mathrm{b}}$.

10. Autres fables d'Esope, fol. $105^{\mathrm{b}}-109^{\mathrm{a}}$.

11. L'histoire de Mār Yohanan de Dailam en mètres de douze syllabes, fol. $109^{\mathrm{a}}-120^{\mathrm{b}}$.

12. L'histoire des huit jeunes gens d'Ephèse, fol. $121^{\mathrm{a}}-131^{\mathrm{a}}$.

13. L'histoire de Mār Christophos, fol. $131^{\mathrm{a}}-141^{\mathrm{b}}$.

14. L'histoire de Mār Daniel, fol. $141^{\mathrm{b}}-153^{\mathrm{b}}$.

15. L'histoire de la Vierge Marie, fol. $153^{\mathrm{b}}-184$.

Le programme du manuscrit indique que le texte des Dormants était intégré dans le cadre d'une liturgie annuelle festive. Les vies pieuses et les passions devaient êtres lues au jour correspondant à la célébration des saints en fonction des fêtes et du calendrier. De nombreux ménologes syriaques mentionnent en effet la célébration du martyre des Dormants à différentes dates. Dans la tradition syrienne occidentale, on célèbre les enfants d'Ephèse, les $2^{13}$ et 13 août $\mathrm{t}^{14}$. Un ménologe daté du $12^{\mathrm{e}}$ siècle les célèbre le 20 avril ${ }^{15}$. Le martyrologe de Rabban Sliba, daté de la fin du $13^{\text {e }}$ siècle, nous donne la date du 2 août pour leur martyre et place leur réveil le 24 octobre $^{16}$. Dans le calendrier oriental récent, ils sont fêtés le 4 octobre et chez les Syriaques occidentaux, le 24 octobre $^{17}$.

\section{Les folios édités (fol. $121^{\mathrm{a}}-131^{\mathrm{a}}$ )}

Le texte est disposé en une colonne d'écriture de 27 à 30 lignes par page et parfois l'alignement à gauche des lignes est obtenu par la dilatation de l'écriture du dernier mot en un simple trait horizontal. Le quadruple point final * sépare le titre du texte et marque la fin du texte. L'écriture est régulière et claire; le texte est vocalisé mais le titre et l'explicit sont illisibles car écrits avec une

13 F. NAU, «Martyrologes et ménologes orientaux. Un martyrologe et douze ménologes syriaques », dans PO, 10, fasc.1, Turnhout, 1912, p. 83 et 125.

${ }^{14}$ ID., p. 101 et 112.

15 ID., p. 55.

16 P. PeEters, «Le martyrologe de Rabban Sliba », dans $A B 27$ (1908), p. 190 et 166.

${ }^{17}$ J.-M. FIEY, Saints syriaques (Studies in Late Antiquity and Early Islam 6), Princeton, 2004, p. 74. 
encre de couleur différente de celle du corps du texte. Le copiste a recours par endroit à des abréviations : les finales sont réduites à un trait de forme très simple placé au-dessus de la dernière lettre.

On trouve également en marge des additions du copiste même. Ce sont des mots omis dans le texte. Au fol. $124^{\text {b }}$, à la cinquième ligne, deux mots sont raturés; deux points entourés d'un demicercle posé en vis-à-vis nous renvoie à la marge droite où la correction s'étend verticalement des lignes 5 à 10 : حسم حله احتك $\sim \mathrm{x}$.

Au fol. $128^{\mathrm{a}}$, à la septième ligne, le copiste nous renvoie dans la marge à droite, où il écrit une portion de texte qu'il a visiblement omise. Il utilise un signe composé de deux petits demi-cercles situés en haut et en bas d'un point. Le texte est écrit verticalement

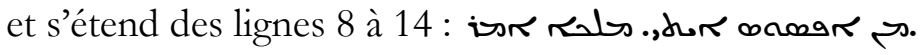

La seule numérotation que nous pouvons observer a été apposée à une époque moderne en chiffre arabe et à l'angle extérieur du fol. $121^{\mathrm{a}}$, ainsi que dans la marge inférieure des fol. $124^{\mathrm{b}}$ et $125^{\mathrm{a}}$ où des lettres en caractères gras, entourées de sobres ornementations, indiquent la numérotation des cahiers 13 et $14^{18}$.

A l'angle extérieur et en haut des folios de droite, on observe un petit signe formé de quatre points disposés en losange en haut à droite de la page, dans la marge. Il devait sans doute indiquer au scribe dans quel sens il fallait prendre le bifolio ${ }^{19}$.

\section{Principes d'édition}

La présente édition reproduit les folios $121^{\mathrm{a}}-131^{\mathrm{a}}$ du manuscrit Cambridge Syr. Add. 2020. Le texte ne présente pas de subdivision mais nous l'avons divisé en chapitres numérotés de 1 à 19 selon la numérotation du texte de grec de la PG (vol. CXV, col. 427-448), ainsi que le présente Allgeier dans son édition. La ponctuation originelle du manuscrit est respectée.

L'apparat indique les corrections que nous avons apportées à $J$, là où il présentait des erreurs ou des corruptions. Les erreurs, peu nombreuses, sont de différents types: erreur de vocabulaire, d'orthographe grammaticale (par exemple un accord en genre et en nombre) ou d'orthographe lexicale. La majorité des corrections concerne surtout l'orthographe des mots d'origine grecque qu'il s'agisse de noms propres ou de noms communs. Nous reprenons la leçon commune aux autres témoins ou celle qui présente le plus de cohérence. En l'absence de correspondance et en cas de corruption du texte nous notons simplement des crochets. C'est le cas une seule fois dans le titre.

\footnotetext{
${ }^{18}$ Cf. specimen à la fin de l'article.

${ }^{19}$ Briquel-Chatonnet, Manuscrits syriaques. Catalogue, p. 14.
} 
Les signes diacritiques distinguent les formes verbales suivantes : le participe actif peal (un point est placé sur la première radicale); tous les temps du pael excepté le mode participe (un point est placé sur la première radicale); le participe afel (un point est placé sur la préformante mim); tous les temps du etpaal (le point diacritique est placé sur la première radicale et sur le taw en cas de métathèse). Pour toutes ces formes, le point est reporté sur la deuxième radicale si la première est un i.

Un point distingue également :

- le prétérit de la troisième personne f. s. (le point est placé sous le taw de la terminaison), du prétérit de la deuxième personne $\mathrm{m}$. s. (le point est placé sous la troisième radicale);

- les pronoms démonstratifs des pronoms personnels de la troisième personne (un point est placé sur le m);

- le pronom is (marqué d'un point supérieur) de la préposition $>$ qui est dépourvue de point.

Enfin, lorsqu'une lettre est quiescente, elle est marquée d'une ligne occultante ; c'est le cas notamment dans certains substantifs

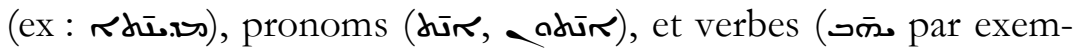
ple mais dans certains cas seulement) ou encore lorsque le verbe « être » est enclitique.

\section{Sigles et abréviations}

$\begin{array}{ll}{[\ldots]} & \text { corruption du texte } \\ <> & \text { conjecture } \\ \text { [fol.] } & \text { folio } \\ \text { cf. } & \text { confer } \\ \text { in marg. } & \text { in margine } \\ \text { l. } & \text { linea } \\ \text { om. } & \text { omisit }\end{array}$




\section{Edition}

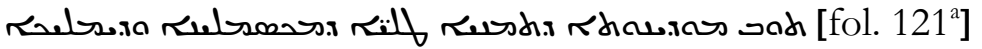
o

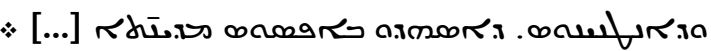

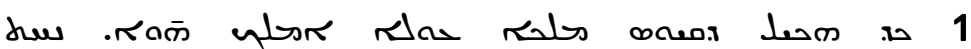

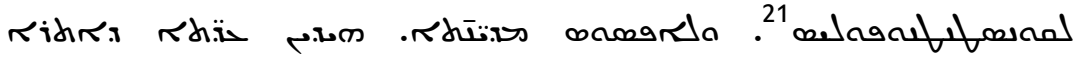

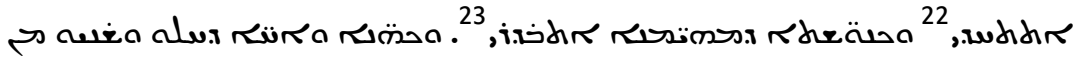

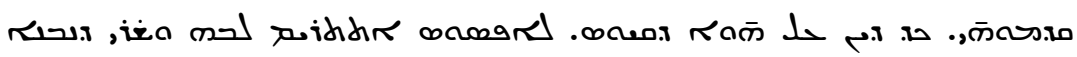

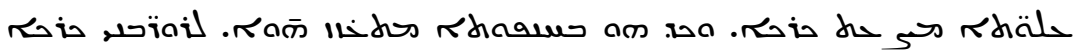

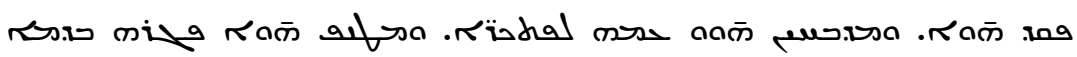

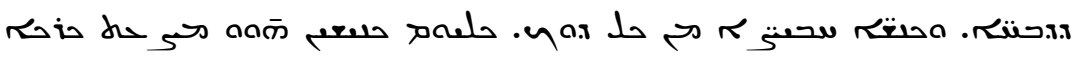

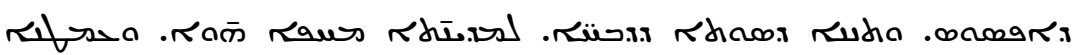

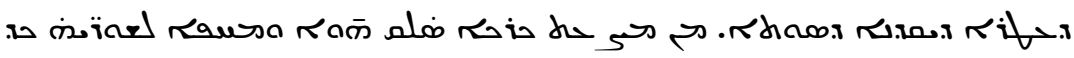

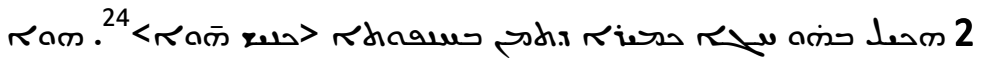

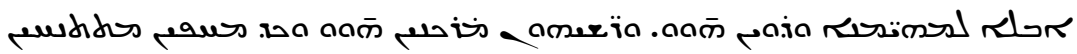
anō

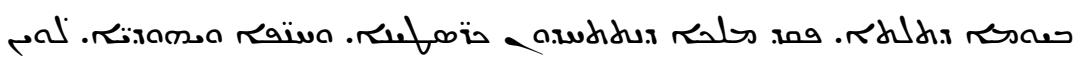
anm

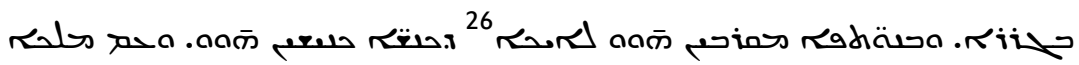

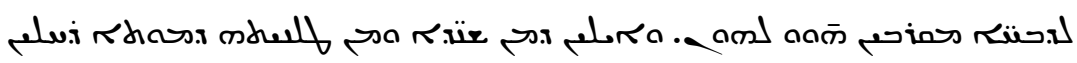
anō

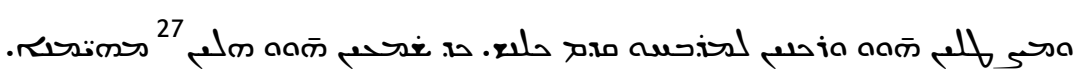

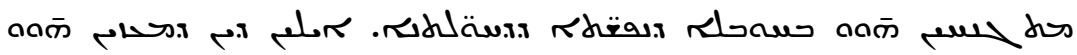

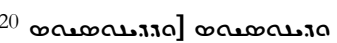

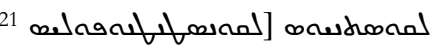

22 ,ustidire] rudidio

23 ristisis

24 om.] Ram̄ حس. Le verbe est omis dans J. Le texte restitué s'appuie sur

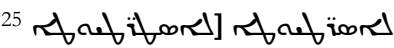

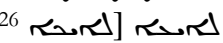

27 in
} $B D S$. 


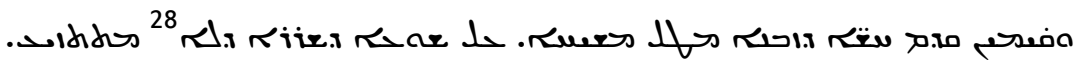

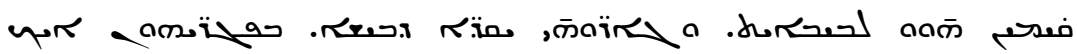

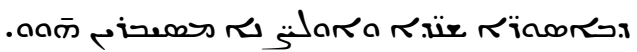

3

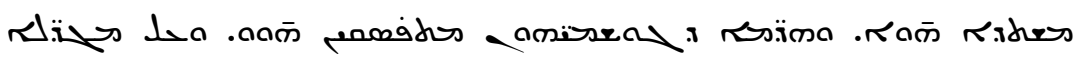

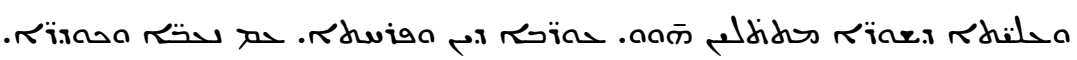

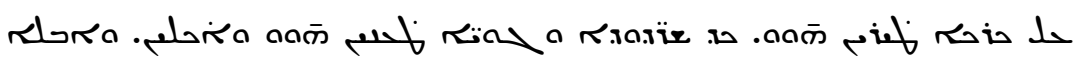

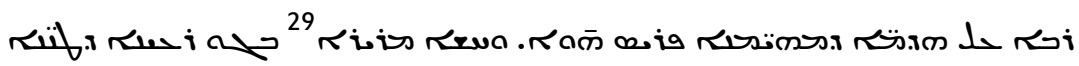

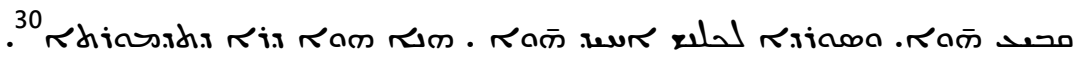

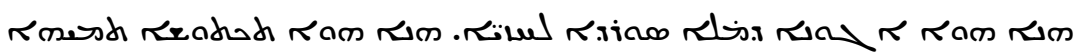

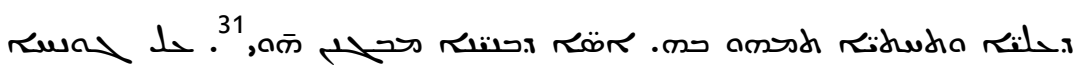

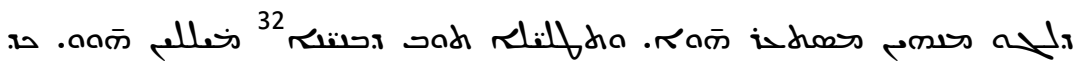

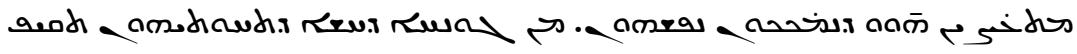

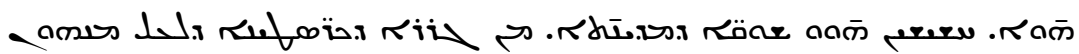

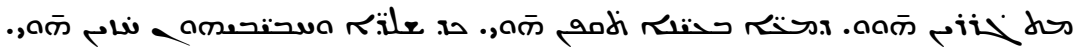

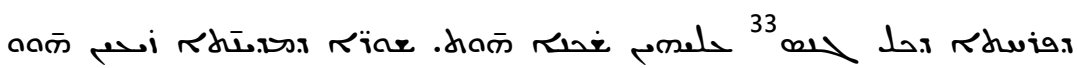

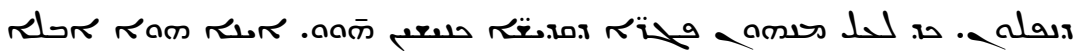

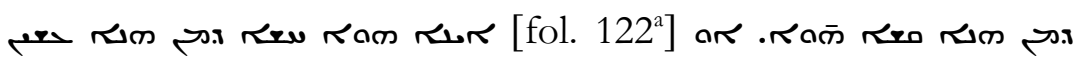
דَ"

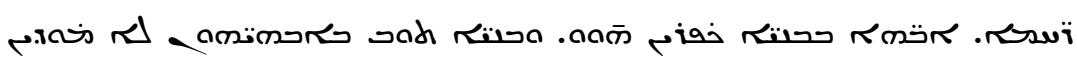

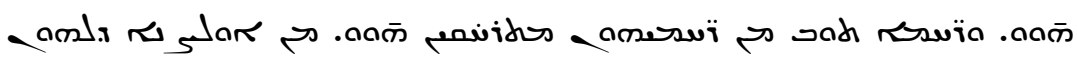

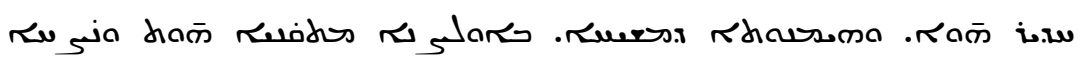

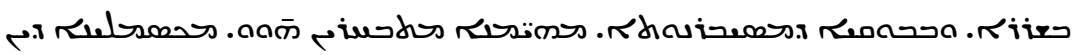

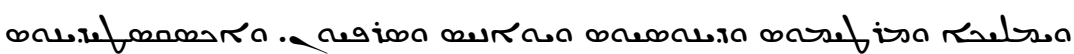
ח

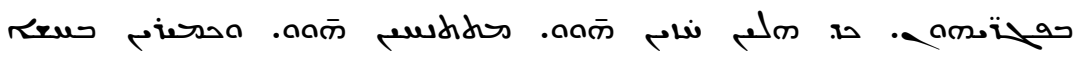
ä́

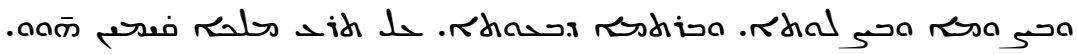

\footnotetext{
$\left.{ }^{28} \pi \mathrm{x}\right] \mathrm{s}$

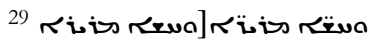

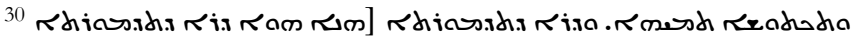

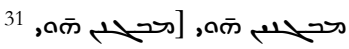

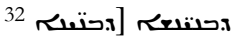

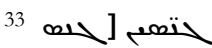

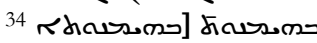




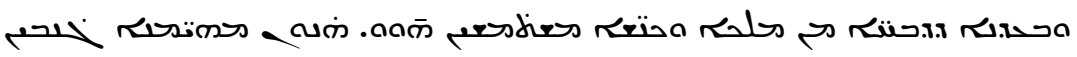

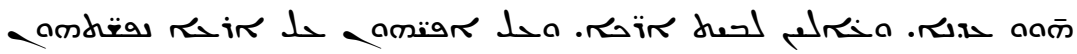

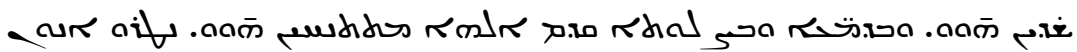

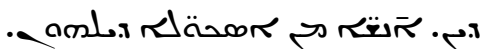

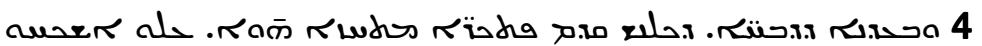

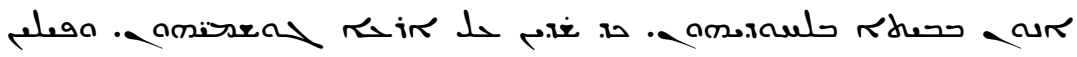

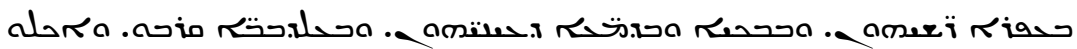

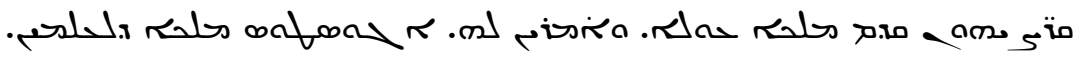

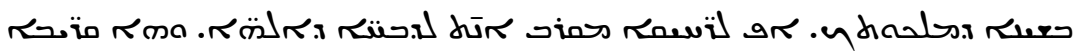

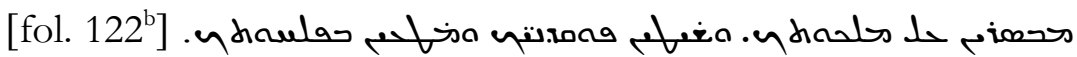

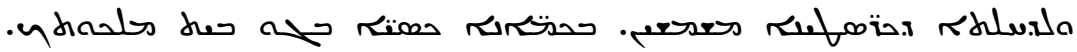

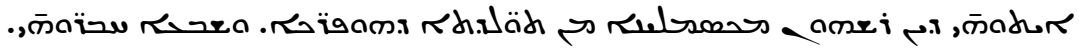

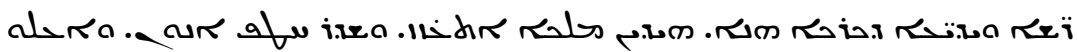

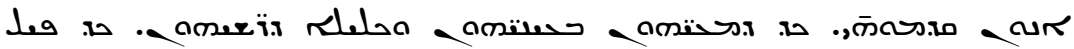

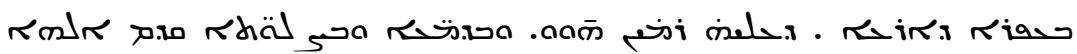

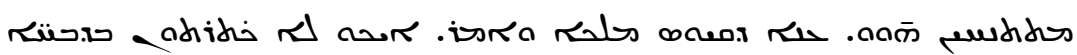

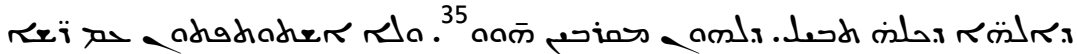

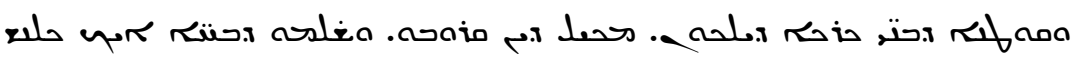

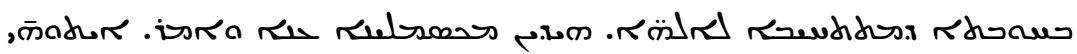

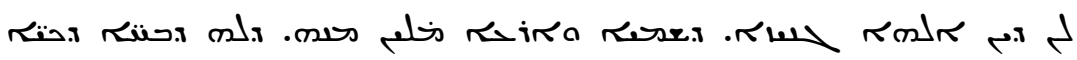

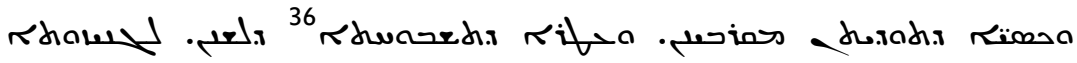

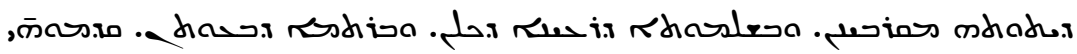

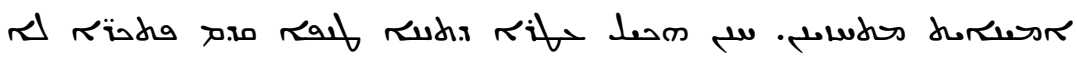

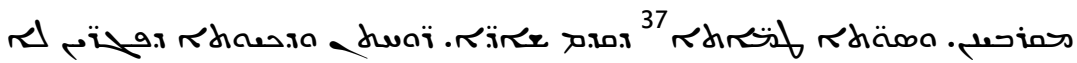

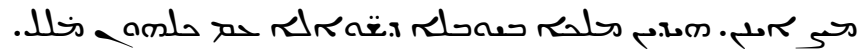

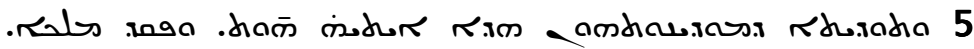
مאלdis

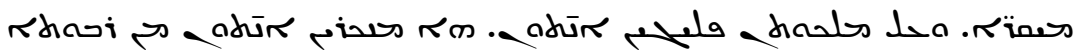
ז.

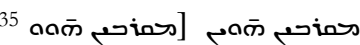

36 זhurdis]

37 riñib] Rdist

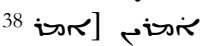




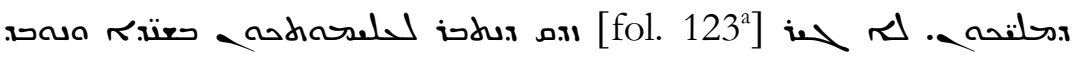
39

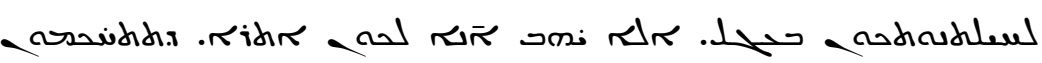

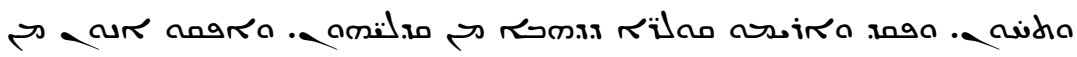

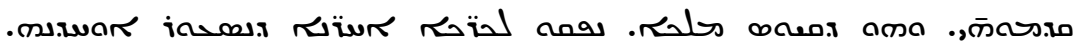
.

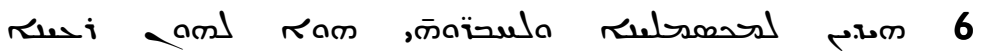

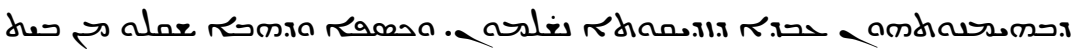

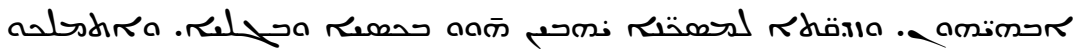

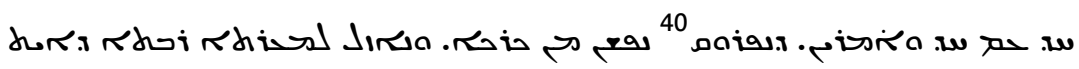

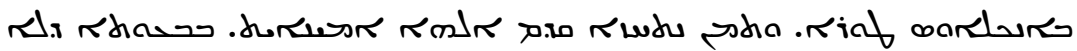

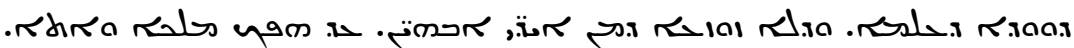

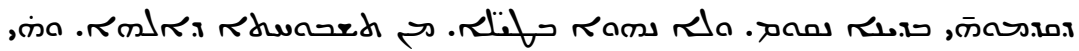

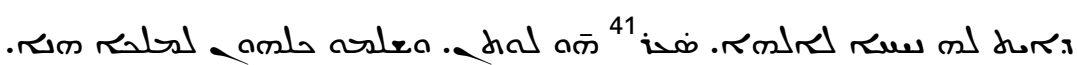

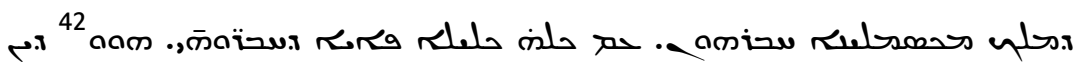

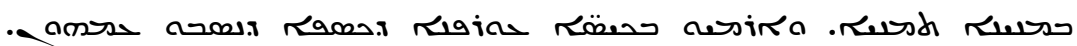
חolas

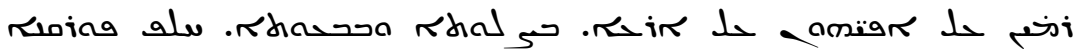

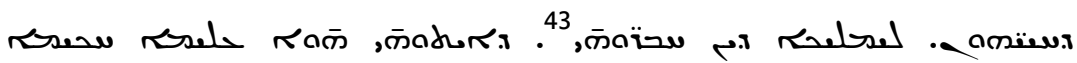

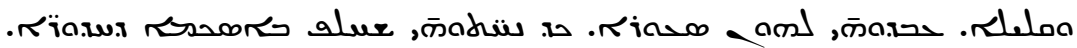

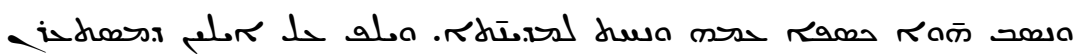
כמד. .

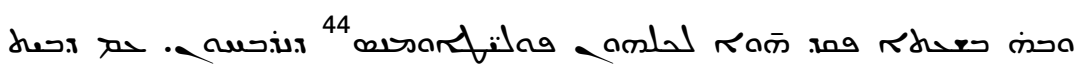

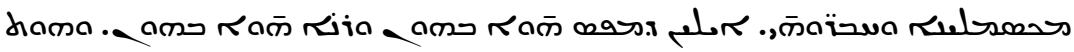

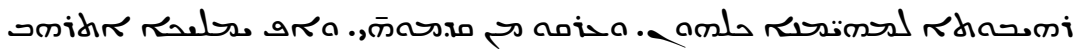

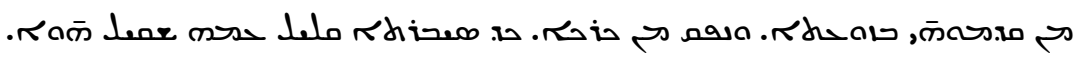
olos

\footnotetext{
39 I. [.

40 ת.

محن [فن

42 anm]

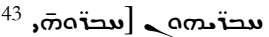

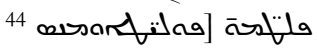

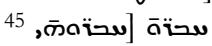




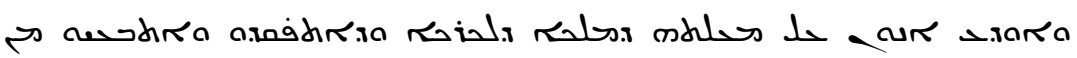

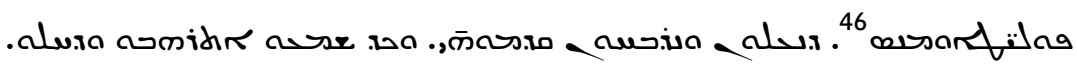

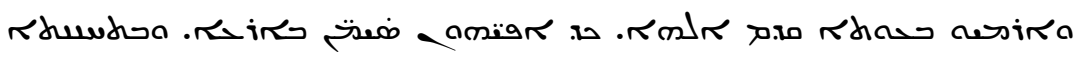

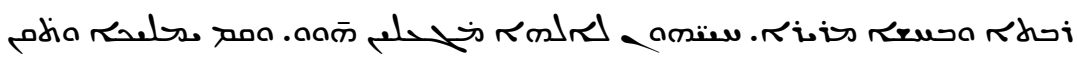
ח

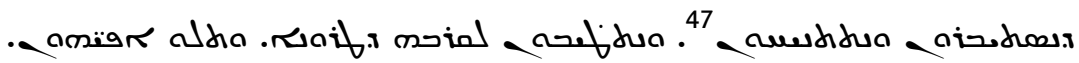

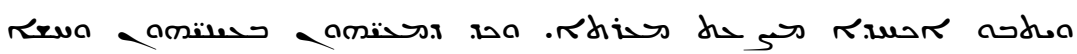

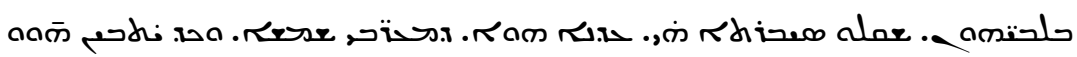

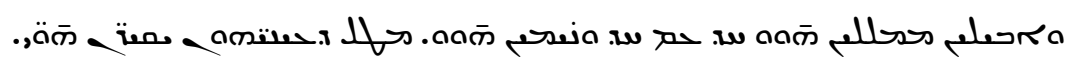

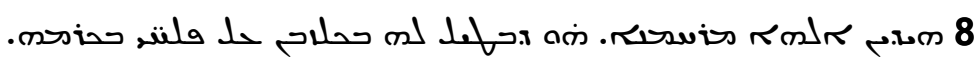

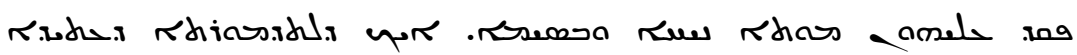

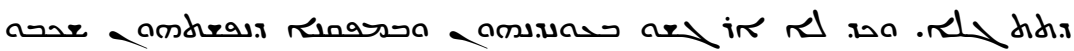

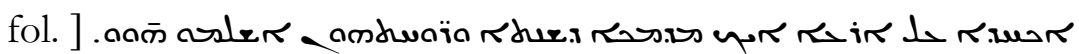
[124 ح. $^{a}$

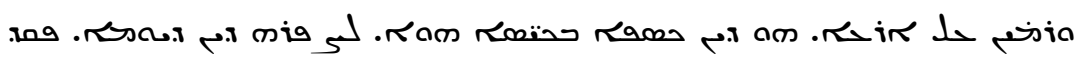

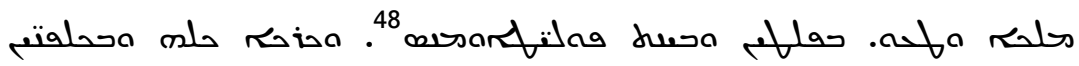

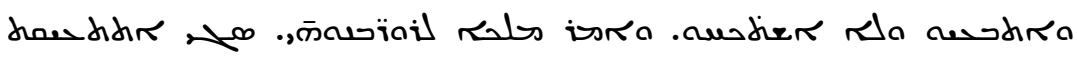

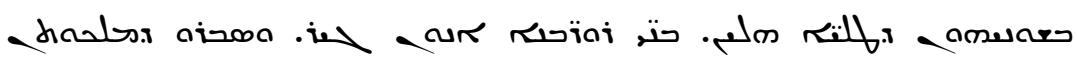

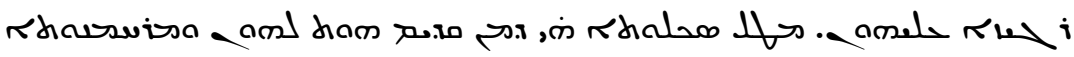

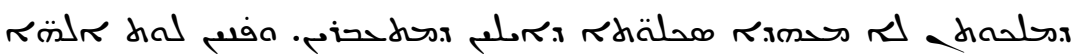

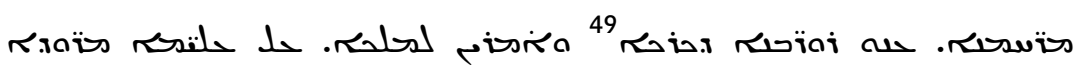

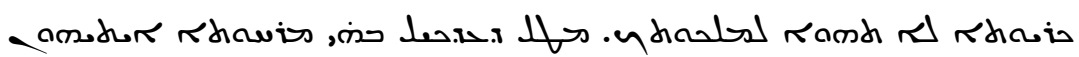

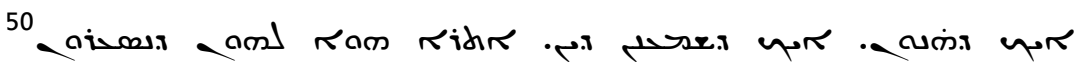

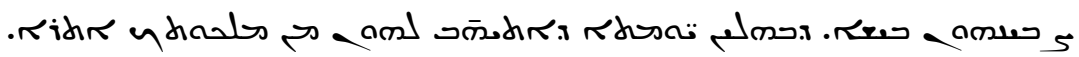

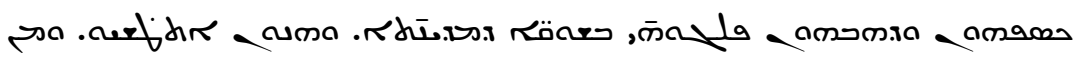
a.rubids

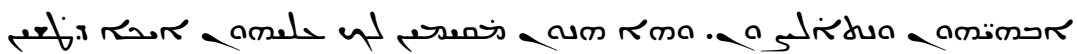

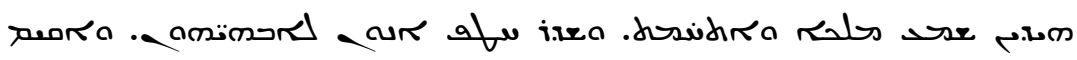

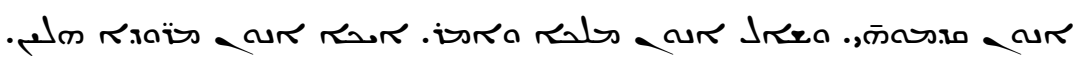

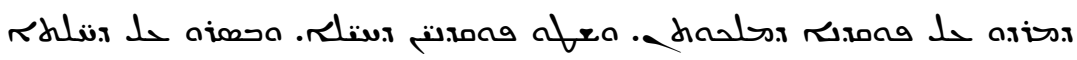

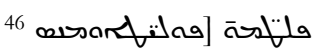

47 austidua] arustidua

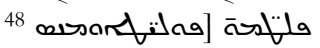

49 x.

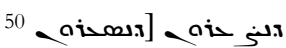




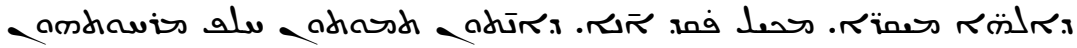

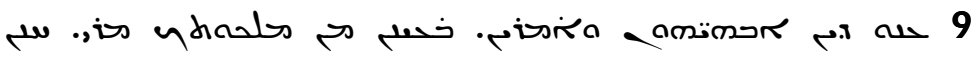

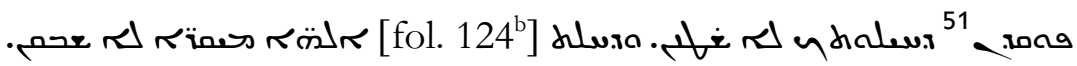

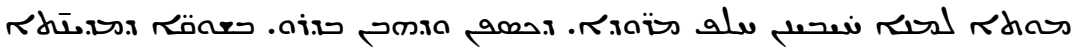
ه rma

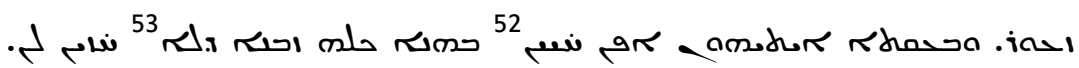

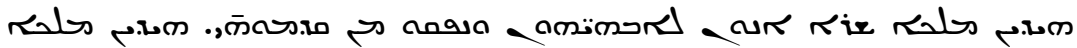

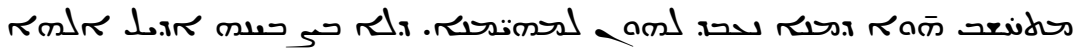

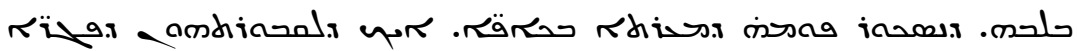

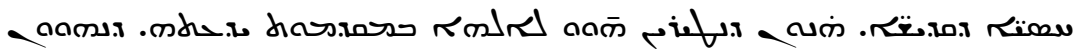

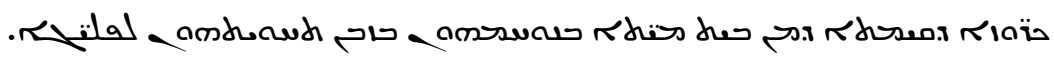

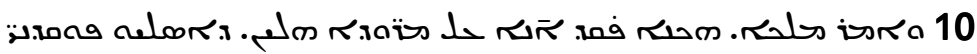
تі

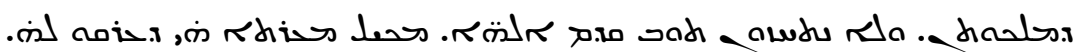

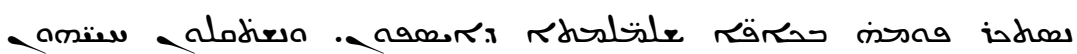

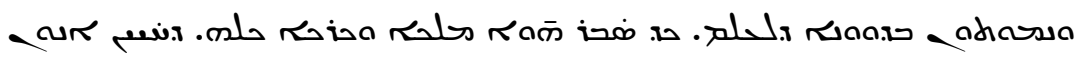

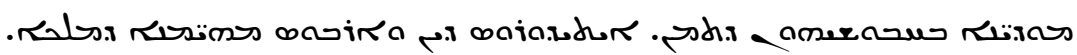

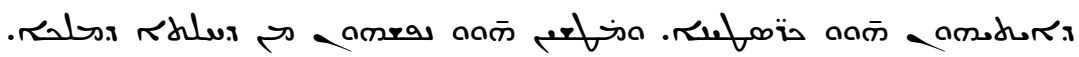

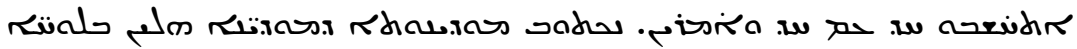

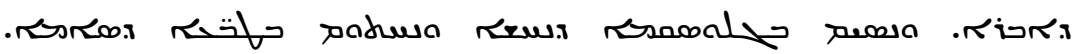

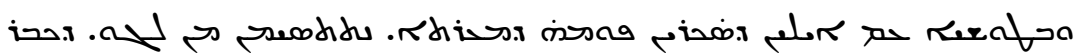

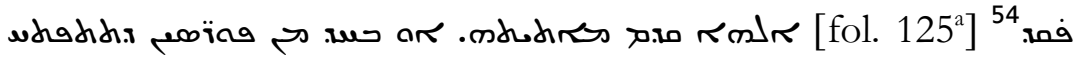

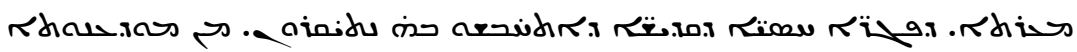

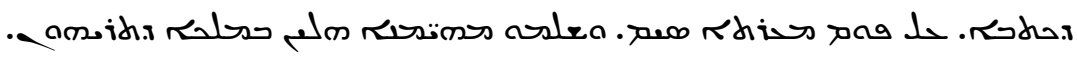

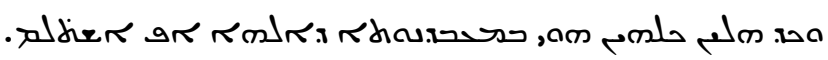

\footnotetext{
51 ז.

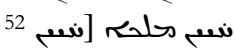

53 in marg.

פم. [فم: 54
} 


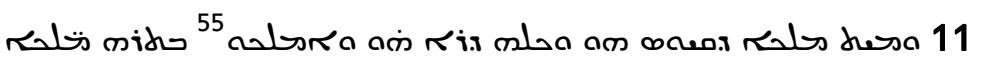

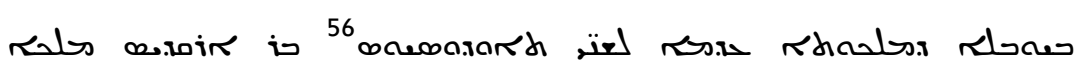

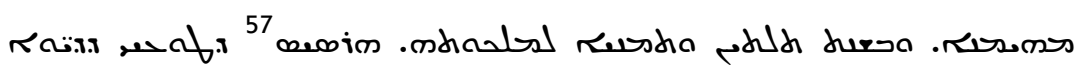

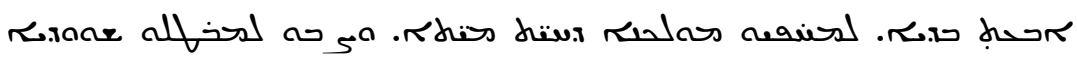

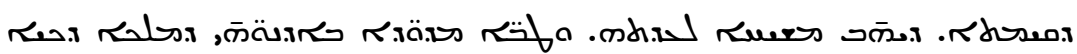

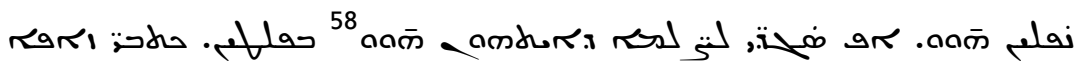

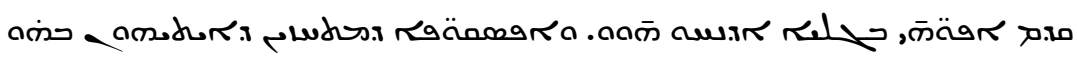

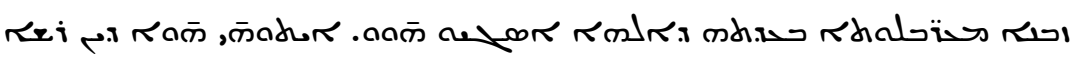

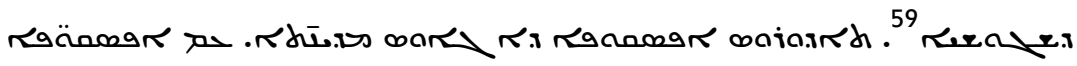
אملe x.

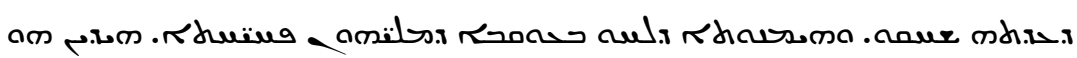

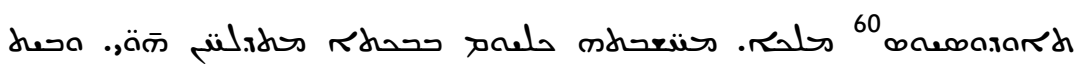

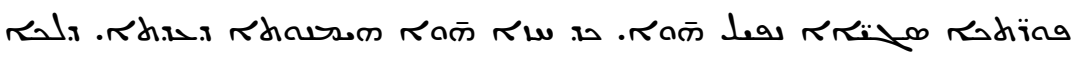

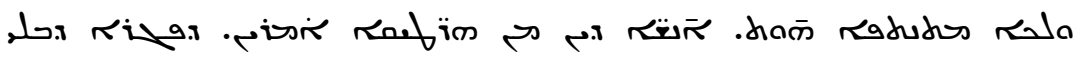

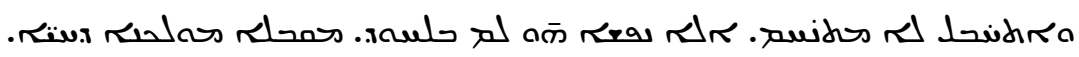

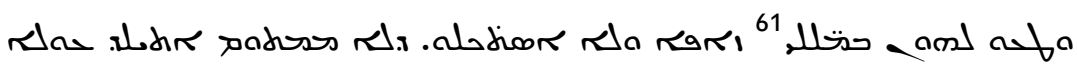

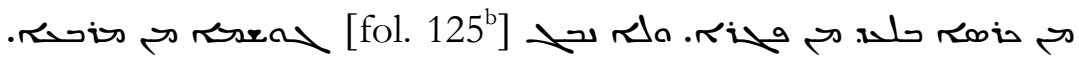

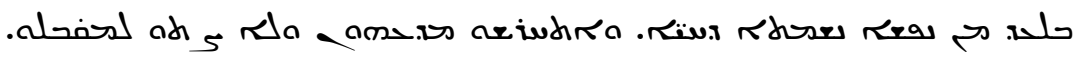

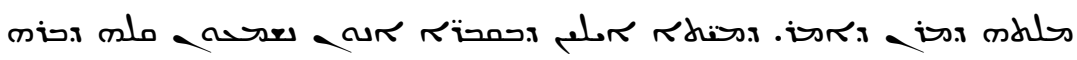

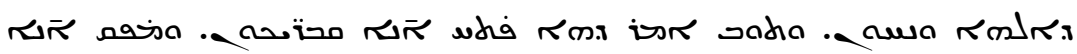

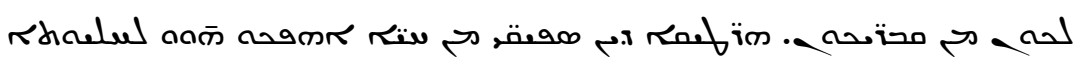

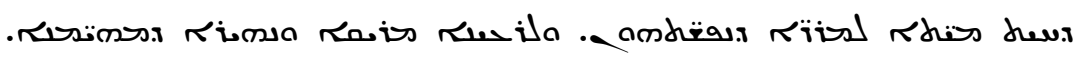

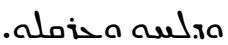

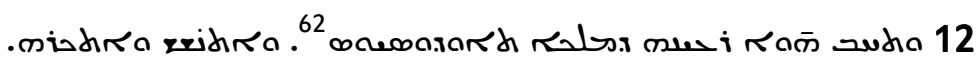

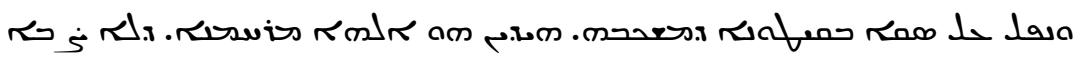

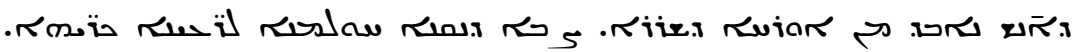

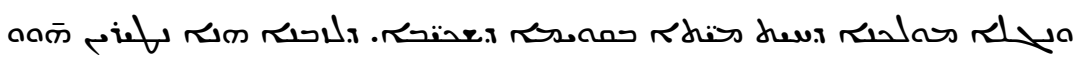

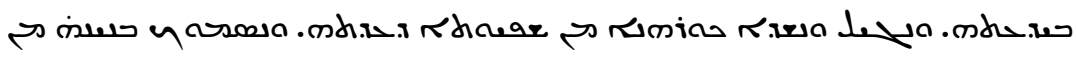

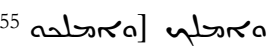

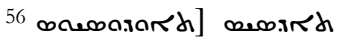

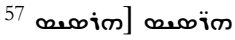

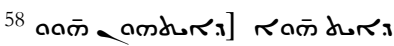

59 ביעם

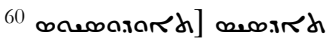

تهلe, [حتىلل, 61

62 m
} 


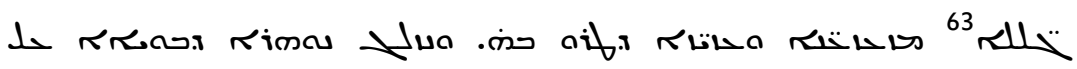

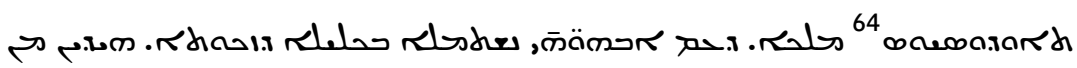

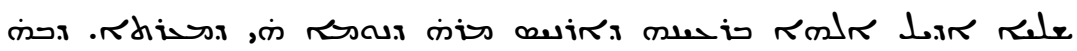

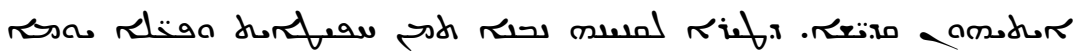

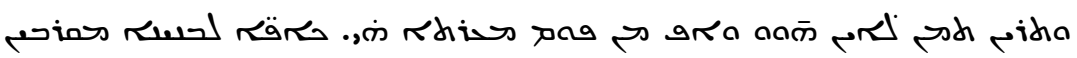
anom

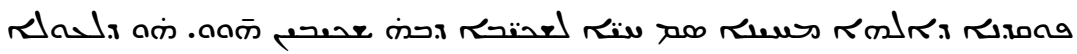

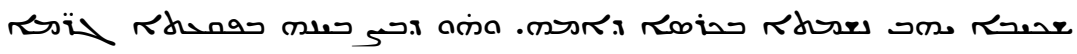

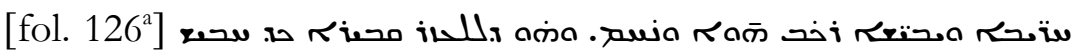

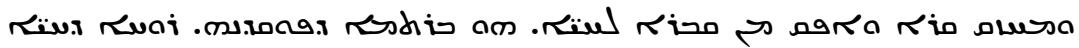

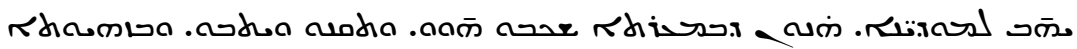

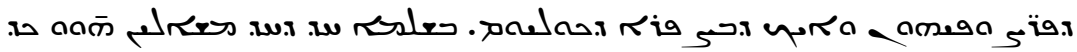

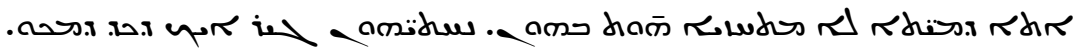

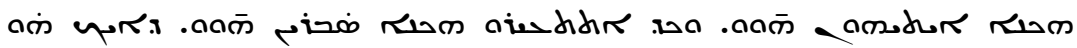

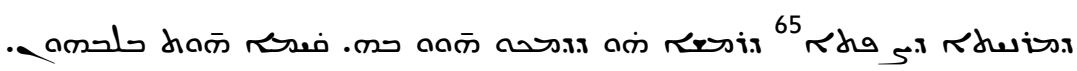

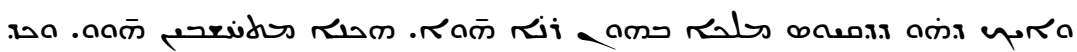

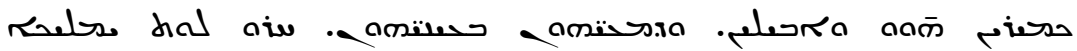

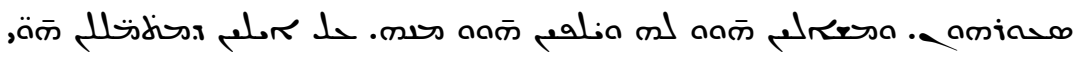

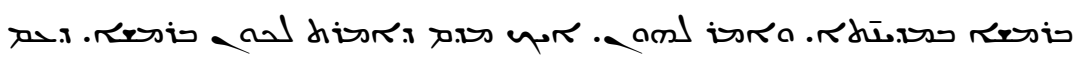
פملنfro

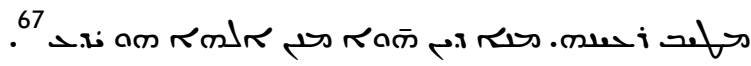

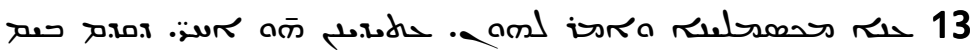

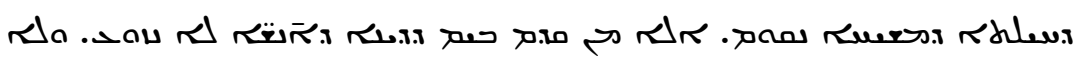

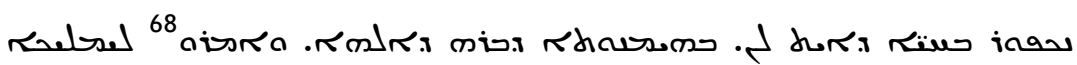

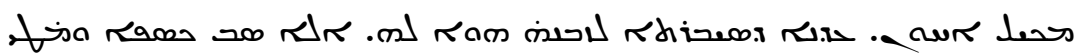

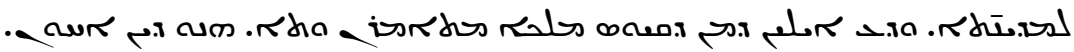

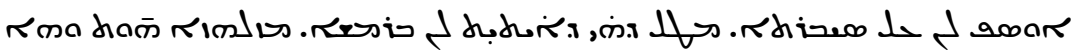

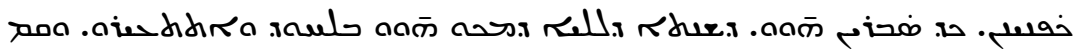

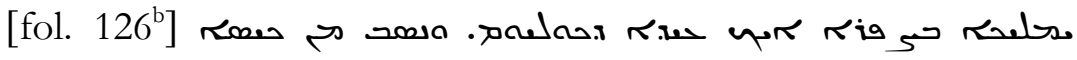

\footnotetext{
63 [لس

14 momaxard] menirh

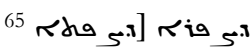

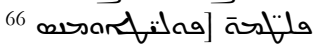

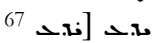

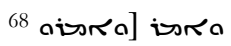




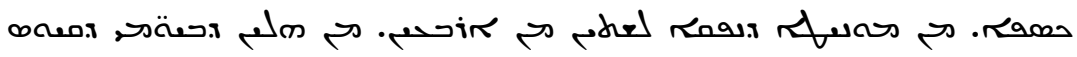

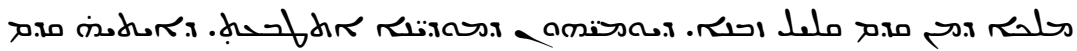

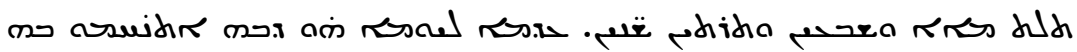

(20)

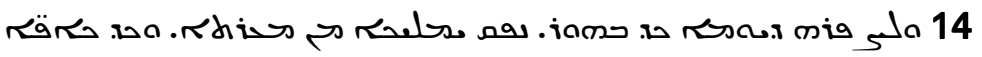

היפשتק שמم א

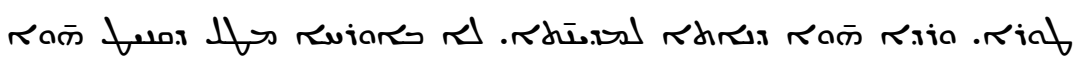

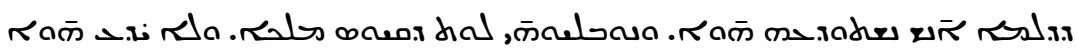

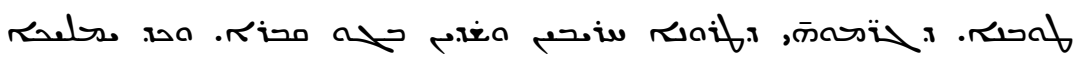

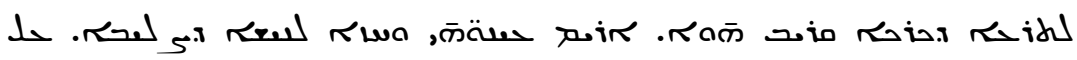

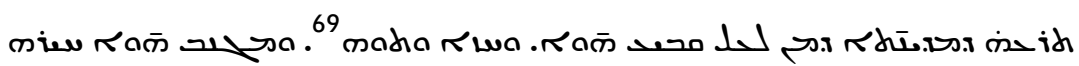


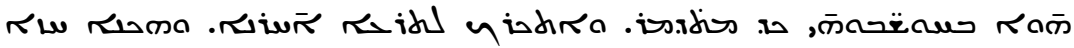
مل

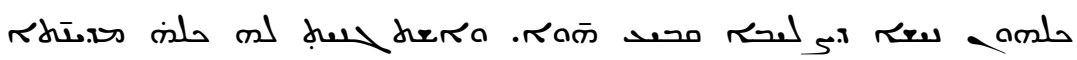

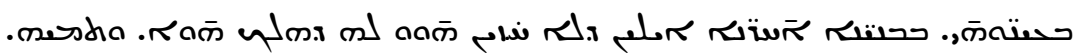

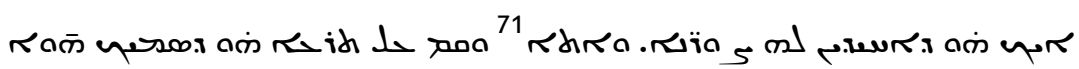

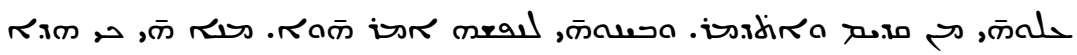

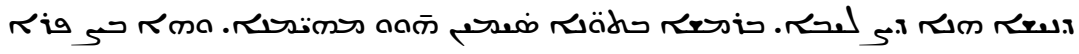

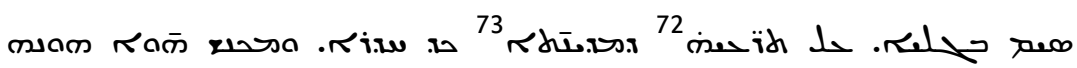

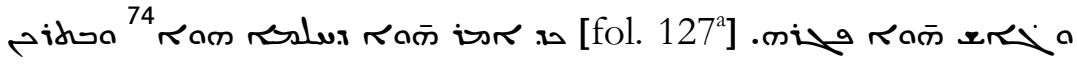

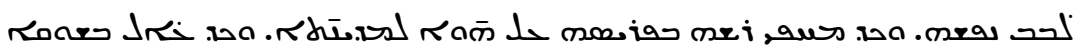
عدى

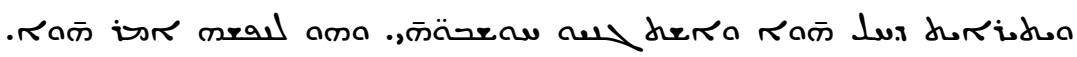

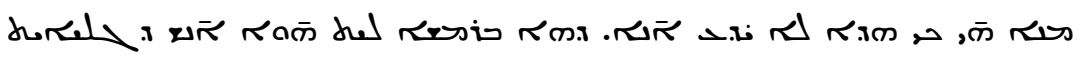

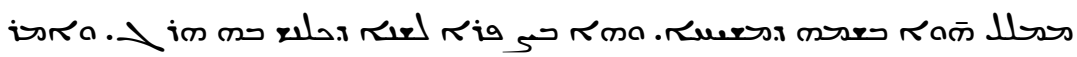

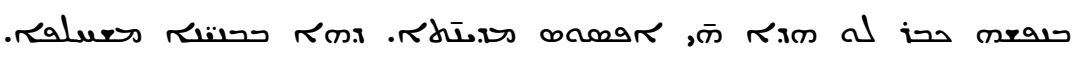

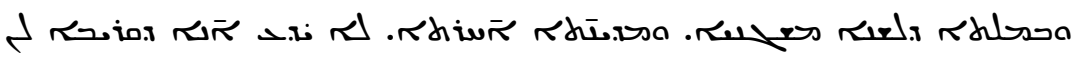

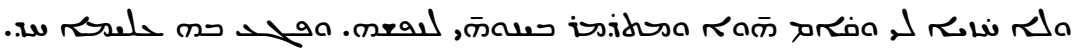

69 matia] matio

70 estia] issho

71 rira] diro

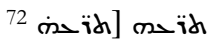

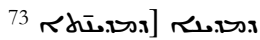

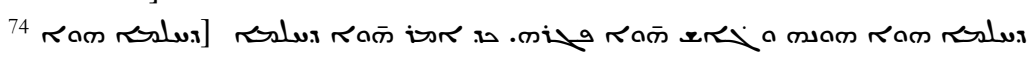

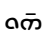




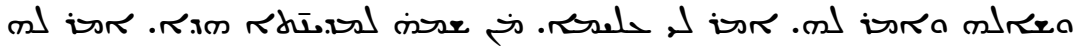

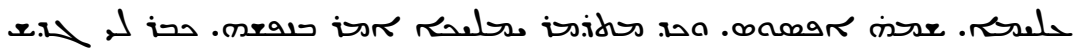

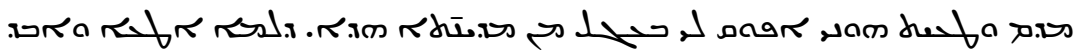

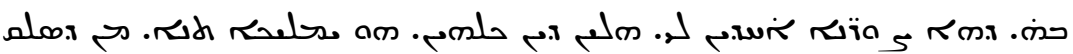

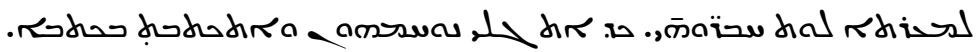

15 דسד. 15

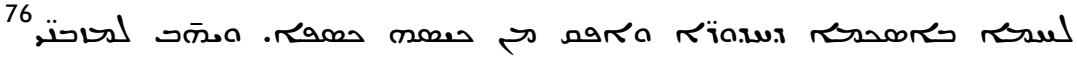
arsostio

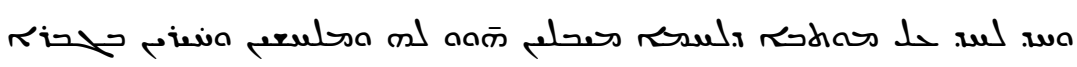

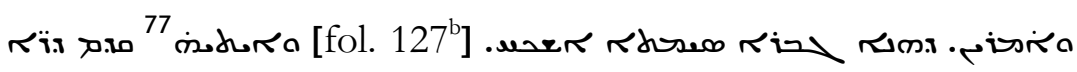

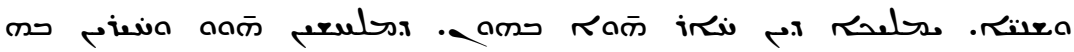

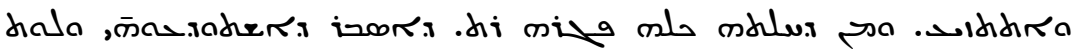

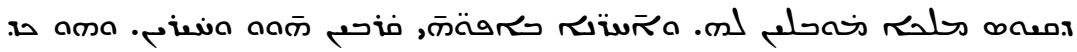

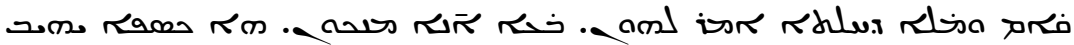

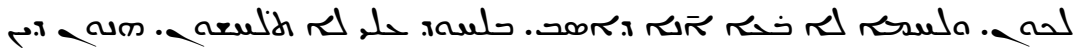

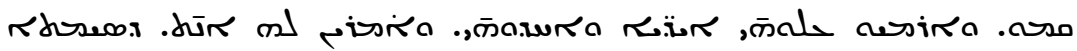

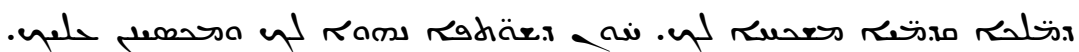

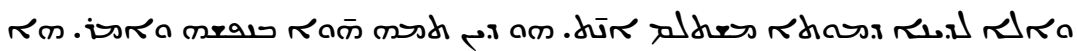
ד ק m, אקוע

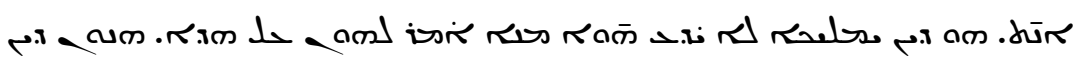

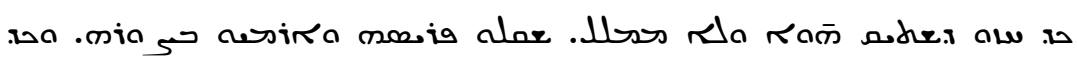

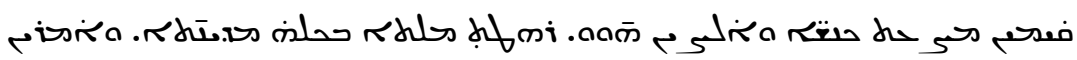

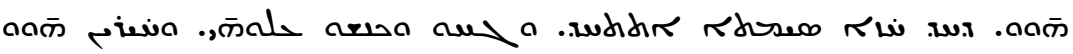

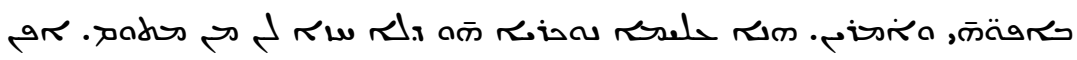

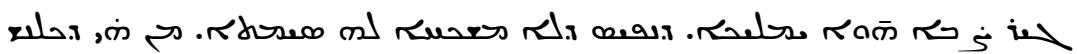
مrs

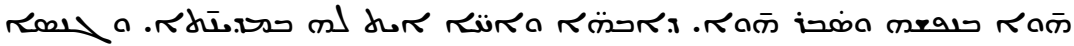

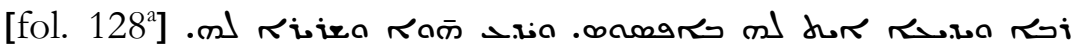

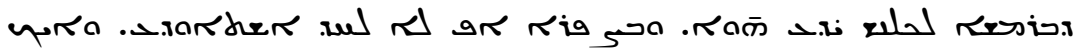

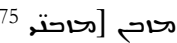

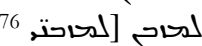

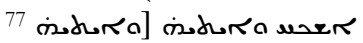




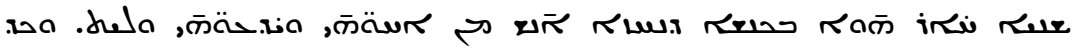

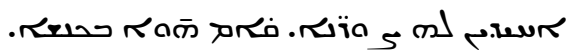

16 مس 16 sivil

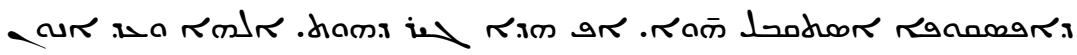

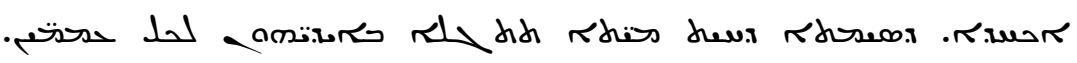

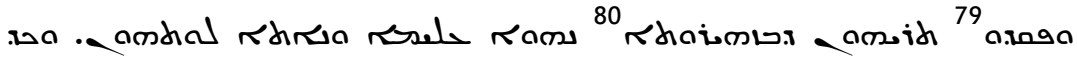

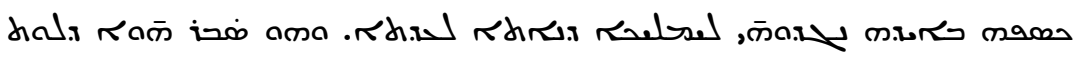

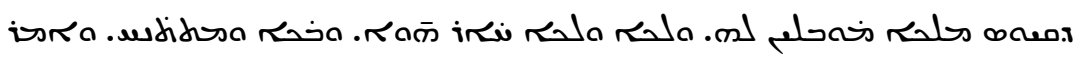

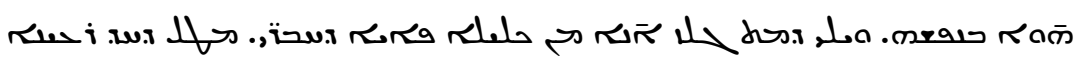

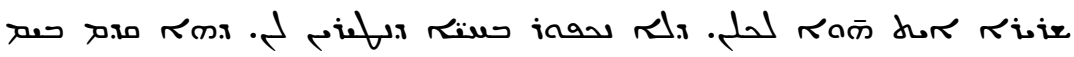

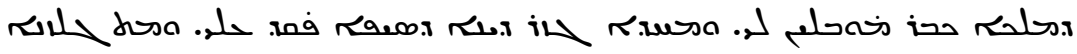

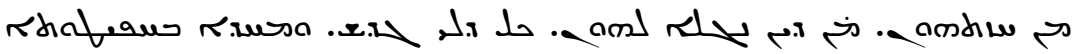

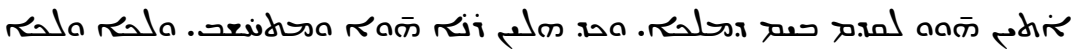

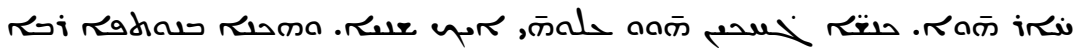

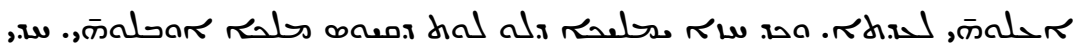

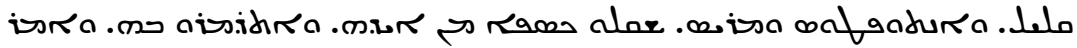

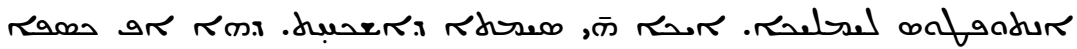

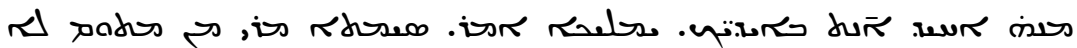
[fol. 128b]

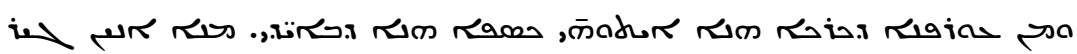
חלק .

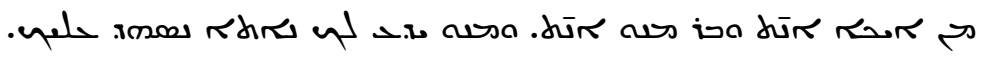

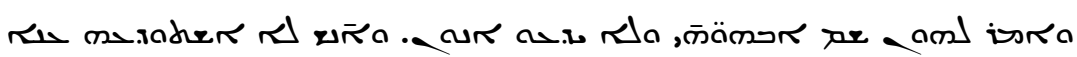

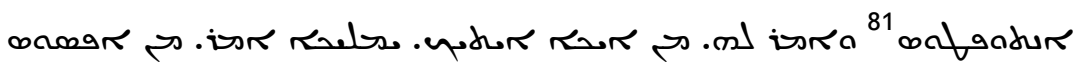

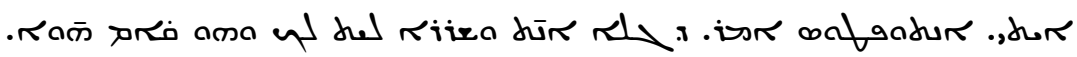

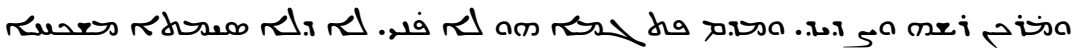

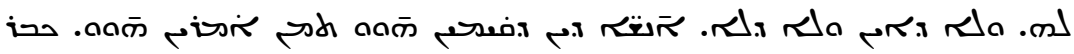

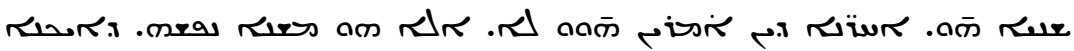

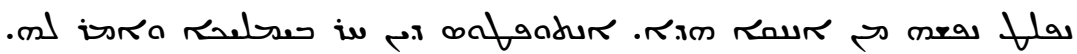

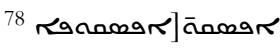

مפمr [مפمו.ם 79

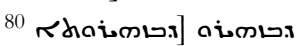

81 orfadur]
} 


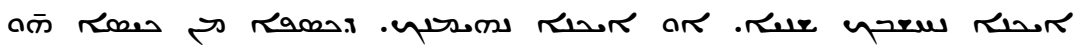

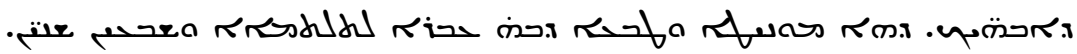

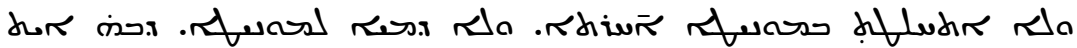

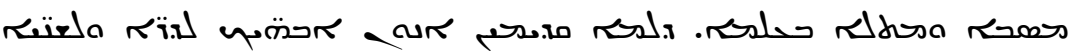

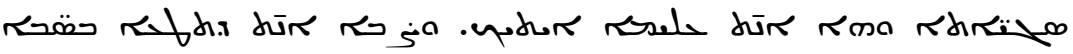

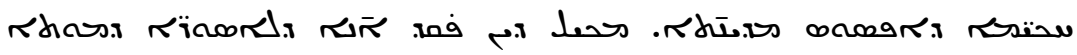

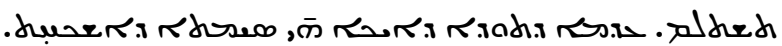

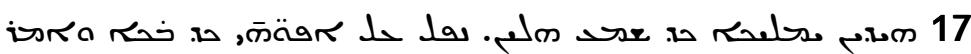

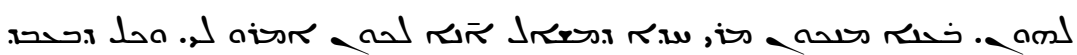

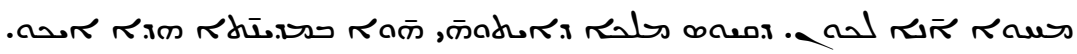

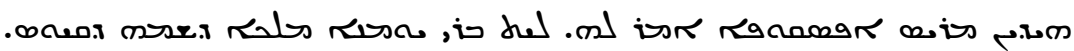

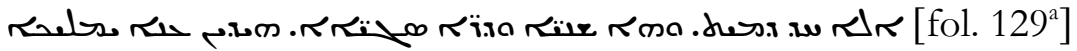

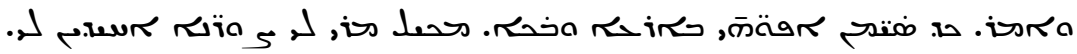

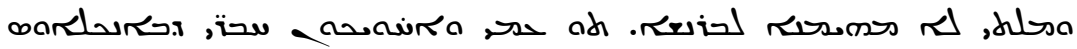

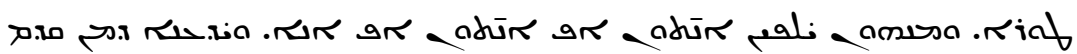

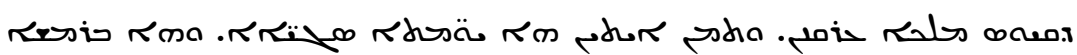

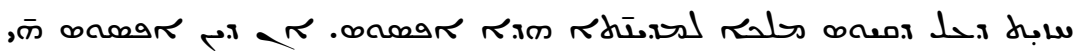

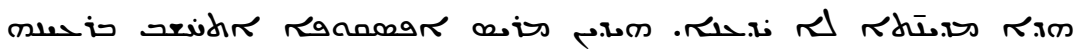

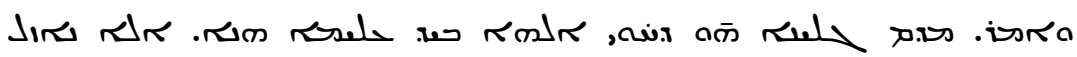

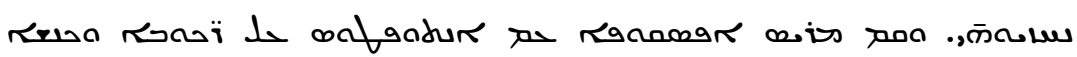

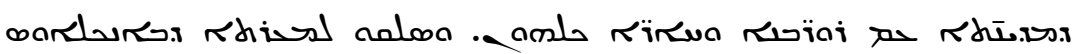

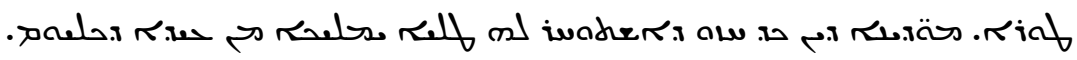

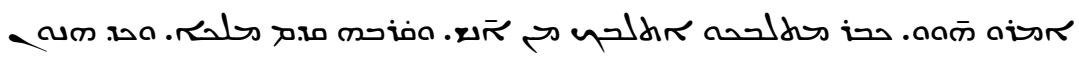

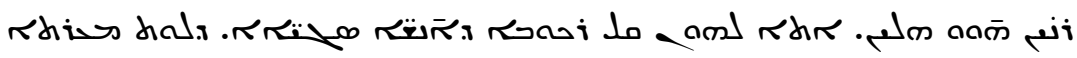

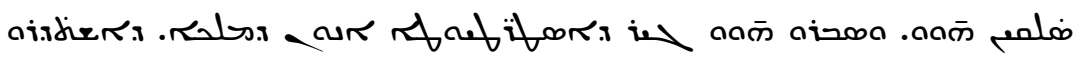

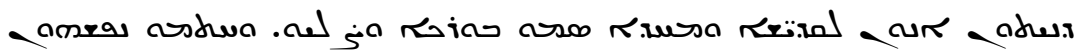

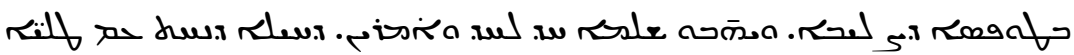

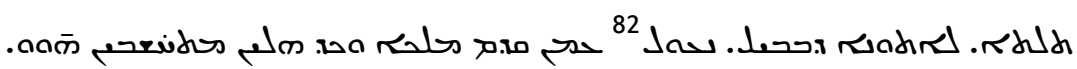
ح. is

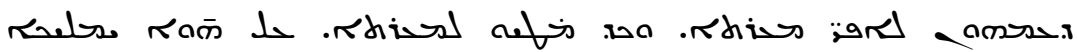

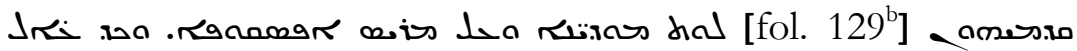

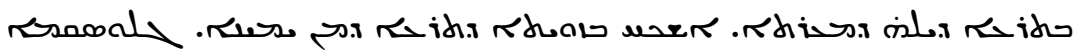

\footnotetext{
حمد [عهد
} 


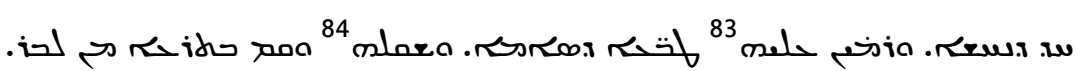

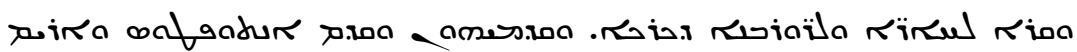


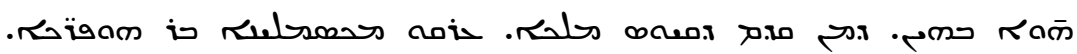

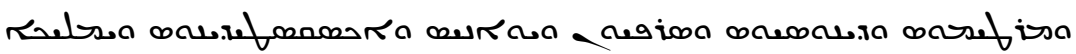

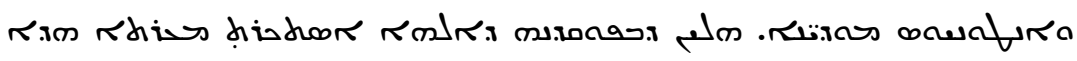

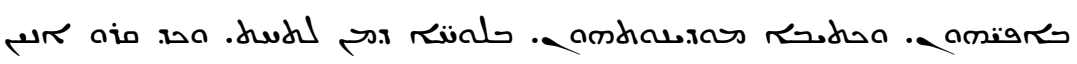

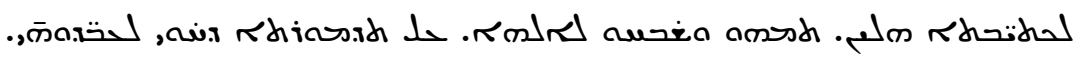

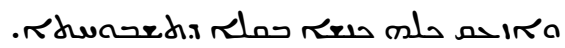

18 a 18

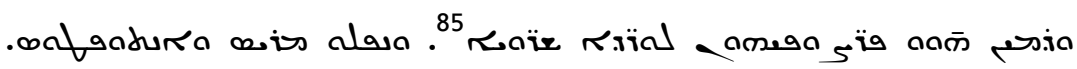

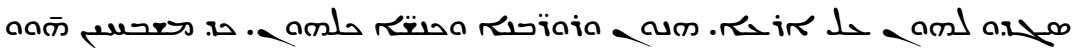

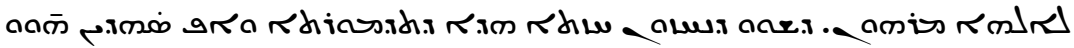

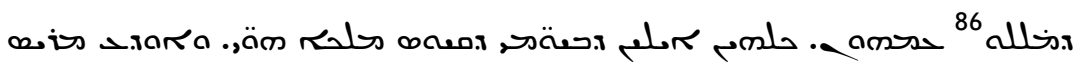

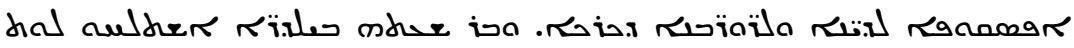

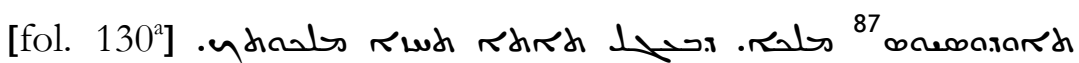

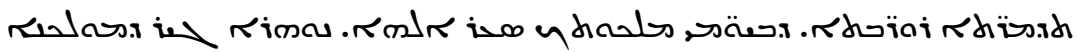

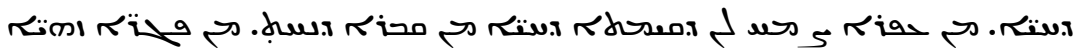

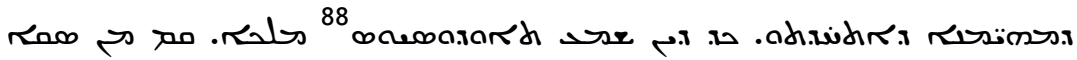

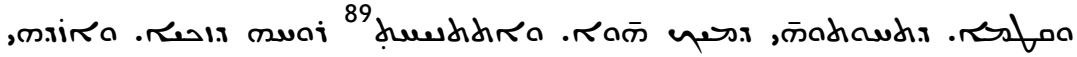

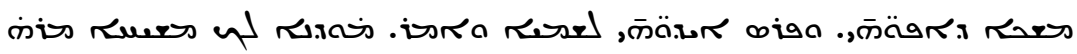
ו.

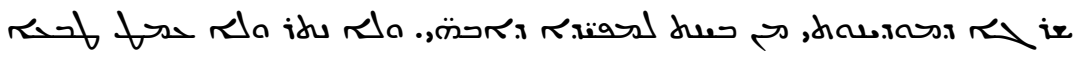

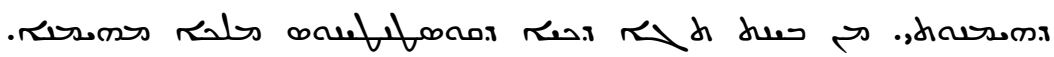
م

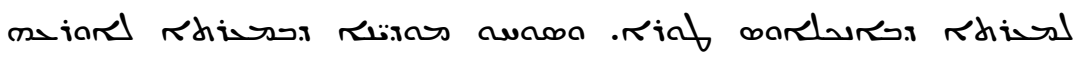

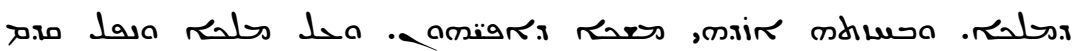

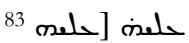

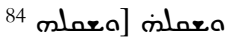

85 raiz] rair

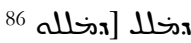

87 momasard] meosirh

88 cremaxard] meoxrsh

89 duestidiro] dwutidiro

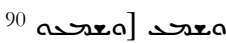

محتحم [محنحم 91
} 
i

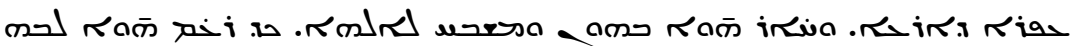

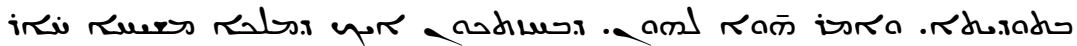

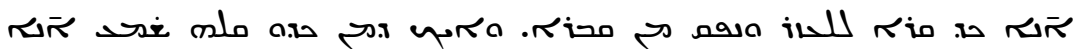

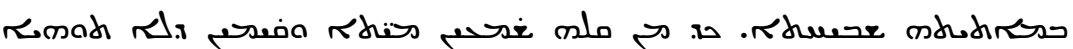

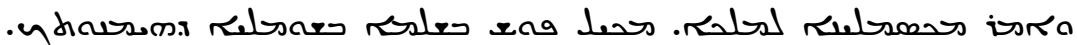
psmbith.

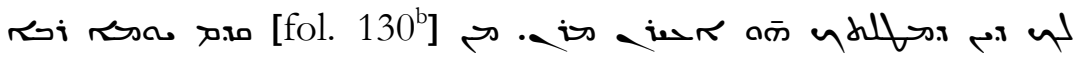

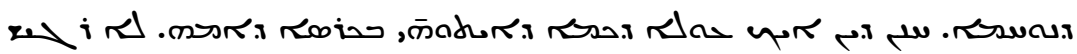

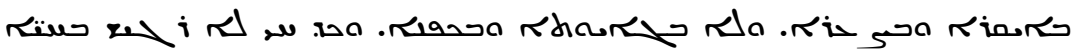

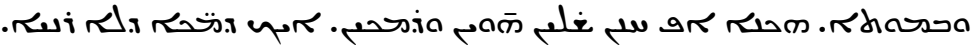

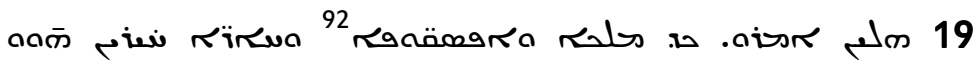

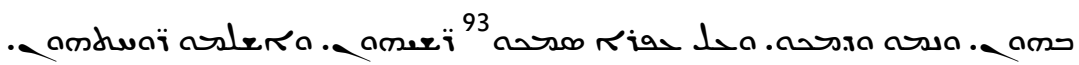

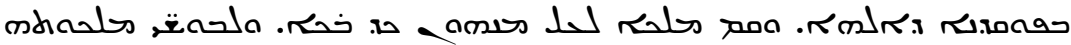

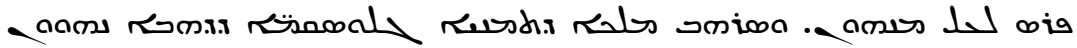
لح

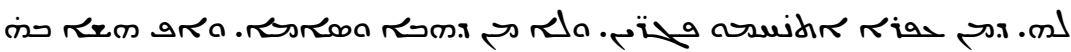

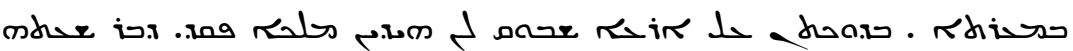

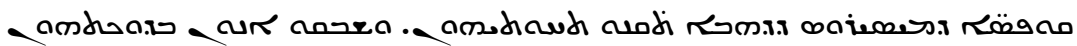

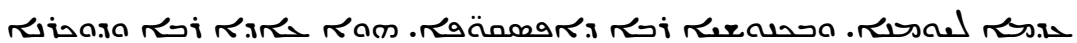

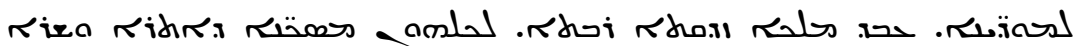

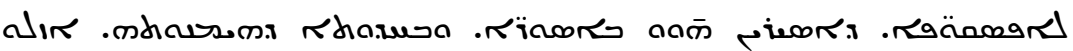

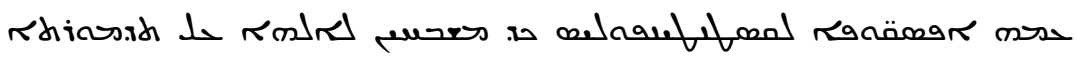

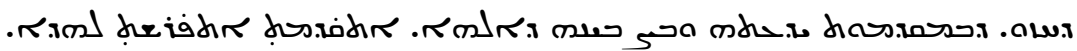

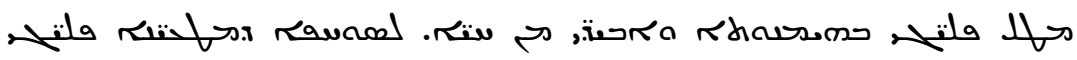

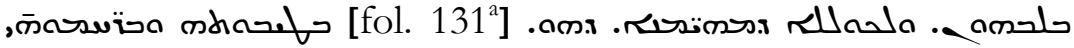
נi.

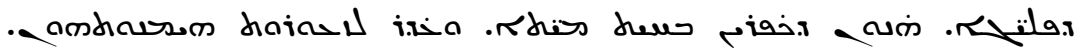

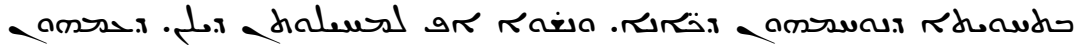

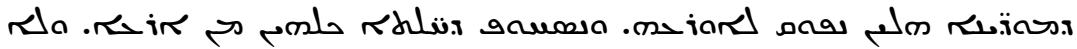

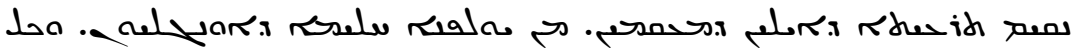

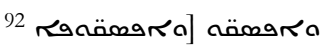

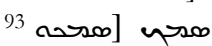

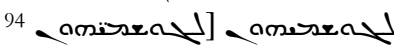




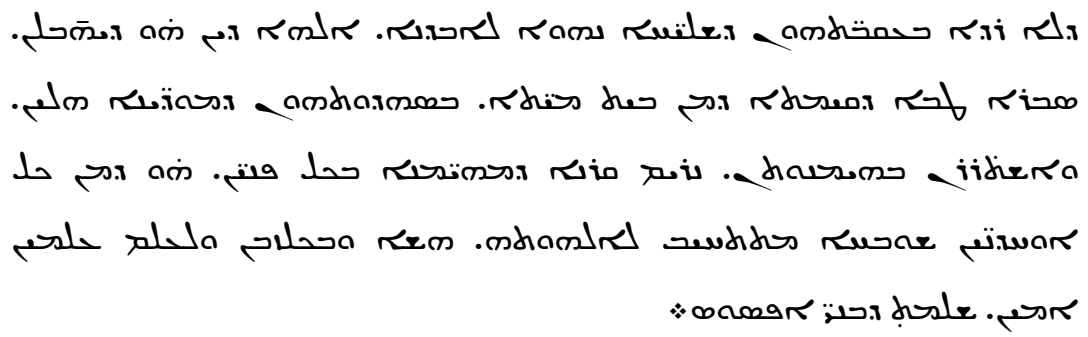

\section{Principes de traduction}

Afin de faciliter la lecture, nous avons eu recours à des ajouts mis entre parenthèses : il s'agit généralement de liens logiques ou de répétitions lorsqu'il pouvait y avoir confusion entre le sujet et l'objet d'une même phrase.

Dans le texte syriaque, certains noms propres ont gardé leurs désinences grecques en $ø$ ou $œ$, d'autres ont été syriacisés avec une terminaison en $\kappa$. Ils ont généralement été retranscrits phonétiquement, excepté lorsqu'ils avaient un pendant en français.

D'un point de vue de la grammaire, les tournures passives et impersonnelles sont courantes en syriaque et cet emploi est fréquent dans notre texte. Nous l'avons rendu le plus souvent par le pronom impersonnel « on ».

Concernant les temps : après un parfait, గañ exprime le plusque-parfait, mais il a également le sens de passé indéfini par opposition au passé défini (que rend le parfait seul). C'est pourquoi, nous rendons le parfait tantôt par un passé simple tantôt par un plus-que-parfait (ou passé antérieur) en fonction de la concordance des temps et du rapport d'antériorité ou de simultanéité entre les actions.

\section{Les notes}

Les éléments que nous abordons dans les notes qui accompagnent la traduction concernent différents points. Il y a tout d'abord les ajouts de $B, D$ et $S^{95}$ de plus de 3 lignes et des passages plus courts qui donnent des éléments de compréhension au texte de J. D'autres notes fournissent :

- une traduction littérale des passages pour lesquels nous avons donné une traduction plus littéraire au texte ;

- des indications qui sont essentiellement de nature informative et descriptive: elles concernent des données sur les indications géographiques, historiques (les personnages, les

${ }_{95}$ Ce sont les témoins que nous avons utilisés pour situer $J$ dans l'ensemble de la tradition manuscrite syriaque des Dormants (cf. chapitre consacré à l'étude des variantes majeures de $J$ ). 
dates...) ou fournissent des explications sur certains passages obscurs ;

- les références de citations bibliques (ou les réminiscences bibliques) qui sont signalées entre guillemets anglais (le discours indirect étant signalé par des guillemets français);

- certaines explications grammaticales et remarques lexicales pour les termes qui posent problème ;

- des remarques sur les préoccupations apologétiques et doctrinales du récit.

\section{Traduction annotée}

[fol. 121 ${ }^{a}$ Encore ${ }^{96}$, confession des huit jeunes gens, Maximilien, Jamblique, Martimos, Dionysios, Johannis, Serapion, Cons$\operatorname{tantin}^{97}$ et Antoninos, qui furent martyrs dans la ville d'Ephèse $[\ldots]^{98}$

1. Ainsi quand Dèce le roi impie accéda au trône ${ }^{99}$, il descendit aux villes de Constantinople ${ }^{100}$ et Ephèse ${ }^{101}$. Alors, on ferma les églises du pays et on dispersa les assemblées de croyants ; les prêtres et les frères, prirent peur et s'enfuirent devant lui. Lorsque Dèce fut entré dans Ephèse, son cœur s'exalta; il commença à bâtir des autels au milieu de la ville, et comme il grondait ${ }^{102}$ de

${ }^{96}$ Le mot sał indique le début d'un nouveau récit dans une collection de textes.

${ }^{97}$ L'orthographe des noms propres des Dormants varie selon les manuscrits.

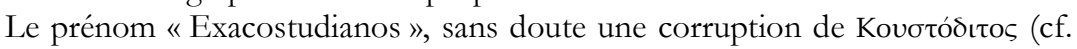

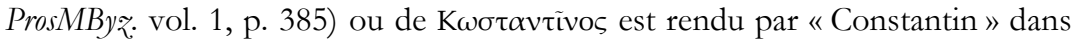
notre traduction. Cependant, puisqu'il est commun à toutes les versions comptant huit jeunes gens (on le retrouve également dans l'épitomé de Siméon Mé-

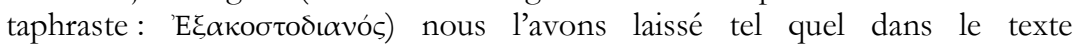
syriaque.

${ }^{98}$ Le microfilm est ici illisible ; la leçon de $S$ mentionne « aux jours de Dèce » et $B$ une date « en l'année 311 de notre Seigneur ».

${ }^{99}$ Dèce (249-251) : afin d'assurer l'unité de l'empire autour de la religion officielle, en 249, il publia un édit ordonnant à la population de sacrifier aux dieux tutélaires de l'Etat. Des commissions locales étaient constituées afin de contrôler l'exécution des sacrifices ; un certificat était alors remis aux personnes qui s'étaient conformées à l'édit, tandis que les réfractaires encouraient des peines sévères (l'exil, la confiscation de leurs biens, la torture ou la mort).

100 Anachronisme pour «Byzance» (dans D), Constantinople ayant été fondée en 330.

${ }^{101}$ Ephèse : capitale ecclésiastique de l'Asie et du diocèse de ce nom constitué par Dioclétien (245-313) ; la ville exerçait une juridiction ecclésiastique sur les onze provinces qui formaient le diocèse. $D S$ ajoutent «depuis la ville de Carthage ».

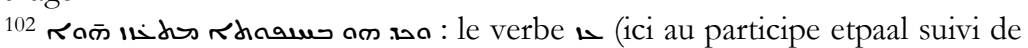
l'enclitique $r a \bar{m})$ peut être traduit de différentes façons selon le lexique auquel on se rapporte. Ainsi, à côté des sens de «devenir fort» (le verbe à la forme simple a déjà le sens de la forme dérivée) et «rugir», on trouve dans PAYNESMITH un sens précis tiré de notre texte qui est rendu par une expression : «to be abandonned to paganism ». Mais il s'agit d'un sens isolé qu'on ne retrouve 
paganisme, il ordonna aux grands de la ville de sacrifier ${ }^{103}$ aux idoles avec lui et souillait son corps avec le sang des sacrifices. Des masses denses se rassemblaient chaque jour de tout lieu au milieu de la ville d'Ephèse, la fumée de l'holocauste des sacrifices recouvrait la ville et une épaisse fumée noire (provenant) de la combustion de l'holocauste montait depuis le milieu de la ville et en voilait les remparts tout autour.

2. Alors, pendant cette triste fête où l'on s'était rassemblé dans le paganisme, ce fut le deuil pour les croyants : ils étaient malheureux mais obéissaient ${ }^{104}$ et en (le) cachant, se lamentaient et se couvraient le visage d'un voile par crainte des persécuteurs. Soudain, le troisième jour, le roi ordonna qu'on s'emparât des chrétiens $^{105}$. Les païens et les juifs accompagnaient les soldats; ils faisaient sortir les croyants de (leurs) refuges et de (leurs) asiles avec violence et pendant les distractions, (les) conduisaient ${ }^{106}$ là où les masses étaient réunies et où elles offraient des sacrifices avec le roi. Ceux qui craignaient les tortures et "l'ombre de la mort"107 s'écartaient de la vérité de la foi vivante [fol. 121 b et tombaient ${ }^{108}$; ils apostasiaient et acceptaient de sacrifier en public ${ }^{109}$. Lorsque les croyants entendaient cela, ils étaient troublés par la corruption spirituelle ${ }^{110}$ des lâches, mais ceux qui étaient vaillants

pas dans les autres dictionnaires. Sans doute faut-il voir là un calque du texte grec : en effet, l'épitomé de Siméon Métaphraste donne à cet endroit le verbe

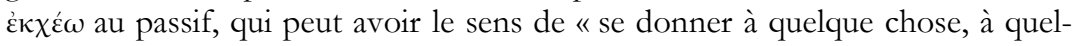
qu'un» (cf. BAILLY). Dans COSTAZ, le verbe au etpaal utilisé avec la préposition - (ou un complément direct) a le sens de «menacer». SOKOLOFF en rapporte lui aussi plusieurs acceptions dont « devenir fort », « frémir » mais également « gronder » et « être irrité ». Il renvoie ici à Jean 11,33 et 11,38 avec l'un

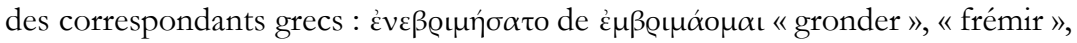
«s'irriter» ou alors « être fortement ému, troublé, agité » (selon CHANTRAINE le verbe signifie " gronder» en parlant de chevaux et «être irrité, gronder » en parlant de personnes). Dans la Peshitta, en ces deux endroits, on trouve respec-

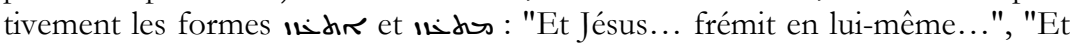
Jésus, frémissant en lui-même...". Mais dans le contexte péjoratif de la narration, nous avons retenu le verbe " gronder».

103 Littéralement «il commandait et ils sacrifiaient», mais deux verbes coordonnés expriment souvent deux actions unies avec ans si l'ordre a été exécuté.

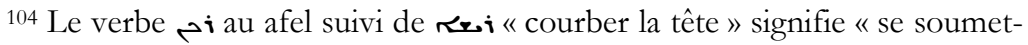
tre », « obéir » (PAYNE-SMITH).

105 La persécution de Dèce ne visait cependant pas uniquement les chrétiens, mais également les adeptes des cultes qui n'étaient pas officiels.

106 «... faisaient approcher... ».

107 Ps 22,4 .

108 Il s'agit des lapsi, terme désignant les chrétiens qui avaient renié leur foi sous les persécutions du $3^{\mathrm{e}}$ siècle. Sous la persécution de Dèce, on distinguait ceux qui avaient offert une victime animale aux divinités (les sacrificati), ceux qui avaient offert de l'encens devant la statue des dieux ou de l'empereur (les thurificati) et enfin ceux qui s'étaient fait délivrer un faux certificat attestant qu'ils s'étaient conformés à l'édit impérial (les libellatici). Une quarantaine de ces certificats ont été conservés et retrouvés en Egypte cf. J.H. KNIPFING, «The Libelli of Decius Persecution », dans Harvard Theological Review 16 (1923), p. 345-359.

109 «... devant tout le monde... ».

${ }^{110}$ Littéralement « la corruption des âmes », par opposition à la corruption des corps qui est décrite par le rédacteur dans le paragraphe suivant. 
et résistaient aux "souffrances du temps"111 à cause du Christ, se tenaient courageusement sur le rocher inébranlable de la vérité et enduraient "les traits enflammés du malin"112 dans leur corps comme si dans des prisons ${ }^{113}$ ils (supportaient) tortures et souffrances.

3. La chair de leur corps pourrissait et était jetée sur le sol comme du fumier ${ }^{114}$. On découpait les membres de leur corps et on les suspendait aux tours et aux créneaux des murs ${ }^{115}$. Des corbeaux et des oiseaux ainsi que ${ }^{116}$ des orfraies et des vautours survolaient la ville: emportant squelettes et intestins, ils (les) mangeaient. Une grande lamentation se répandait sur les dépouil$\operatorname{les}^{117}$ des croyants, une amère souffrance était ancrée $e^{118}$ dans l'esprit des zélés et la terreur s'emparait de tous. C'était un miraculeux combat ${ }^{119}$. C'était un combat qui remplissait les spectateurs de frayeur. C'était un combat prodigieux qui stupéfia ${ }^{120}$ les anges et les hommes ${ }^{121}$. Les murs des édifices criaient contre l'horreur qui était faite en leur sein, et même les toits des édifices pleuraient lorsqu'ils étaient contraints de subir l'horrible et intense souffrance qu'ils abritaient ${ }^{122}$. Les marchés de la ville souffraient de la contrainte (avec laquelle) on y trainnait les chrétiens. A la vue des cadavres et de leurs bien-aimés sur lesquels étaient perchés des oiseaux de toute sorte, les larmes dans les yeux redoublaient ${ }^{123}$. Les murs de la ville tremblaient au point de tomber lorsqu'on y rassemblait les corps des saints. Quelle tristesse plus dure que celle-ci [fol. $122^{2}$ ] ou quelle souffrance plus intense ${ }^{124}$ ? Lorsque les croyants se réfugiaient les uns (chez) les autres pour échapper aux mains d'ennemis ${ }^{125}$, les pères reniaient leurs fils, les fils aussi

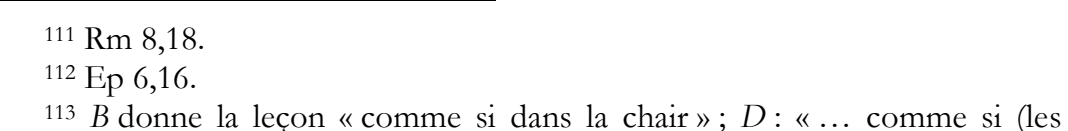
traits traversaient) un bouclier, et ils supportaient tortures et souffrances...»; $S:$ :... comme si dans des boucliers...». C'est également une allusion à Ep 6,16 où il est dit: "Prenez par-dessus tout cela le bouclier de la foi avec lequel vous pourrez éteindre tous les traits enflammés du malin...".

114 Il s'agit d'une allusion à Jr 8,2 et 16,4 où les corps sont laissés sans sépulture « comme du fumier sur le sol».

${ }^{115}$ Le rédacteur insiste sur la décomposition de la chair (حم) et du corps ( $\sim$ ive et piliers en bois aux portes de la ville alentour... ». $S$ comporte le même ajout, avec une variante : «... leur tête...».

${ }^{116}$ La préposition حم signifie " avec », " ainsi que » (PAYNE-SMITH).

117 «... les membres...».

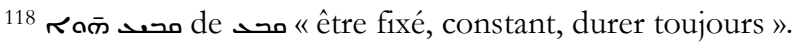

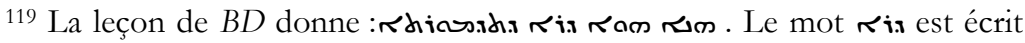
avec un point suscrit ("génération»); il correspond à $\gamma \varepsilon v \varepsilon \alpha ́$ dans le texte grec

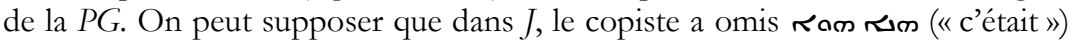
et que la portion de texte suivante rmash readadio est une corruption ou erreur d'écriture.

120 «... dont s'étonnèrent... ».

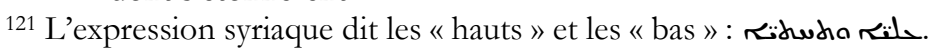

122 «... l'horreur de la souffrance qui était intense sous eux...».

123 «... étaient plus fortes...».

${ }^{124}$ Le syriaque répète « que celle-ci ».

125 «... de gens qui n'étaient pas des amis... ». 
ne reconnaissaient plus leurs pères et les amis s'éloignaient de leurs amis à cause de la douleur qui les entourait... Mais la foi dans le Christ ${ }^{126}$ était renforcée dans l'affliction, elle brillait dans la vérité et les croyants étaient éprouvés par la patience ${ }^{127}$. Maximilien, Jamblique, Martimos, Dionysios, Johannis, Serapion, Constantin et Antoninos, affermis dans la foi au Fils de Dieu et portant dans leur corps sa souffrance, gémissaient lorsqu'ils voyaient cela ; dans la douleur, leurs traits ${ }^{128}$ étaient empreints de tristesse et l'éclat de leur visage devenait sombre et laid. Ils se tenaient à la porte du roi ${ }^{129}$, pratiquant veille, jeûne, prière et murmure de supplication ${ }^{130}$, et pendant que les sacrifices étaient célébrés par le roi et les masses, ces croyants saisissaient l'occasion d'entrer secrètement ${ }^{131}$ dans les archives (du palais) ${ }^{132}$, se jetaient le visage contre terre et gémissaient, en larmes et en prière devant Dieu ${ }^{133}$. Des condisciples ${ }^{134}$ les gardèrent ${ }^{135}$.

126 «dans le Christ»: le complément du nom introduit par $\mathbf{x}$ a ici un sens objectif, « la foi du Christ» pour dire « la foi que l'on a dans le Christ».

127 «... éprouvés par l'épreuve de la patience...».

${ }^{128}$ Litt. « leur face » ou « leur apparence ».

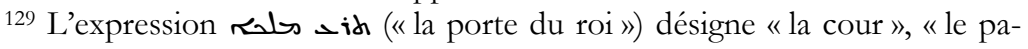
lais » (PAYNE-SMith), cf. Dn 2,49 et Est 3,$2 ; 4,2 ; 5,9$. Ce qui signifie que les jeunes gens étaient attachés à la cour royale. C'est ce qui est dit explicitement dans $B D:$ « ... ils étaient à la porte du roi parce qu'ils étaient des serviteurs et des enfants du palais ainsi que (fils) de chefs et de notables de la ville...»; $S$ comporte le même ajout, avec une variante : «... de toute la ville».

130 «... dans la veille, dans le jeûne, dans la prière et dans le murmure de la supplication...».

${ }^{131}$ L'expression « voler un moment » signifie « saisir l'occasion » (PAYNESMITH).

${ }^{132}$ Littéralement « dans la maison des archives », que nous rendons par « les archives » (sous-entendu « du palais »).

$133 S:$ «... ils gémissaient et ainsi, au moment des sacrifices, alors que le roi et les foules qui étaient avec lui faisaient des offrandes, ces bienheureux offraient à Dieu le sacrifice de la confession de leur cœur, en suppliant et en disant: Christ qui t'es abaissé pour le salut du genre humain et (qui) as revêtu un corps de la sainte Vierge, Dieu de Dieu, Lumière de Lumière, consubstantiel au Père dans les mains de qui tout repose - ce qui est dans les cieux et sur la terre -, toi qui t'es livré par ta volonté au bois de la croix, dirige tout à la connaissance de ta vérité ! Car par toi, Seigneur, sont amenés tous les peuples à l'adoration de ton Père ainsi que de toi et de ton Esprit vivant et saint, Trinité insondable et impénétrable. Toi, mon Seigneur, par ta volonté tu fus appelé (Һiohr) en sacrifice, aussi, maintenant, mon Seigneur, aie pitié des hommes rachetés par ton noble sang! Car voici que leurs corps sont souillés par des sacrifices (offerts) aux idoles. Mets un terme à l'erreur parmi tes créatures, notre Seigneur, et donne aux chrétiens l'assurance de t'adorer et de te glorifier! Et tandis qu'ils agissaient quotidiennement de la sorte...», cf. M. VAN ESBROECK, op. cit., p. 195.

134 Selon Allgeier, il s'agit de désigner les soldats de la garde palatine d'une même $\sigma \chi 0 \lambda \eta$. Après Constantin, le terme «schola » désigne "certains groupements militaires ou de fonctionnaires militarisés [...]. Chaque corps était composé de cinq cents hommes. » (voir R. CAGNAT «Schola », DAGR, v. 4.2, p.

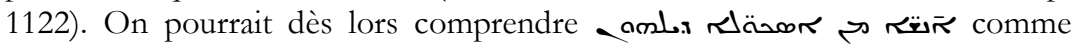
étant «des membres de leurs scholes », lecture propre au ms $J$. La leçon de $B$ et

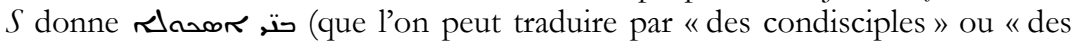
membres de leur schole» au singulier). Le copiste ou le rédacteur de $D$ note

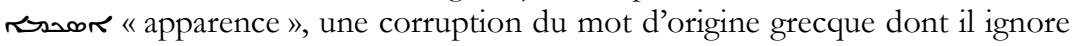
sans doute le sens. 
4. Mais au moment des sacrifices où tout le monde se montrait devant les idoles, on entra et on les trouva seuls dans la maison (des archives), pendant qu'ils se jetaient ${ }^{136}$ contre terre, la tête couverte de poussière ${ }^{137}$, en pleurs et les yeux en larmes. Des ennemis approchèrent et les calomnièrent devant le roi impie. Ils lui dirent: "Auguste roi éternel, dans la paix de ton royaume, tu fais offrir des sacrifices aux dieux même par ceux qui sont au loin. Or, voici que des proches méprisent ta Majesté, dédaignent tes ordres et corrompent ton service. [fol. 122 ] Ils célèbrent le culte des chrétiens dans des lieux secrets au sein de ton palais. Leur chef est Maximilien de génération préfectorale et ses sept compagnons sont des chefs et des notables de cette ville ». Alors le roi fut irrité : il envoya les saisir ${ }^{138}$. On les fit entrer devant lui, alors qu'ils étaient en larmes et que la couronne de leur tête (était) couverte de la poussière ${ }^{139}$ sur laquelle étendus ${ }^{140}$, ils gémissaient, en larmes et en prière devant Dieu. Le roi Dèce prit la parole ${ }^{141}:$ «Pourquoi ne restez-vous pas pendant les sacrifices qui sont offerts aux dieux de toute la terre et (pourquoi) ne vous joignez-vous pas aux chefs et au peuple de votre ville ${ }^{142}$ ? Désormais, approchez, et comme tout le monde, accomplissez les sacrifices ainsi qu'il sied aux divinités ${ }^{143}$ ! » Alors Maximilien répondit et dit : « Nous avons un Dieu caché ${ }^{144}$ dont sont remplis les cieux et la terre à qui nous offrons les sacrifices purs et secrets de notre confession ${ }^{145}$. Nous offrons l'encens d'action de grâce de nos langues à la nature mystérieuse de son essence. Nous apparaissons continuellement devant lui dans notre entière dévotion ${ }^{146}$ et dans le murmure de notre prière. Ainsi, nous n'offrirons ni l'encens d'une fumée impure devant des idoles ni des holocaustes impurs devant les démons! Nous ne souillerons ni nos âmes ni la pureté de nos

135 Le verbe $\downarrow$ 《 garder » dans le sens de « surveiller », 《 tenir l'œil sur ».

136 «... en jetant leurs corps...».

137 Selon l'usage biblique, en signe de deuil ou de tristesse, on jetait de la poussière sur sa tête cf. Jb 2,10 (voir aussi note 198).

138 «il envoya les saisir»: les deux verbes sont juxtaposés; ils expriment deux actions étroitement unies.

139 «... la poussière du sol...».

140 «... dans laquelle ils s'étaient étendus...».

141 «... Le roi Dèce répondit et dit... ».

142 «... du peuple des gens de votre ville... ».

143 «... avec la dette qui est due aux divinités... ».

144 Dans BJS, Dieu est qualifié de Dieu «caché », «invisible ». Cette idée peut renvoyer à Col 1,15: "Il est l'image du Dieu invisible, le premier né de toute création..." ou encore au discours de Paul à Athènes en Ac 17,23 qui se termine sur l'allusion à la résurrection, idée que refusent les grecs : «Lorsqu'ils entendirent parler de résurrection des morts, les uns se moquèrent, et les autres dirent: Nous t'entendrons là-dessus une autre fois » (Ac 17,32). Notons que seul $D$ donne le mot "puissant» corruption ou mauvaise lecture de حس Кルル.

145 La leçon de $S$ fait écho au credo de Nicée (325) : «Nous avons un Dieu caché dont sont remplis les cieux et la terre. A lui et à son Fils qui a été envoyé au monde par lui, et à l'Esprit saint avec lui, Trinité indivisible, nous offrons...»

146 «... dans la perfection de la pensée de nous tous... ». 
corps!» Alors, le roi interrogea successivement chacun d'entre $\operatorname{eux}^{147}$.

5. Mais c'était la confession de leur profession de foi. Le roi ordonna de couper les ceintures de huit d'entre eux en disant: «Puisque vous êtes en désaccord avec le culte de nos honorables dieux et avec notre Majesté, vous voilà étrangers à la grandeur du service de notre royaume ${ }^{148}$ ! (Cependant) jusqu'à ce que j'aie l'occasion (de vous réinterroger), vous serez mis à l'épreuve par les questions (que l'on vous posera) concernant vos paroles ${ }^{149}$. [fol. $\left.123^{a}\right]$ En effet, il serait injuste de vous briser sous la torture dans la force de l'âge ${ }^{150}$, mais je vous donne l'occasion de vous assagir... et vous vivrez!» Le roi ordonna qu'on ôtât les chaînes d'or de leur $\operatorname{cou}^{151}$ et on les congédia ${ }^{152}$. Le roi Dèce sortit ${ }^{153}$ vers d'autres villes pour $(\mathrm{y})$ exercer son pouvoir et il reviendrait à Ephèse avec cette pensée (à l'esprit).

6. Alors Maximilien et ses compagnons eurent, en vertu de leur foi, l'idée d'accomplir un acte de charité ; ils prirent de l'argent et de l'or dans la maison de leurs parents, et, en secret et en public, donnaient des aumônes aux pauvres. Ils se consultèrent (ensuite) en disant : «Eloignons-nous ${ }^{154}$ de la ville, rendons-nous à la grande caverne qui est sur la montagne Onchelos ${ }^{155}$ et présentonsnous là constamment en prière devant Dieu, sans l'agitation du monde ni le trouble de nos parents, jusqu'au retour du roi devant qui nous nous tiendrons en jugement. Nous ne cesserons de glorifier Dieu et Dieu fera de nous selon sa volonté ». Tous furent

147 «... parla avec chacun d'eux (en posant) une suite de questions... ».

148 Si les dormants sont effectivement des militaires attachés au service de l'empereur, le terme syriaque œosas (du grec $\zeta \omega ́ v \eta)$ désigne alors le ceinturon du soldat romain ("cingulum»). Défaire le ceinturon d'un soldat est en effet un signe de dégradation militaire, voir E. SAGLIO, «Cingulum », DAGR, v. 1. 2, p. 1178.

149 «... les questions de vos propos...».

150 «... il ne serait pas juste de briser votre jeunesse sous les tortures ni de vite détruire votre force....».

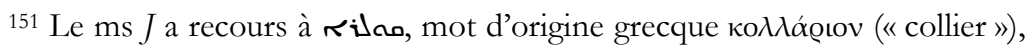
alors que BDS utilisent le terme rir d'origine sémitique, qui signifie « chấne ». $J$ propose un sens singulier à ce passage : on ôte le collier en or d'un noble en signe de disgrâce; le collier était porté au cou. BDS s'éloignent de cette signification : «il (Dèce) ordonna qu'on ôtât les chaînes de fer ( $\left(\nabla_{1}\right.$ iq. $\left.\mathbf{x}\right)$ de leurs

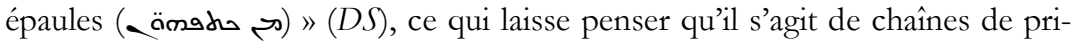
sonnier; $B$ propose un sens intermédiaire : «il ordonna qu'on ôtât les chaînes d'or de leurs épaules ».

152 «... on les fit sortir de devant lui...»».

153 Dans notre édition du texte syriaque, nous avons laissé le verbe sa avec le a final bien que le sujet soit m. s., considérant qu'il s'agit du pronom de la $3^{\mathrm{e}} \mathrm{m}$. s. am (celui-ci peut se contracter avec le parfait).

${ }^{154}$ Le futur en syriaque sert à rendre les modes volitifs : l'ordre à la deuxième personne (impératif) ou à la troisième (jussif), ou encore l'exhortation à la première personne (cohortatif).

155 Dans l'hagiographie grecque, la montagne où les jeunes gens ont dormi

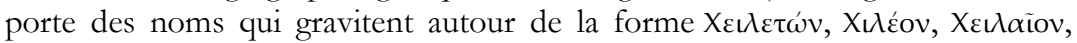

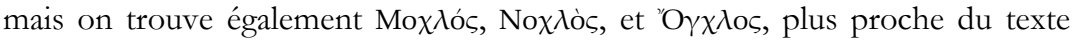
syriaque, cf. H. LECLERQ, «Sept Dormants d'Ephèse », DACL, vol. 15/1, col. 1256. 
d'accord avec ce conseil donné par Maximilien ${ }^{156}$, leur compagnon - (ce dernier) ainsi que ${ }^{157}$ tout le beau cercle ${ }^{158}$ de ses condisciples étaient donc au nombre de huit. Ils jetèrent des pièces de monnaie ${ }^{159}$ qu'ils avaient prises avec eux dans des bourses, montèrent à la caverne qui est sur la montagne Onchelos et y demeurèrent plusieurs jours, le visage contre terre ${ }^{160}$, dans la prière et dans la supplication pour avoir la vie sauve. Alors, de Jamblique qui était le plus débrouillard, le plus sage et le plus subtil ${ }^{161}$, ses compagnons firent leur exécutant. Comme il s'était déguisé en mendiant ${ }^{162}$, il prit l'argent avec lui, descendit en ville et s'informa des événements ${ }^{163}$.

7. Le jour arriva où Dèce revint à la ville [fol. 123 $3^{b}$ d'Ephèse. Il ordonna aussitôt à tous les magistrats - ceux qu'il connaissait et ceux auxquels il avait pensé - de sacrifier avec la famille de Maximilien et (celle de) ses compagnons. Ce fut l'épouvante pour tous les croyants : ils fuirent devant lui. Jamblique aussi, dans la frayeur, prit la fuite devant (Dèce) ; il quitta la ville, et comme il emportait un peu de nourriture avec lui, il remonta à la caverne auprès de ses compagnons. Troublé et perturbé par le danger, il les informa de l'entrée du roi dans la ville, et qu'on avait ordonné et exigé des magistrats d'entrer et de sacrifier en présence (du roi). A ces mots, ils furent effrayés et saisis de crainte. Ils adressèrent une prière à Dieu, le visage contre terre, ${ }^{164}$ et dans une grande supplication et une amère souffrance, ils confiaient leur vie à

\footnotetext{
156 «... avec le conseil que Maximilien conseilla...».

157 Cf. note 116.

${ }^{158}$ Le mot signifie " couronne ", mais il a ici le sens de « compagnie »,
} « cercle», cf. PAYNE-Smith (par ex : «cercle de disciples »). D: «Tout le beau cercle des croyants fut d'accord avec ce conseil : ils étaient au nombre de huit». $B$ ajoute « (huit) d'entre eux ». $S$ dit simplement: « et huit d'entre eux furent d'accord avec ce conseil », tandis que $Z$ (la version de Zacharie le rhéteur qui compte sept dormants) a pour leçon: «et les sept furent d'accord avec ce conseil». Dans certaines recensions grecques (le groupe de manuscrits $G_{1}$ décrit par Huber, cf. HuBER, p. 49), on trouve l'expression «couronne incor-

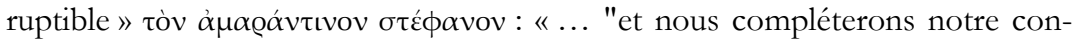
fession devant le roi et prendrons la couronne incorruptible préparée pour les fidèles". Et ainsi, les sept furent d'accord à ce sujet». L'épitomé de Siméon Métaphraste dans la $P G$ utilise le terme $\sigma \tau \varepsilon ́ \phi \alpha v o \varsigma$ dans le même contexte mais ne mentionne pas le nombre des confesseurs : «..."et nous compléterons notre belle confession devant le tyran, et nous porterons la couronne incorruptible préparée pour les fidèles", et ils approuvèrent ». C'est une allusion à 1 P 5,4 : «Et quand paraitra le souverain, vous obtiendrez la couronne de gloire incorruptible » qu'on ne retrouve pas dans la tradition syriaque.

159 «... de la monnaie de l'argent...».

160 «... en (se) jetant le visage... ».

${ }^{161}$ Le syriaque ne possédant pas de forme propre pour le comparatif et le superlatif, un adjectif peut par lui-même avoir le sens d'un élatif quand plusieurs individus sont mis en parallèle.

162 «... Comme il avait changé ses vêtements en l'apparence (de ceux) d'un mendiant...».

163 «... de ce qui se faisait en ville ». BDS: « ... de ce qui se passait dans le palais du roi. De la bourse qu'il avait sur lui et du pain (qu'il avait) en guise de nourriture, il donna des aumônes aux pauvres, puis remonta auprès de ses compagnons et les informa de ce qui se passait en ville... ».

164 «... posé sur le sol...». 
Dieu. Jamblique se leva, prépara et posa devant eux le peu de nourriture qu'il avait apportée. Il les fit lever afin qu'ils se nourrissent, se reposent et se préparent à affronter le tyran. Ils levèrent le visage, s'assirent ensemble au milieu de la caverne et, les yeux en larmes et le cœur douloureux, ils prirent à manger ${ }^{165}$. Arriva le coucher du soleil ${ }^{166}$ et alors qu'ils étaient assis en pleurant et qu'ils parlaient entre eux ${ }^{167}$, ils s'assoupirent car leurs paupières ${ }^{168}$ étaient lourdes.

8. Alors, Dieu miséricordieux qui en tout temps prend soin "de ceux qui travaillent dans sa vigne"169, décréta à leur égard une mort tranquille et douce comme pour le miracle à venir qui allait être révélé : sans qu'ils ne sentent ni leur mort ni leur âme sortir (de leur corps), ensemble, ils dormirent à terre comme (sur) un lit de repos et rendirent l'âme [fol. 124'], avec la confession de Dieu dans la bouche, alors que leur argent (était posé) ${ }^{170}$ à côté d'eux et qu'ils étaient pareillement étendus sur le sol ${ }^{171}-$ l'argent était donc dans des bourses. Le matin de ce jour-là, le roi ordonna qu'on les cherchât ${ }^{172}$ dans le palais, parmi les magistrats, (dans) toute la ville et dans tous les coins. On (les) chercha mais on ne (les) trouva pas. Le roi dit à ses nobles: "Je souffre beaucoup du départ de ces jeunes gens car ils sont fils de notables. Ils ont pensé que notre Majesté était en colère contre eux en raison de leur faute passée $^{173}$. Mais la clémence de notre Majesté ne se souvient pas des fautes de ceux qui pèchent à condition qu'ils retournent vers les dieux cléments ». Les notables de la ville répondirent en disant au roi : «Que ta Majesté n'aie point de chagrin pour ces jeunes gens rebelles car ils sont encore dans la même effronterie qu'auparavant. Comme nous l'avons appris, ils ont eu l'occasion d'accomplir leur mauvaise volonté : pendant ces jours où l'occasion leur a été donnée par ta Majesté, ils ont dilapidé leur argent et leur or dans les marchés de la ville et se sont cachés. Depuis, on ne les a plus vus. Si ta Majesté désire qu'ils comparaissent ${ }^{174}$ devant elle, on s'emparera de leurs parents et on les torturera. Ils t'informeront dès lors de l'endroit où (ceux-là) sont cachés ». A ces mots, le roi se mit en colère. Il envoya amener leurs parents. Il les fit comparaitre devant lui. Le roi leur demanda et dit : «Où sont ces rebelles qui se sont révoltés contre le décret de notre Majesté, qui ont dédaigné nos redoutables commandements et méprisé les cultes des honorables dieux ? A présent, j’ordonne que vous mouriez pour leur impudence!»

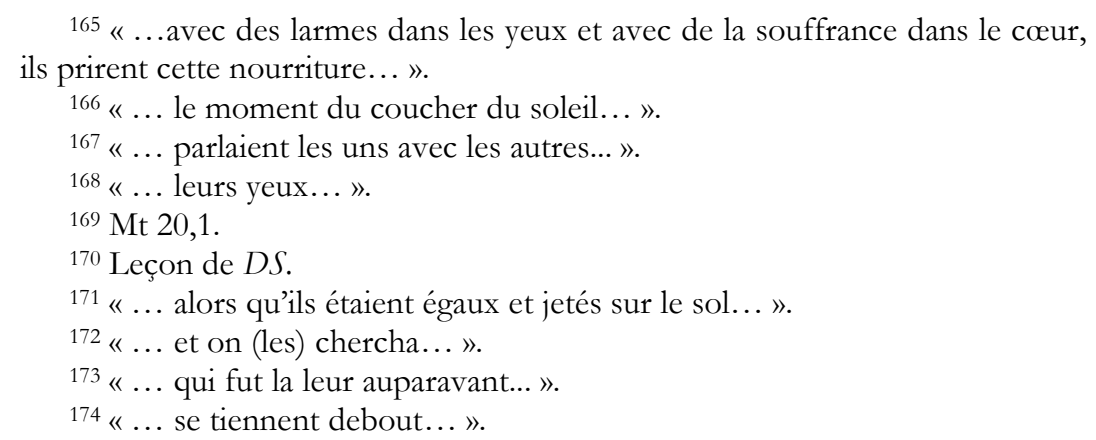


9. Leurs parents répondirent en disant: «De grâce ${ }^{175}$, ta Majesté! Mon Seigneur, nous n'avons pas méprisé l'ordre de ta grandeur ni [fol. 124 ${ }^{\mathrm{b}}$ ] abandonné les cultes des honorables dieux! Pourquoi sommes-nous condamnés à mort à la place des rebelles qui ont dilapidé notre argent et notre or dans les marchés de la ville ? Les voici cachés dans une caverne qui se trouve sur la montagne Onchelos, un endroit qui n'est pas très éloigné de la ville. Ils sont en difficulté, bien qu'ils soient vivants, depuis tout ce temps où nous ne les avons pas vus ». Alors le roi libéra leurs parents et ils purent disposer ${ }^{176}$. Le roi réfléchit donc au sort des croyants ${ }^{177}$ et Dieu lui inspira ${ }^{178}$ contre son gré de fermer la porte de la caverne à l'aide de pierres, en guise de tombeau pour les corps purs des saints, ceux qui seraient conservés par Dieu en vertu de sa prescience pour être des hérauts de la résurrection d'entre les morts par leur résurrection au temps où (ils serviraient) d'exemple aux hérétiques.

10. Le roi dit: «Ainsi, j'ordonne que ces rebelles qui ont rejeté nos chers et doux commandements et qui se sont révoltés contre le culte des dieux soient bannis ${ }^{179}$ de la gloire de notre royaume! Qu'ils ne se montrent plus devant les dieux et que l'entrée de cette caverne où ils ont fuit soit désormais condamnée ${ }^{180}$ au moyen de blocs de jaspe ${ }^{181}$ ! Que la vie leur soit ôtée et que dans une misère éternelle, ils meurent!» (En effet) le roi et toute la ville pensaient que les confesseurs étaient en vie dans leur refuge ${ }^{182}$ qui (se trouvait) là. Or, Ithidoros et Arabos, des familiers du roi qui étaient chrétiens mais se cachaient par crainte du souverain, réfléchirent ensemble en disant: «Ecrivons le témoignage de ces confesseurs sur des tablettes de plomb et mettons(les) dans un coffre de cuivre que nous scellerons avec des sceaux d'argent; (ensuite) elles seront posées secrètement à l'intérieur avec ceux qui fermeront l'entrée de la caverne. Peut-être Dieu ordonnera-t-il [fol. 125 ${ }^{\mathrm{a}}$ ] avant son avènement ou par un (autre) moyen, que l'on ouvre la caverne afin que les corps purs des saints qui y sont emprisonnés soient honorés grâce à la confession de foi écrite posée $e^{183}$ à l'entrée de la caverne... ». Les croyants approuvèrent le conseil de ces deux-là ${ }^{184}$. Lorsque toutes ces choses advinrent par l'action de Dieu, (tout cela) se réalisa également.

175 «... Nous te prions...».

176 « ... sortirent de devant lui... ».

177 «... à ce qu'il allait faire aux croyants... ».

178 «... suscita dans son cœur...».

179 «... étrangers à... ».

180 «... fermée... ».

181 «... de pierres entières de jaspe...».

$182 S:$ «... mais l'impie ignorait que par la volonté de leur Seigneur, ils dormaient d'un sommeil paisible et qu'ils ne ressentaient rien de ce qui leur était fait de la main de l'impie... ».

${ }^{183}$ Le texte utilise 0 part. passif masculin alors que rhousos féminin, mais en syriaque, un passif peut demeurer invariable (DUVAL, p. 306 a) : litt. « qu'il y a posée ».

${ }^{184}$ Ithidoros et Arabos. 
11. Le roi Dèce mourut ainsi que toute cette génération et des dynasties de rois lui succédèrent sur le trône ${ }^{185}$ jusqu'aux années de Théodose ${ }^{186}$ fils d'Arcadius, le roi croyant. En l'an 38 de son règne ${ }^{187}$, une hérésie d'erreur démoniaque produisit des inepties en vue de cacher la promesse de la résurrection. On voulut anéantir la promesse de la résurrection que le Christ avait donnée à son Eglise. De troublantes rumeurs arrivèrent aux oreilles ${ }^{188}$ du roi pur. Même les idolâtres qui étaient dans le palais lui présentaient ouvertement des livres mensongers, et les évêques qui paraissaient être en ce temps-là des discutailleurs ${ }^{189}$ dans l'Eglise de Dieu devenaient (de plus en plus) nombreux. Le meneur de la perturbation était Théodore, évêque de la ville d'Aegae ${ }^{190}$, avec des évêques dont il ne convient pas d'écrire les noms dans ce livre de confesseurs car ils ont tourmenté l'Eglise et troublé la foi par la recherche $^{191}$ de leurs vains propos. Ainsi, les pensées du roi Théodose étaient chaque jour agitées par les pleurs. Il sombrait dans beaucoup d'incertitude lorsqu'il voyait la foi de l'Eglise être traînée de toutes parts ${ }^{192}$. Certains hérétiques disaient ${ }^{193}$ que le corps qui est pourri et corrompu ne ressuscitera pas, mais que seule l'âme recevra la promesse de la vie. Ils étaient séduits par

185 «... après lui, régnèrent des rois en succession de la royauté... ».

186 Il s'agit de Théodose II (401-450), petit-fils de Théodose premier (379395). Ce dernier fit du christianisme une religion d'Etat (380) et interdit toute pratique païenne. A sa mort, il partagea l'empire entre ses deux fils, Honorius et Arcadius.

${ }^{187}$ Ce qui correspond à l'an 446 de notre ère.

188 «... tombèrent dans les oreilles... ».

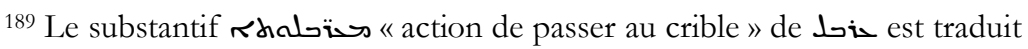
par «discutailleurs». Dans la version de Zacharie le rhéteur, il est clairement question de ז ras », " embrouillamini » et $S$ rhadoiحdos ("perplexité »), deux termes issus du parel de حمل (" tordre », " embrouiller»).

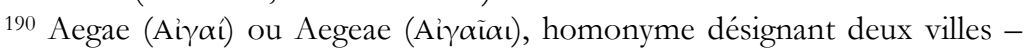
l'une en Eolide, l'autre en Cilicie - dont aucune ne figure dans les Noticiae episcoparum, cf. S. PETRIDEZ, «Aegae », DHGE, vol. 1, col. 645. Le Quien en fait cependant "un évêché suffragant d'Ephèse » et lui attribue des évêques dont le Théodore mentionné dans le récit des Dormants, LE QUIEN, Oriens christianus, t. 1, col. 779. Notons que dans l'un des témoins grecs (PG CIV, col. 101), le texte parle d'un personnage et non pas d'une ville; il y est en effet question de deux

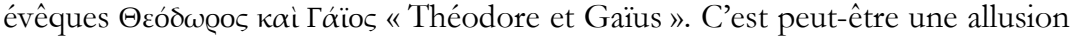
à Gaïus, patriarche d'Alexandrie qui défendait les positions de Julien d'Halicarnasse sur l'incorruptibilité du corps du Christ avant la résurrection (voir note 212). Les adeptes de Julien d'Halicarnasse étaient appelés « julianistes », « aphtarodocètes », "phantasiastes », mais ils étaient aussi connus sous le nom de « gaïanites » (cf. M. JUGIE, « Gaïanites » dans DTC, nº (1915), col. 999-1002). Ces derniers considéraient le corps humain comme impur, c'est pourquoi ils étaient également accusés de manichéisme (cf. A. GRILLMEIER, Le Christ dans la tradition chrétienne, II/4. L'Eglise d'Alexandrie, la Nubie et l'Éthiopie après 451, Paris, 1996, p. 86). Sans doute est-il intéressant de souligner que le ms $J$ - c'est le seul - compare les corps «à des prisons ».

${ }^{191}$ Le terme حمor désigne ici la «recherche» sur des questions théologiques (PAYNE-SMITH).

192 " ... ici et là... ».

193 BDS : «... qu'il n'y avait pas de résurrection des morts et d'autres disaient aussi... ». 
des paroles de mensonge ${ }^{194}$ et ne comprenaient pas que jamais un enfant ne naissait du ventre (de sa mère) sans corps et que le corps ne quittait pas [fol. 125 $5^{\mathrm{b}}$ ] l'utérus sans une âme, un souffle de vie. Leur intelligence devenait sourde et ils n'entendaient pas pour accepter la parole de notre Seigneur qui dit : "Les morts qui sont dans les tombeaux entendront la voix du Fils de Dieu et vivront ${ }^{195}$ ". Il dit également : "Voici, j’ouvrirai vos sépulcres et vous

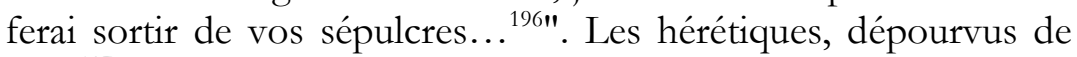
salut ${ }^{197}$, avaient échangé la douceur de la résurrection contre l'amertume de leur âme; ils avaient troublé et embrouillé l'opinion pure et claire des croyants.

12. La raison du roi Théodose avait faibli, (alors) il s'affaiblit et tomba malade; il s'allongea sur un $\mathrm{sac}^{198}$ dans sa chambre à coucher. Alors Dieu miséricordieux qui ne veut pas que l'on s'égare du chemin de la vérité, voulut procurer la guérison aux esprits malades et révéler la promesse de la résurrection des morts en rétablissant les dormants ${ }^{199}$ qui pendant ce temps avaient été conservés par sa connaissance. (Il voulut) dissiper et repousser le mal loin de la sérénité de son Eglise, soutenir son édifice contre les vagues agitées et violentes qui la frappaient ${ }^{200}$, et faire briller la lumière de la consolation sur le roi Théodose qui avec ses pères se vouait au service de la couronne de justice ${ }^{201}$. Alors, Dieu inspira soudain à Arinis $^{202}$ - le propriétaire du domaine qui abritait la caverne $^{203}$ où se trouvaient les saints - de construire avec zèle un enclos pour son troupeau à cet endroit ${ }^{204}$. Des ouvriers travaillaient là pendant un jour ou deux et ôtaient des pierres (qui provenaient) aussi de l'entrée de cette caverne en vue de la construc$\operatorname{tion}^{205}$. La nuit du deuxième jour, lorsque la porte de la caverne

194 On suppose un ح ou un ه devant 2 « et ils étaient séduits par des pa-

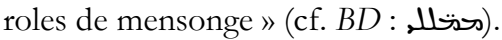

195 Allusion à "... les morts entendront la voix du Fils de Dieu et ceux qui l'entendront vivront... " Jn 25,5 et "... ceux qui sont dans les sépulcres, entendront sa voix et en sortiront..." Jn 25,8. BDS ajoutent : « ... et il est dit également: "Ceux qui dorment dans la poussière seront ressuscités et glorifieront..."...» Dt 2,3.

$196 \mathrm{Ez} 37,12$.

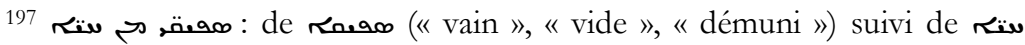
(« vie » ou « salut» cf. Lc 3,6 : «Et toute chair verra le salut de Dieu »). Les hérétiques sont « dépourvus de vie » ou « dépourvus de salut», dans la mesure où ils n'ont pas foi en la résurrection.

198 sal : «il se jeta» (COSTAZ) ou «il s'étendit»(PAYNE-SMITH). Selon l'usage biblique, en signe de deuil ou de pénitence, on échangeait ses habits ordinaires contre un sac, c'est-à-dire une étoffe grossière, et on s'allongeait sur la cendre, cf. $B D S$ « il s'allongea sur un sac et sur la cendre ».

199 «... par le rétablissement des dormants...».

200 «... frappèrent... ».

$2012 \operatorname{Tm} 4,8$.

202 «... suscita dans l'esprit d'Arinis... ».

203 « ... celui de la caverne... ».

204 « ...là.... ».

205 BDS sont plus clairs: les ouvriers «faisaient rouler des pierres de l'entrée d'autres tombeaux et (en ôtaient) de l'entrée de cette grotte également pour la construction... ». 
fut enfoncée, l'ordre de Dieu vivificateur donna vie ${ }^{206}$ aux dormants qui y reposaient ${ }^{207}$. Celui qui donne le souffle de vie à l'enfant endormi dans le ventre de sa mère, celui qui par sa volonté a recomposé les ossements détruits et desséchés dans la plaine et (les) a ressuscités ${ }^{208}$, celui qui a appelé et fait sortir Lazare enterré, alors qu'il était enfermé et ceint (de bandelettes) ${ }^{209}$ [fol. 126 ${ }^{2}$ ] du tombeau à la vie, (lui) par le murmure de son commandement, insuffla la vie ${ }^{210}$ aux confesseurs - ceux qui avaient dormi dans la caverne. Ils se levèrent, s'assirent et le visage resplendissant ${ }^{211}$ comme lors d'un matin ordinaire, ils se saluèrent mutuellement sans qu'une trace de mort ne fût visible sur $\operatorname{eux}^{212}$. Leurs vêtements étaient tels que lorsqu'ils s'étaient endormis et à leur réveil $^{213}$, ils ressentaient l'impression d'inquiétude de l'affaire avec laquelle ils avaient dormi le soir $^{214}$ et (s'imaginaient que) le roi Dèce songeait à eux. C'est ce qu'ils pensaient, et alors qu'ils étaient tristes et pleuraient, les yeux en larmes, ils regardèrent vers Jamblique, leur exécutant, l'interrogèrent et s'informèrent auprès de lui de ce que le soir, on disait en ville. Il leur dit: "Comme je vous l'ai dit hier ${ }^{215}$ : on nous ordonne et on nous demande de sacrifier aux idoles devant (le roi) avec les magistrats. (Dèce) a pris sa décision ${ }^{216}$. Dès lors, Dieu sait ce qu'il adviendra de nous!»

13. Maximilien répondit et leur dit: «Mes frères, nous sommes prêts à nous tenir debout devant le tribunal redoutable du Christ, mais nous ne tremblerons pas devant le tribunal de la justice des hommes, ni ne renierons la vie que nous avons dans la foi au Fils de Dieu!» Ils dirent à Jamblique : «Pour l'instant, notre frère, il est temps de manger. Prends l'argent, rends-toi en ville, informetoi de ce qui est dit par le roi Dèce et revient. Notre frère, voici donc, fais pour nous davantage de provision de nourriture ${ }^{217}$ car celle que tu nous as apportée hier est insuffisante et nous avons

\footnotetext{
206 «... plaça la vie... ».

207 «... dormaient... ».

208 Ez 37,1-14.

209 Jn 11,1-44.

210 «... donna le souffle de la vie... ».

211 «... avec la splendeur de leur visage... ».
}

212 Dans toutes les recensions syriaques, l'absence de corruption de la chair est démontrée par le fait que les corps des Dormants conservent leur intégrité. Le thème fait écho à l'aphtartodocétisme, doctrine défendue par Julien d'Halicarnasse (6e siècle). Selon lui, le corps du Christ était incorruptible (ou non-corrompu) avant la résurrection, idée à laquelle Sévère d'Antioche était fermement opposé. Cette querelle entre «sévériens » et «julianistes » éclata en Egypte dans les années 518-528 et s'étendit ailleurs dans l'empire (cf. A. GRILLMEIER, Le Christ dans la tradition chrétienne, II/2. L'Eglise de Constantinople au VTe siècle, Paris, 1993, p. 123).

213 «... quand ils furent réveillés...».

214 Il s'agit d'une comparaison dont le premier membre est introduit par אתמ ת (" comme, de même, tel quel ») et le second membre par... ils pensaient donc comme si l'inquiétude de l'affaire avec laquelle ils avaient dormi au soir était présente dans leurs cœurs... ».

$215 \ll$... au soir...».

216 «... voici, il a préparé son idée... ».

217 «... ajoute pour nous de la nourriture... ». 
faim... », (dirent-ils), comme ils pensaient avoir dormi une nuit ${ }^{218}$ seulement et s'être réveillé. Jamblique se leva comme chaque matin $^{219}$ et d'une bourse, prit [fol. 126 ] des pièces de monnaie (d'une valeur) de 60 (et) environ $40^{220}$ parmi celles qui étaient en usage $^{221}$ au temps du roi Dèce. (Cette monnaie) avait été frappée peu de temps avant les jours des confesseurs et datait ${ }^{222}$ de 372 ans avant le jour où les confesseurs avaient été ressuscités ${ }^{223}$.

14. Le matin de ce jour-là, alors qu'il faisait sombre, Jamblique sortit de la caverne. Lorsqu'il vit les pierres qui étaient déplacées $^{224}$, il s'étonna mais ne comprit pas ce que c'était ${ }^{225}$. Il descendit de la montagne et avança pour se rendre en ville (mais) non par la route, car il craignait que quelqu'un ne le reconnût et ne le conduisît au roi Dèce ; le bienheureux ignorait que les os du tyran pourrissaient et gisaient à l'intérieur d'une tombe! Comme Jamblique approchait de la porte de la ville, il leva les yeux et vit l'emblème de la croix qui était fixé au-dessus de la porte de la ville. Il (le) vit, fut surpris et le regarda à la dérobée. Il alla ici et là, à l'extérieur et revint. Il pensait et réfléchissait ${ }^{226}$ avec étonne$\mathrm{ment}^{227}$. Il fit le tour vers l'autre porte et vit (qu'il en était) de même et fut stupéfait. Il fit le tour de toute la ville, (regarda) audessus de toutes les portes et vit que sur toutes le signe de la croix était fixé. La ville lui semblait complètement changée en raison d'édifices différents qu'il n'avait (jamais) vus ${ }^{228}$. Il avançait, avec stupéfaction, comme pris de vertiges. Il revint et se tint debout près de la porte près de laquelle il s'était tenu ${ }^{229}$ auparavant et s'étonna. Il se dit en lui-même : "Que signifie ce signe de la croix que les croyants (dé)posaient au soir dans (leurs) chambres et que voici au matin publiquement posé sur les portes de la ville, tout

218 « ... le sommeil d'une seule nuit...».

219 «... le matin, selon l'habitude de chaque jour...».

$220 \mathrm{La}$ préposition $>$ suivie d'un nombre signifie «dans les...» (cf. COSTAZ). Le rédacteur de $J$ (ou le copiste) semble avoir abrégé ce passage, car BDS mentionnent des valeurs exactes ( 62 et 44 , au lieu de 60 et « environ $40 »$ ), valeurs communes au texte grec de la $P G$ et au groupe de $m_{s s} G_{1}$ établi par Huber.

221 sمa: "en usage", "to be current, in use (of coin)» (SOKOLOFF, p. 933).

222 «et qui était»: גo suivi de x a le sens de «avoir», «appartenir» (DUVAL, p. 299).

223 «... parmi celles (en usage) aux jours du roi Dèce, (monnaie) qui avait été frappée peu de temps avant les jours des confesseurs (et) qui était avant 372 ans jusqu'au jour où les confesseurs...».

${ }^{224}$ Litt. «posées ». Cette description évoque ce passage de l'Evangile : "Le premier jour de la semaine, Marie de Magdala se rendit au sépulcre dès le matin, comme il faisait encore obscur ; et elle vit que la pierre était ôtée du sépulcre..." Jn 20,1.

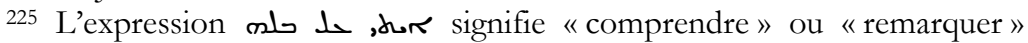
(SOKOLOFF, p. 110-111).

226 «... il pensait et réfléchissait dans ses pensées... ».

227 «... tout en étant surpris... ».

228 «Toute la ville était changée à ses yeux de par des édifices différents qu'il n'avait (jamais) vus ».

229 «... appuyé... ». 
autour ?» Et il reprenait ${ }^{230}$ ses esprits et se pinçait ${ }^{231}\left[\right.$ fol. $\left.127^{a}\right]$ en disant : "C'est un rêve ». Ensuite, il se donna du courage et, se couvrant la tête de son manteau, il entra dans la ville. En pénétrant au marché, il entendit que beaucoup lorsqu'ils parlaient, juraient par le nom du Christ. Il eut très peur et fut perturbé ${ }^{232}$. Il se dit: "Qu'est-ce que cela signifie? Je ne sais pas! Voilà qu'au soir personne ne parlait ouvertement au nom du Christ et voici qu'au matin... il est sur toutes les lèvres ${ }^{233}$ ! » Il se dit : «Peut-être n'est-ce pas la ville d'Ephèse puisque les édifices sont méconnaissables et que la langue parlée est différente ${ }^{234}$. Mais je ne connais pas d'autre ville qui nous soit proche et je n'en vois pas». Il se tenait debout avec stupéfaction ${ }^{235}$. Il rencontra un garçon, lui demanda et lui dit: "Dis-moi, garçon, quel est le nom de cette ville ? » Le garçon lui dit: "Son nom est Ephèse ». (Alors) Jamblique se dit avec étonnement ${ }^{236}:$ "Peut-être m'est-il arrivé quelque chose et que je divague? Je vais quitter cette ville rapidement, de peur de m'égarer et de m’y perdre. Me voilà pris de vertiges!» Toutes ces choses, Jamblique les répéta lorsqu'il monta à la caverne auprès de ses compagnons lorsque leur résurrection fut révélée et qu'elle fut consignée dans un livre ${ }^{237}$.

15. Alors, Jamblique pressé de quitter la ville, approcha des vendeurs de pain, déguisé en mendiant ${ }^{238}$. Il sortit ${ }^{239}$ l'argent de sa bourse et (le) donna aux vendeurs de pain. Ils regardèrent l'argent, et à la vue d'une monnaie d'aussi grande valeur ${ }^{240}$, ils furent frappés d'étonnement. Ils se la faisaient passer ${ }^{241}$ sur l'étalage du pain, murmuraient, regardaient l'homme et disaient: "Cet homme a trouvé un trésor [fol. $127^{\mathrm{b}}$ ] (qui) date d'il y a des générations et des années!» Jamblique les regardait murmurer et l'observer. Il tressaillit et tout son corps trembla de peur, car il pensait qu'on l'avait reconnu et qu'on allait le conduire au roi Dèce. D'autres approchaient de son visage et (le) dévisageaient. Alors qu'il était debout et rempli de crainte, il leur dit: "Je vous en prie! Voici l'argent, je vous (le) donne. Je ne veux pas prendre de pain. Seulement, ne murmurez pas à mon sujet! » Alors, ils se dressèrent, levèrent la main ${ }^{242}$ sur lui, se saisirent de (sa personne) et lui dirent: "Toi qui as trouvé un trésor de rois anciens, montre(-le) nous pour que nous soyons tes associés et nous garderons le se-

\footnotetext{
230 «... rassemblait... ».

$231 \ll \ldots$ touchait son corps... ».

232 «... ses pensées changèrent...».

233 «... il occupe la langue de tout le monde...».

234 «.... puisque celle-ci est changée dans les constructions et que la langue parlée est différente...».

235 «.... en s'étonnant à l'intérieur de lui...».

236 «... tout en étant étonné ... ».

237 «... écrite dans un livre... » (leçon de $B D J)$; dans $S$, on a simplement : « écrite ».

238 «... sous l'apparence d'un mendiant...».

239 «... fit sortir...».

240 «... de la monnaie qui était aussi énorme...».

241 «... ils le portaient l'un à l'autre... ».

$242 \ll$... les mains...».
} 
cret te concernant! Sinon, tu seras livré et condamné à mort ${ }^{243}$ !» Alors lui s'étonna intérieurement et dit : "Voilà une chose dont je n'ai pas peur, une crainte de plus pour moi!» Ces hommes lui dirent : «Tu ne peux pas cacher le trésor, ô garçon, comme tu en as l'intention... ». Jamblique ne savait pas quoi leur dire à ce propos. Lorsqu'ils virent qu'il se taisait et ne parlait pas, ils le tirèrent par le manteau et le saisirent par le cou en se tenant au milieu de la foule ${ }^{244}$ tandis que l'on s'attroupait. Le bruit se répandit dans toute la ville. On disait : «On s'est emparé de quelqu'un qui a vu un trésor !» On afflua et on se rassembla autour de lui. On regardait son visage et on disait : «Ce garçon est un étranger que nous n'avons jamais vu». Bien que Jamblique voulait (les) persuader qu'il n'avait pas trouvé de trésor, parce que tout le monde disait: "Je ne le connais pas », il demeurait stupéfait et s'abstenait de parler. (Mais) il gardait ${ }^{245}$ confiance en lui (car) il pensait avoir des parents et des frères dans la ville, ainsi qu'une ${ }^{246}$ famille importante et connue à Ephèse. Il savait et avait la certitude [fol. 128'] qu'au soir il connaitrait tout le monde. Or, au matin, il ne reconnaissait pas même une personne! Comme un fou il regardait dans la foule pour voir quelqu'un de ses frères ou de ses connaissances, mais personne! Et pris de vertiges, il se tenait debout parmi la foule.

16. Alors la ville fit grand bruit, et la rumeur se répandit jusqu'à Mares, évêque et chef de la ville. A ce moment-là Auguste, le proconsul $^{247}$, arrivait également auprès de l'évêque ${ }^{248}$. Cela aussi advint (en vertu de) Dieu au moment où ils seraient ensemble afin que le trésor de la résurrection des morts fût révélé par leur intermédiaire à toutes les nations. Les deux (hommes) ordonnèrent que le garçon restât sous bonne garde et qu'on le conduisît auprès d'eux ${ }^{249}$. On traîna Jamblique (qui tenait) à la main son argent, pour le faire venir ${ }^{250}$ à l'église (mais) lui, pensait qu'on le conduisait à Dèce et regardait ici et là, en pleurant et en gémissant. Il se dit en lui-même : "Malheur à moi, je vais être séparé du beau cercle ${ }^{251}$ de mes compagnons! Parce que nous partageons ${ }^{252}$ la ferme intention de ne pas renier la vie qui nous est réservée, peut-être me conduit-on devant le tribunal du roi et qu'en même temps il me condamnera à mort ? Je ne les reverrai plus ${ }^{253}$ ! Qui leur révélera alors tout ce qui m'est arrivé ? Ils auraient voulu venir (eux aussi) devant le roi (mais malheureusement ils ne le peu-

\footnotetext{
243 «... tu seras livré au jugement de la mort...».

244 «... des foules...»».

245 «... avait...».

246 «... et avoir une... ».

247 orbadur, du grec $\alpha \dot{v} \theta u ́ \pi \alpha \theta$ os (« proconsul »).

248 L'évêque Marès et le proconsul Auguste: il semble que ces deux personnages soient fictifs ; ils ne sont pas historiquement identifiables.

249 «... qu'il soit sous surveillance et qu'il vienne à eux... ».

250 «... pour qu'il vint... ».

${ }^{251}$ Cf. note 158. On peut également traduire le mot حلف par «couronne », cf. Ph 4,1 : "Ainsi donc mes frères bien-aimés, ma joie, ma couronne...".

252 «... nous avons tous...».

253 «... je serai privé de leur vue... ».
} 
vent pas) $!^{254} »$. Alors qu'il pensait de la sorte ${ }^{255}$, réfléchissait et regardait de part et d'autre, les masses se moquaient de lui comme (d')un fou ${ }^{256}$. Alors, on le fit entrer dans l'église avec une grande violence. Lorsque Jamblique vit qu'on ne le conduisait pas à Dèce, il se réjouit un peu. De sa main, le proconsul et Mares prirent l'argent, et ils furent saisis d'étonnement. Le proconsul dit à Jamblique: "Où est le trésor que tu as trouvé (et) dont tu tiens d'ailleurs de l'argent en main?» Jamblique dit: "Mon seigneur, jamais [fol. 128 $8^{b}$ je n'ai trouvé de trésor comme on (le) dit de moi ! Mais je sais que cet argent qui est en ma possession provient de la bourse de mes parents, et que c'est de la monnaie de cette ville... J'ignore ce qu'il en est ! Le proconsul lui dit : «D'où estu et de qui es-tu le fils? Qui te connait ? Qu'il vienne (et) qu'il témoigne!» Il leur dit le nom de ses parents mais on ne les connaissait pas et personne ne le reconnut. Le proconsul répondit et lui dit: «D'où es-tu ? » Jamblique dit : «Je suis d'Ephèse ». Le proconsul dit: "Tu es un menteur et il n'y point de vérité en toi !». Alors qu'il était debout, (Jamblique) inclina la tête, le regard fixe et ne répondit pas un mot. Il ne nia pas avoir trouvé de trésor, pas un oui, pas un non. Les gens qui se tenaient là disaient: «Peut-être est-ce un fou ? » D'autres disaient : «Non, mais il feint (la folie) afin de se tirer d'affaire ${ }^{257} »$. Le proconsul regarda Jamblique et lui dit: "Comment te tenir pour fou ? Ou comment te croire : l'argent qui provient de (cette) bourse appartient à tes parents ? Or, voici que (cette) monnaie et l'effigie qu'elle porte ${ }^{258}$ datent d'il y a plus de 370 ans : elle n'est pas mêlée à une autre monnaie et ne ressemble pas à l'argent dont on se sert pour faire du commerce ${ }^{259}$ dans le monde! Tes parents seraient-ils vieux de plusieurs générations et années alors que toi, tu es un jeune garçon ? Et tu veux tromper les sages anciens de la ville d'Ephèse ! A présent, j'ordonne donc que tu sois livré à la prison à vie ${ }^{260}$, jusqu'à ce que tu avoues où se trouve $e^{261}$ le trésor que tu as découvert ».

${ }^{254}$ Un ajout qui figure dans $S$ traduit dans la note 256 permet de mieux comprendre le sens de cette phrase.

255 «... ces choses...»».

$256 S:$ «... les larmes se mirent à couler sur ses joues, il regarda le ciel et dit: Christ qui dans le ciel es assis à droite de celui qui l'a envoyé, entre avec moi devant le roi ! Il se mit également à pleurer et à dire : Malheur à moi ! Je vais être séparé de mes compagnons! Qui donc leur révèlera tout ce qui m’est arrivé ? Voici qu'on me fait entrer devant le roi et en même temps (s'ils savaient), aussitôt (mes compagnons) descendraient de la caverne dans la joie et me rejoindraient devant le tribunal, parce que nous avons une même et belle volonté de ne pas renier Dieu (pour) rendre grâce aux idoles. Malheur à moi ! Je ne les verrai plus! Car ils ont dit: Nous se serons pas séparés, pas même dans la mort. Et j'ignore mon sort : peut-être du coup, le roi me condamnera-til à mort et que je ne reverrai plus mes compagnons... Ils l'emmenaient et le traînaient à l'église... ».

257 « ... afin de sauver son âme de cette nécessité... ».

258 «... qui (est) sur elle...».

259 « ... avec lequel on fait du commerce...».

260 «... à mort....".

$261 \ll \ldots$ est...». 
17. Alors, quand Jamblique entendit cela, il tomba sur son visage $^{262}$ en pleurant et leur dit : "Je vous en prie! Mon seigneur, répondez à une seule question ${ }^{263}$ et je vous montrerai tout ce qu'il en est en réalité. Le roi Dèce qui était dans cette ville, où est-il ? » Alors l'évêque Mares lui dit : «Mon fils, il n'y a pas aujourd'hui de roi du nom de Dèce [fol. 129'] si ce n'est un (roi) qui est mort mais voilà plusieurs années et générations ». Alors Jamblique répondit et dit, le visage contre terre ${ }^{264}$ et en pleurant: «Mon seigneur, alors je suis pris de vertiges et aucun homme ne croira mon propos! Venez avec moi et je vous montrerai mes compagnons qui (sont) sur la montagne Onchelos. Vous apprendrez d'eux, aussi bien que de moi (ce qu'il en est). Je sais que nous avons fui devant le roi Dèce, que nous sommes (restés) là-bas pendant de nombreux jours et qu'au soir j'ai vu que le roi Dèce était entré dans cette ville, Ephèse. Si cette ville est bien Ephèse... Je ne sais pas!» Alors l'évêque Mares réfléchit en son for intérieur et dit: "(C'est) une sorte de révélation que Dieu nous a montrée par l'intermédiaire de ce garçon, mais allons voir!» L'évêque Mares prit une monture ${ }^{265}$, de même que le proconsul, ainsi que la foule (des habitants) de la ville, avec les grands et tous les nobles, puis ils montèrent vers la caverne qui se trouve sur la montagne Onchelos. Lorsque les confesseurs virent que le jeune homme, Jamblique, tardait inhabituellement ${ }^{266}$, ils dirent : «Peutêtre qu'il a été pris par quelqu'un (qui) l'aura conduit chez le roi ? » Et alors qu'ils pensaient ainsi ${ }^{267}$, l'écho $^{268}$ d'une troupe de nombreux cavaliers qui montaient en direction de la caverne leur parvint. Ils pensèrent donc que c'étaient les soldats du roi qui avaient été envoyés pour emmener les saints et aussitôt ils se mirent à genoux ${ }^{269}$, prièrent et se scellèrent du signe de la croix. Ils se saluèrent mutuellement en disant : "Que la force qui est descendue avec les trois jeunes gens dans la fournaise de Babylone entre avec nous devant le roi ${ }^{270}$ !» Et alors qu'ils pensaient cela en s'asseyant dans la caverne, l'évêque Mares arriva à l'entrée de la caverne, ainsi que le proconsul et la foule qui les accompagnait. Lorsqu'ils arrivèrent à la caverne, Jamblique les précéda ${ }^{271}[$ fol.

${ }^{262}$ Expression biblique cf. Nb 16,4 et 1 R 18,7.

263 «... dites-moi une chose que je vous demande...».

264 «... posé contre terre... ».

265 «... se leva sur des montures... » Le verbe est au singulier; lorsqu'il y a plusieurs sujets, le verbe peut s'accorder avec le plus rapproché.

266 «... plus que l'habitude de chaque jour...».

267 «... ces choses...»».

268 «... le bruit...».

269 «... posèrent le genoux... ».

270 On trouve également une allusion aux jeunes gens de la fournaise dans $D$ (cf. Dn 3). Le verbe حمل est corrigé en سحمل dans l'édition car le verbe de la proposition relative hus (dont le sujet est reve) est à la troisième personne du singulier.

${ }^{271} B S:$ «... il les précéda en gémissant dans son cœur. Les larmes lui coulaient des yeux. Lorsque les confesseurs virent qu'il pleurait, eux aussi élevèrent une voix pleine de sanglots et l'interrogèrent au sujet de tout ce qui lui était arrivé. Jamblique leur dit tout ce qui s'était passé. Alors les bienheureux comprirent qu'ils avaient dormi et qu'ils étaient restés au repos durant de longues et 
$129^{b}$ ] auprès des confesseurs (ensuite) l'évêque Mares entra ${ }^{272}$. Et en entrant par la porte de la caverne, il trouva dans l'angle droit de la porte ${ }^{273}$, un coffre ${ }^{274}$ de cuivre sur lequel étaient posés des cachets d'argent. Il le souleva et se tint sur le seuil ${ }^{275}$ pour (en) lire (le contenu) aux nobles et aux grands de la ville, en leur présence et en présence du proconsul. Il ôta les sceaux, ouvrit et trouva deux tablettes de plomb sur lesquelles il était écrit ceci : «Devant le roi Dèce ont fui les confesseurs Maximilien fils de préfets, Martimos, Dionysios, Sérapion, Johannis, Constantin, Jamblique et Antoninos, ceux sur qui cette caverne a été fermée par ordre de Dieu ». Leur confession était écrite sur des tablettes qui (se trouvaient) en-dessous et lorsqu'on eut lu ces inscriptions, on s'émerveilla et on glorifia Dieu pour le miracle qu'il avait montré à ses serviteurs, et toute la foule cria d'une voix de louange.

18. Ils entrèrent et trouvèrent ces confesseurs assis dans un coin de la caverne. Leurs visages étaient semblables à des roses fraîches. Mares et le proconsul tombèrent à terre et les vénérèrent, ainsi que les grands et les masses entières en glorifiant Dieu, leur Seigneur parce qu'ils avaient été jugés dignes de voir cette vision miraculeuse et parce qu'ils avaient attesté avoir parlé avec eux de tout ce qui était arrivé au temps de Dèce. L'évêque Mares informa les juges et les grands de la ville et aussitôt, on envoya des émissaires auprès du roi Théodose: «Vite! Que ta Majesté vienne voir [fol. $130^{a}$ ] les grands miracles que Dieu a réalisés sous ${ }^{276}$ ton règne! En effet, la lumière de la promesse de la vie a brillé pour nous de la poussière, car la résurrection de la vie à partir de la tombe a rayonné des splendides corps des croyants qui ont été restaurés ». Le roi Théodose, apprenant la nouvelle $e^{277}$, se leva du sac et de la cendre sous lesquels il était couché et l'esprit du victorieux fut apaisé. La peau de son visage s'éclaira, il tendit les mains vers le ciel et dit: "Je te loue, Christ, Seigneur du ciel et de la terre! Car du soleil de justice ${ }^{278}$, une lumière venant de toi s'est levée pour nous : la lampe de ma confession ne s'est pas éteinte d'entre les lampes de mes pères ${ }^{279}$, le sceau de ma foi ne s'est pas

nombreuses années et qu'en guise de signe et de miracle, le Christ les avait réveillés à cause de la division d'opinion de ceux qui ne croient pas en la résurrection des morts... ».

272 Allusion à l'arrivée de Jean au tombeau, suivi de Pierre cf. Jn 20,3 et sq.

273 « ... dans l'angle de la porte, à droite... ».

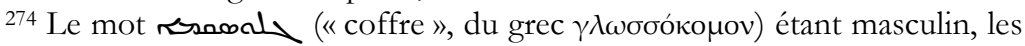
suffixes de حلف ("sur lequel») et ("il le souleva ») doivent être masculins (voir édition).

275 « ... à la porte, à l'extérieur...».

276 «... aux jours de...».

277 «... Lorsqu'il entendit (cela)...».

278 Expression tirée de Ml 3,20 : "Pour vous qui craignez mon nom, le soleil de justice se lèvera portant la guérison dans ses rayons...". Dans le texte, ce nom n'est pas appliqué au Christ. La leçon de $S$ donne : «...car du soleil de ta justice, la lumière de tes miséricordes s'est levée sur moi...».

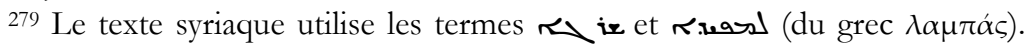
Dans l'Ancien Testament, la lampe des méchants est éteinte par châtiment cf. Pr 13,9 et 24,20. La lampe allumée symbolise la continuité dynastique, cf. $2 \mathrm{~S}$ 21,17 ; 2 R 8,19; 2 Ch 21,7. 
terni et il n'est pas tombé de la couronne pure de Constantin, le roi croyant!». A cette nouvelle ${ }^{280}$, les évêques, les grands et (les habitants de) la ville arrivèrent et montèrent auprès des confesseurs à la caverne qui se trouve sur la montagne Onchelos. Les confesseurs qui étaient dans la caverne se précipitèrent au-devant du roi et en le voyant, la peau de leur visage s'éclaira. Le roi entra et tomba à leurs pieds. Il les embrassa et pleura à leur cou. Il s'assit devant eux dans la poussière ${ }^{281}$. Il les regardait et glorifiait Dieu. Comme son cœur résonnait de louange, il leur dit : «En vous voyant, c'est comme si je voyais le Christ Roi quand il a appelé Lazare et que (ce dernier) sortit du tombeau. Comme si j'entendais déjà sa voix lors de son glorieux avènement, lorsque les morts entendront sa voix et se lèveront sans délai ${ }^{282} »$. Maximilien dit au roi: "A présent, demeure en paix dans l'intégrité de ta foi, et Jésus, le Christ, Fils de Dieu, préservera ton royaume des troubles du malin; et crois que notre Seigneur nous a réveillés à cause de toi [fol. $\left.130^{b}\right]$ avant le grand jour de la résurrection. Comme l'enfant endormi qui est dans le sein de sa mère, est insensible au mépris, à l'honneur, à l'orgueil, à la faim, et lorsqu'il vit, ne sent ni la vie ni la mort, de la même façon nous sommes demeurés et avons dormi, comme des dormants sans inquiétude $»$.

19. Sur cette parole, alors que le roi, les évêques et les notables les regardaient, ils furent pris de sommeil, se couchèrent, posèrent la tête sur le sol et rendirent l'âme par ordre de Dieu. Le roi se leva en pleurant et étendit sur eux ses habits royaux. Le roi s'empressa d'ordonner qu'il y eût huit coffres en or pour leurs corps. (Mais) la nuit-même, le roi eut une vision en rêve lui disant $^{283}$ : «Nos corps ont été ressuscités de la poussière, non pas de l'or, ni de l'argent. Aussi, laisse-nous à notre place, sur le sol, ici, dans (cette) même caverne ». Alors, le roi ordonna que sur le champ on érigeât des mosaïques (sur une stèle) en bois ${ }^{284}$ et en or en-dessous (des corps, et) on les laissa à leur place jusqu'à aujourd'hui. Il y eut une grande fête et une commémoration pour les confesseurs lors d'un important rassemblement d'évêques. Le roi fit une large aumône en faveur de tous les pauvres du pays et libéra les évêques qui étaient emprisonnés ${ }^{285}$, et dans la joie de la foi $^{286}$ (du roi Théodose), les évêques se rendirent avec lui à Constantinople en glorifiant Dieu pour le miracle qu'ils avaient vu, (miracle) qui par la prescience et la volonté de Dieu a été ac-

$280 \ll \ldots$ ayant appris (cela)...»».

281 «... sur la poussière du sol... ».

282 Allusion à Jn 5,25 et 5,28.

283 «... Ainsi lui fut-il dit...».

284 øaivess: dans SOKOLOFF (p. 753-754), on trouve les mots rinas

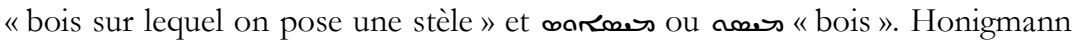

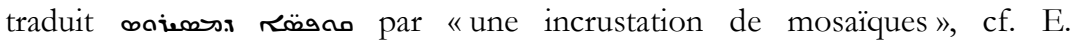
HonigmanN, "Stephen of Ephesus and the Seven Sleepers » (Studi e Testi 173), Vatican, 1953, p. 134.

285 «... emprisonnés dans les prisons...».

286 «... de sa foi...». 
cordé avant l'heure ${ }^{287}$ à cause des hérétiques dans la foi et (à cause de) ceux qui sont privés de la vie (éternelle) ${ }^{288}$, pour détruire les séducteurs hérétiques dans le cœur, et pour couronner ${ }^{289}$ les croyants. [fol. 131'] Car dans sa bonté et ses miséricordes, il élèvera la corne ${ }^{290}$ de son Eglise couronnée ${ }^{291}$ : il nous a accordé la vision des confesseurs pour confondre les hérétiques ${ }^{292}$, ceux qui nient la résurrection, et il aidé la faiblesse de leur foi (en leur donnant $)^{293}$ en exemple la résurrection des justes; et il traitera de la même façon notre faiblesse ${ }^{294}$ : à son avènement ${ }^{295}$ il sortira avec les confesseurs, renversera tous les cultes de la terre et n'assoira pas l'opinion de ceux qui pervertissent la saine doctrine de l'Evangile. Et tout ce qui ne marche pas sur les traces des apôtres sera perdition. Ainsi, Dieu, celui qui nous a donné la bonne espérance de la résurrection d'entre les morts par le témoignage des confesseurs et nous a affermis dans notre foi, élèvera la corne des croyants en tout lieu. Celui dont la divinité est digne de gloire sur toute la terre ${ }^{296}$. Maintenant, en tout temps et de toute éternité. (Ici) s'achève (l'histoire) des fils d'Ephèse.

\section{Etude des variantes majeures du ms Cambridge Syr. Add. 2020}

Il s'agit maintenant de déterminer la place qu'occupe le manuscrit Cambridge Syr. Add. 2020 dans l'ensemble de la tradition manuscrite syriaque des Dormants. L'inventaire des témoins sera suivi d'une présentation des familles de textes et des témoins utilisés pour l'analyse; viendra ensuite l'analyse des variantes qui permettra de situer $J$.

\section{Les manuscrits}

L'histoire des Dormants en syriaque est conservée dans une dizaine de témoins s'étalant entre le $5^{\mathrm{e}}$ et le $19^{\mathrm{e}}$ siècle :

$\mathrm{A}=$ Leningrad, N.S.4, parchemin, fin du $5^{\mathrm{e}}$ siècle/début $6^{\mathrm{e}}$, écriture estrangela. Le manuscrit est composé d'une série de quinions

287 « ... a été prédéterminé et accordé... ».

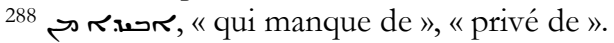

289 «Couronner» dans le sens de « honorer», cf. Ps 8,6.

290 «Elever la corne » est une expression biblique signifiant « élever la puissance ", cf. Ps 92,10; 1 S 2,10.

${ }^{291}$ La couronne est ici une marque de puissance, cf. Ez 21,26.

292 « ... pour la confirmation des hérétiques... ».

293 «... par l'exemple de...».

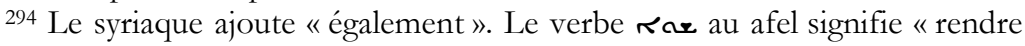
digne de, accorder» mais ici, il a le sens de «traiter de la même façon » cf. PAYNE-SMITH (autres sens : « aplanir », « égaliser »).

295 « . . a au devant de lui... ».

296 «... Celui à la divinité duquel la gloire est due par toutes les puissances....». 
dont plusieurs sont incomplets. Il a été décrit avec précision par Pigulevskaja $^{297}$ et van Esbroek ${ }^{298}$. Il s'agit d'un recueil d'histoires de saints qui contient la Doctrine d'Addä̈, la Doctrine de Pierre, l'Histoire de Jean d'Ephèse, l'Invention de la Croix, le Martyre de Judas Cyriaque, la Vie de Grégoire le Thaumaturge et la Vie de Basile. Le texte des Dormants se trouve aux fol. $92^{\mathrm{a}}-101^{\mathrm{a}}$ mais il est mutilé, avec une lacune de huit feuillets. Il n'a pas fait l'objet d'une édition.

$\mathrm{B}=$ Berlin, Sachan 222, papier, $19^{\mathrm{e}}$ siècle, écriture syro-orientale, 570 folios. Il contient 27 textes, des vies de saints et de martyrs dont les Actes de Thomas, les Actes de Mar Mari, l'Histoire des Martyrs de Karka de Beth Selokh, les Martyrs Himyarites, les Actes de Thècles, l'Histoire de Hormid\%. Celle des Dormants se trouve aux fol. 179'$186^{\mathrm{b}}$. Le manuscrit a été écrit à Alqoš dans le couvent de Rabban Hormidz $z^{299}$. Il a été collationné par P. Bedjan ${ }^{300}$.

$\mathrm{C}=$ Londres, Br. Libr., Add. 14650, parchemin. Le manuscrit est composé de 235 feuillets dont la plupart sont sales et déchirés. Les fol. 1 à 8 et 30 à 60 sont écrits en estrangela et datés du $6^{\mathrm{e}} / 7^{\mathrm{e}}$ siècle. Le reste du volume est écrit en cursive et daté de $875^{301}$. Il s'agit d'un codex mixte qui contient entre autres des écrits d'Evagre, des extraits de l'Histoire lausiaque de Pallade, des vies de saints et des extraits de l'Histoire Ecclésiastique de Jean d'Ephèse. Le texte des Dormants, inclus dans les vies de saints, se trouve aux fol. $81^{\mathrm{b}}-89^{\mathrm{a}}$. Le manuscrit a été collationné par I. Guidi ${ }^{302}$.

$\mathrm{D}=$ Vatican, Syr. 162, parchemin, $9^{\mathrm{e}}$ siècle, écriture estrangela. Le manuscrit est composé de 179 folios dont 173 sont en possession de la Bibliothèque Vaticane ${ }^{303}$ et 6 (les folios 2 à 7) de la British Library, cf. le manuscrit $A d d .14665$ décrit par Wright ${ }^{304}$. Les 123 premiers folios du Vat. 162 sont un palimpseste daté du $8^{\mathrm{e}}$ siècle. Ils contiennent des fragments de la Septante; les autres folios ( $9^{\mathrm{e}}$ siècle) comportent la Chronique de Pseudo-Denys de Tellmabré ou Chronique de Zuqnin. Le texte des Dormants débute au fol. $37^{\mathrm{b}}$ et s'arrête au fol. $39^{\mathrm{b}}$ (jusqu'à la mort de Dèce). Il reprend au fol. $55^{\mathrm{b}}$ et s'achève au fol. $58^{\mathrm{b}}$. Il a été utilisé par O. F. Tullberg $^{305}$ et $\mathrm{P}$. Bedjan ${ }^{306}$ pour la première partie du récit, et par J.-B.

297 N.V. Pigulevskaja, «Katalog sirijkih rukopisej Leningrada », dans Palestinskij Sbornik 6 (69) (1960), p. 142.

298 M. VAN ESBROEK, «Le manuscrit syriaque nouvelle série 4 de Leningrad ", dans P. CRAMER (éd.), Mélanges Antoine Guillaumont. Contributions à l'étude des christianismes orientaux (Cahiers d'orientalisme 20), Genève, 1988, p. 211-219.

${ }^{299}$ SACHAU, Verzeichnis der Syrischen Handschriften, p. 289-291.

${ }^{300}$ P. BEDJAN, AMSS, tome 3, Paris, 1892, p. 528-534.

301 Wright, Catalogue, p. 1103-1107.

302 I. GUIDI, «Bemerkungen zum ersten Banden der syrischen Acta Martyrum et Sanctorum », dans ZDMG 46 (1892), p. 749-750.

303 Assemani, Bibliotheca orientalis Clementino-vaticana, p. 129.

304 Wright, Catalogue, p. 1119.

305 O.F. TuldBerg., Dionysii Telmaharensis Chronici liber primus, Uppsala, 1851, p. $166-177$.

${ }^{306}$ P. BEDJAN, AMSS, tome 1, Paris, 1890, p. 302-311. 
Chabot $^{307}$ dans son intégralité.

$\mathrm{E}=$ Londres, Br. Libr., Add. 14641, parchemin. Le manuscrit est composé de 171 feuillets dont la plupart sont mutilés ${ }^{308}$. La majeure partie, jusqu'au folio 131, est écrite en estrangela ( $6^{\mathrm{e}}$ siècle) ; le reste est de la main d'un autre scribe $\left(10^{\mathrm{e}} / 11^{\mathrm{e}}\right.$ siècle). Le contenu consiste essentiellement en des vies de saints et de martyrs, dont l'histoire des Dormants aux fol. $150^{\mathrm{a}}-157^{\mathrm{a}}$. Il s'agit du texte inséré dans l'Histoire ecclésiastique de Zacharie le Rhéteur. Les variantes du ms ont été collationnées par A. Allgeier dans son appa$\mathrm{rat}^{309}$.

$\mathrm{F}=$ Tubingen, Or. Quarto 1051, papier, $18^{\mathrm{e}}$ siècle, écriture syroorientale $^{310}$. Le manuscrit a été en possession de Mingana, de la Staatsbibliotheek de Berlin, puis la bibliothèque de Tubingen ${ }^{311}$. Il est composé de 237 folios, dont certains sont manquants. Ecrit en 1705 à Alqoš, il contient une collection de vies de saints. Le texte des Dormants se trouve aux fol. $11^{\mathrm{a}}-21^{\mathrm{b}}$. Il n'a pas été édité.

$\mathrm{L}=$ Londres, Br. Libr., Add. 12160, parchemin, deuxième moitié du $6^{\text {e }}$ siècle, écriture estrangela ${ }^{312}$. Le manuscrit est composé de 77 feuillets. Il contient des discours et quelques vies de saints : la Vie d'Abraham Kidunaya, la Vie de Julien Saba, la Vie d'Alexis, l'Histoire de l'evêque Paul et l'histoire des Dormants qui commence au fol. $147^{a}$ et se termine au fol. $151^{\text {a }}$. Le manuscrit a été édité par I. Guidi ${ }^{313}$. Il s'agit de la deuxième partie du récit dont le début est manquant (le chapitre 11 de notre édition). Cette lacune a été comblée par la ms C (fol. $85^{\mathrm{a}}-85^{\mathrm{b}}$ ).

$\mathrm{S}=$ Berlin, Sachau 321, parchemin, $8^{\mathrm{e}}$ siècle, écriture estrangela. Le manuscrit est composé de 189 folios. La plupart des textes sont des traductions du grec (Athanase le Grand, Théophile d'Alexandrie, Zacharie le Scholastique, Théodoret...) mais le manuscrit contient également, comme l'indique Sachau ${ }^{314}$, des biographies, des écrits monophysites, la Doctrine des apôtres, ainsi que le récit des Dormants aux fol. $179^{\mathrm{b}}-186^{\mathrm{b}}$. Le manuscrit a été édité par A. Allgeier ${ }^{315}$.

$\mathrm{P}=$ Paris, BNF, Syr. 235, papier, $13^{\mathrm{e}}$ siècle, écriture syroorientale ${ }^{316}$. Le manuscrit est composé de 341 feuillets dont plu-

307 J.-B. CHABOT, Incerti auctoris Chronicon pseudo-Dionysianum vulgo dictum, Textus I, ser. 3, CSCO 91, 1927, p. 135-144 et 195-206.

308 Wright, Catalogue, p. 1042-1046.

309 A. AlLGEIER, «Die älteste Gestalt der Siebenschläferlegende », OC 7/8 (1918), p. 33-87.

310 ASSFALG, Syrische Handschriften, p. 49.

311 A. DesReumaux, Répertoire des bibliothèques et des catalogues de manuscrits syriaques, Paris, 1991, p. 100.

312 Wright, Catalogue, p. 1090-1092.

313 I. GUIDI, Testi orientali..., p. 376-384.

314 SACHAU, Verzeichnis der Syrischen Handschriften, p. 94-101.

315 A. AllGEIER, «Die älteste Gestalt der Siebenschläferlegende », OC 6 (1916), p. 1-43.

${ }^{316}$ H. ZOTENBERG, Catalogue des manuscrits syriaques et sabéens (mandaïtes) de la Bibliothèque Nationale, Paris, 1874, p. 185-187. 
sieurs sont manquants. Il contient une collection de vies de saints et d'histoires pieuses dont l'Histoire de Jean l'Evangéliste à Ephèse, l'Histoire de Saint Alexis, l'Histoire d'Ephrem le Syrien et l'histoire des Dormants. Le texte est complet: fol. $326^{\mathrm{a}}-336^{\mathrm{b}}$. A. Allgeier a collationné les variantes du ms dans son apparat ${ }^{317}$ et $\mathrm{B}$. Ryssel en a donné une traduction en allemand ${ }^{318}$.

$\mathrm{Z}=$ Londres, Br. Libr., Add. 17202, parchemin, fin du 6 $/$ début du $7^{\mathrm{e}}$ siècle, écriture estrangela, 193 feuillets dont la plupart sont sales et déchirés ${ }^{319}$. Il contient L'Histoire ecclésiastique de Zacharie le Rhéteur. L'histoire des Dormants se trouve aux fol. $49^{\mathrm{b}}-58^{\mathrm{a}}$. Le manuscrit a été édité par J. P. N. Land ${ }^{320}$ et E. W. Brooks ${ }^{321}$.

\section{Les familles de texte}

La recherche sur la tradition syriaque des Dormants, menée principalement par Allgeier et van Esbroeck ${ }^{322}$, a permis de mettre en évidence cinq familles de textes : celle représentée par le seul ms $A$, et les quatre groupes $Z E, D C L, F B$ et $S P$.

Le codex $A$ est le plus ancien témoin mais il est gravement mutilé. Van Esbroek, qui en a fourni une étude détaillée, défend l'idée qu'il serait à la base de tous les autres manuscrits.

Les manuscrits $B$ et $F$ constituent une seconde famille. Il n'est pas impossible, d'après Sims-Williams ${ }^{323}$, que $B$ soit même une copie de F. La conclusion n'étant pas certaine, $B$ peut être conservé dans l'analyse. Cette famille de textes se rapproche davantage de DCL: on y trouve la même introduction, les mêmes tournures de phrases et le même vocabulaire ; mais elle s'en écarte en raison de deux ajouts : dans la conclusion où elle rejoint $P$ et dans une description des jeunes gens avant leur découverte où elle rejoint $S$ et $P$. Ce groupe joue un rôle intermédiaire entre les groupes $S P$ et $D C L$.

Le groupe constitué par les mss DCL: il s'agit de l'histoire des Dormants incluse dans la Chronique de Pseudo-Denys de Tellmabré. Le texte connait une division en deux parties en fonction de la chronologie : la première partie du récit est rapportée sous le règne de Dèce et la seconde, sous celui de Théodose. Ce groupe est cohérent d'un point de vue de la longueur mais souvent divergent dans les détails. $D$ et $C$ ne divergent presque pas ; cependant, par endroits, $D$ rejoint $E$ là où ce même témoin diverge de $Z$. De plus, là où $D C L$ présente une lacune, celle-ci se trouve également dans

317 Voir note 308.

318 B. RYSSEL, « Syrische Quellen abenländischer Erzälungsstoffe. Der Pariser Text der Siebenschläferlegende », dans Archiv SSL 94 (1895), p. 372-388.

319 Wright, Catalogue, p. 1046-1061.

320 J.P.N. LAND, Zachariae Episcopi Mitylenes aliorumque scripta bistorica graece plerumque deperdita, dans Anecdota Syriaca, tome 3, Brill/Leiden, 1870, p. 87-99.

321 E.W. BROOKS, Historia ecclesiastica Zacharias Rhetori vulgo adscripta, CSCO

83, Textus I, Louvain, 1953, p. 106-121.

322 Voir notes 7 et 8.

323 Cité par M. VAN ESBROEK, La légende..., p. 193. 
ZE mais jamais le contraire.

Le groupe formé par les mss $S P$ représente la version longue. $S P$ forme un groupe indépendant des autres en raison d'ajouts, d'omissions et de certaines particularités doctrinales. Ces dernières concernent surtout la christologie : le Christ est «Dieu de Dieu », «Lumière de Lumière »; il « vient du Père » et il a « revêtu un corps ». Cette dernière expression appartient aux débats christologiques du $5^{\mathrm{e}}$ siècle et renvoie aux querelles concernant l'incarnation. Il semble que cette version du récit entend également contester les tenants de la non corporalité du Christ (les docètes et les eutychianistes). A côté de cela, le rédacteur tente de transmettre le credo de Nicée : "Nous avons un Dieu caché dont sont remplis les cieux et la terre. A lui et à son Fils qui a été envoyé au monde par lui, et à l'Esprit saint avec lui, Trinité indivisible...».

$P$ reproduit presque mot à mot $S$ et il contient les mêmes fautes d'orthographe. Pour Allgeier, $P$ dépend directement de $S$ qu'il considère comme le témoin le plus ancien.

Le groupe $Z E$ forme une version indépendante, celle de Zacharie le Rhéteur. C'est le texte le plus court. Il se rapproche davantage des versions éthiopienne et copte que des autres versions syriaques. Il présente plusieurs particularités :

- $\quad$ il se présente sous forme d'hypomnemata ;

- il commence par une introduction plus longue ;

- il compte sept dormants, alors que tous les autres témoins en dénombrent huit ;

- il cite des noms différents: Achillidos, Diomedos, Eugenios, Stephanos, Probatos, Sabbatios et Kuriakos. Comme le souligne Peeters, ces noms sont identiques à ceux rapportés par un pèlerin du nom de Théodose $\left(6^{\mathrm{e}}\right.$ siècle); on les retrouve également dans une ancienne version copte ainsi que dans la tradition éthiopienne ${ }^{324}$;

- il utilise des expressions et des tournures de phrases différentes des autres groupes;

- il est le seul à identifier l'hérésie dont il est question sous le règne de Théodose, à des conceptions attribuées à Origène : «à partir des écrits d'Origène sur la corruption du corps » on disait que « les éléments (du corps) lorsqu'ils se disloquent, se (re)composent avec le reste des uns et des autres éléments plus grands, et que (le corps) ne ressuscite pas; (ils disaient) aussi que les éléments se mélangent comme si le corps de chacun de nous reconnaissait son original dans la résurrection; cependant (le corps) était seulement une apparition spirituelle, comme la transfiguration de notre Seigneur Jésus-Christ, de Moïse et d'Elie sur

324 P. PeEters, «Le texte original de la Passion des Sept Dormants », dans $A B 41$ (1923), p. 370. 
le mont (Thabor)... ${ }^{325} »$. Le texte syriaque reste obscur : il est question d'une sorte de métempsychose ${ }^{326}$.

Les relations entre les témoins se présenteraient donc comme suit :

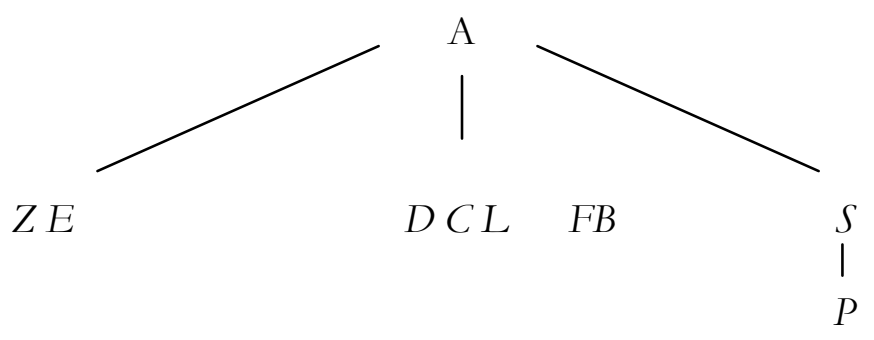

C'est à l'intérieur de ce cadre qu'il faudra situer le manuscrit $J$. En attendant une édition critique qui prendrait en compte la totalité des témoins (dont $A$, considéré par van Esbroeck comme le plus important), les remarques qui suivent doivent être considérées comme provisoires.

Pour procéder à la comparaison, un exemplaire représentatif de chacune des familles de textes a été sélectionné. Un premier critère pratique a guidé le choix : nous avons retenu les témoins dont les éditions permettaient de retrouver le détail du texte. Par ailleurs, nous avons pris en considération la relative parenté des familles de textes et omis les manuscrits qui appartenaient à un groupe clairement indépendant. Ainsi nous ne reprendrons ni le groupe $Z E$ en raison de sa singularité, ni $A$ pour lequel il n'existe pas d'édition. Ont donc été retenus les groupes $B F, D C L$ et $S P$, et pour chacune des familles, les manuscrits $B, D$ et $S$. Les éditions que nous avons utilisées sont les suivantes ${ }^{327}$ : pour $B$, nous avons été tributaires de la collation réalisée par Bedjan dans son supplément paru dans $A M S S$; pour $D$, de la même publication pour la première partie du texte et de l'édition de Chabot pour la deuxième partie ; enfin, pour $S$ nous avons utilisé l'édition d'Allgeier.

\section{Le texte de J}

L'analyse qui suit distingue variantes significatives et variantes majeures. Dans la catégorie des variantes significatives sont rangées les variations qui concernent le libellé du texte syriaque (titre

325 Pour le texte syriaque, cf. E.W. BROOKs, op. cit., p. 115.

326 Une confusion dans la terminologie utilisée dans le Traité des principes d'Origène serait à l'origine de la mauvaise compréhension de ses conceptions sur la résurrection des corps : $\sigma \chi \eta \dot{\mu} \mu \alpha \tau \alpha$, synonyme de ع̌́cદı mot qui au singulier « exprime la forme extérieure, l'état de la substance » dont « la qualité est soumise au changement » serait mis sur le même pied que cĩos qui signifie « apparence extérieure. » cf. H. CROUZEL et M. SIMONETTI, Traité des principes, Origène. Commentaire et fragments, (Sources chrétiennes 253), Paris, 1978, p. 227 228.

326 P. BEDJAN, AMSS, tome 3, Paris, 1892, p. 528-534.

327 Voir les références supra. 
de l'œuvre, variantes lexicales et morphologiques); les variantes majeures regroupent les ajouts et les omissions. Les variantes mineures, celles qui affectent l'orthographe - et elles sont nombreuses en $J$ par rapport aux autres témoins - ne seront pas ici signalées. Mentionnons seulement l'emploi fréquent que le copiste fait des abréviations ${ }^{328}$.

\section{Les variantes significatives}

Le titre est différent dans les quatre manuscrits. Cependant, $J$ rejoint $B$ qui donne le même terme, rhas.sos ("confession»), alors que $D$ parle de rhurd ("histoire») et $S$ à la fois de रhausas ("confession») et de swas ("résurrection»). Les noms propres des huit jeunes gens sont identiques dans BDJS, avec des variantes orthographiques et parfois une inversion dans l'ordre des noms.

Il a été dit plus haut (cf. les familles de texte) que le groupe $B F$ jouait un rôle intermédiaire entre $D C L$ et $S P$, mais de manière générale $B$ suit $D$. Par rapport à ces deux témoins, $J$ présente des variantes qui relèvent du vocabulaire et de l'emploi de mots synonymes qui correspondent généralement à $S$. Toutefois, ce denier a également recours à un lexique différent par endroits. En voici quelques exemples $^{329}$, sans viser à l'exhaustivité. Dans $J, 6,6$, on a

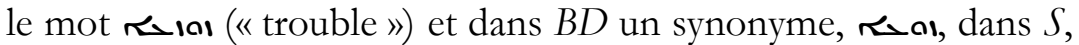
un troisième correspondant qui a le même sens : ๔几а. Dans $J$ 8, 1 "en tout temps 》 et dans BD حصلح. Dans J 9, 8, on a "dans son cœur", la leçon de BD indique mheniło "dans son esprit", dans $S$ on trouve un synonyme de $B D:$ : כi Dans $J, 10,4$ on trouve ishos ("sera fermé ») et dans $B D$, une autre racine à la même forme et au même temps, iح sans BDS 8, 11: : (" ot ils retournent») alors que $J$ donne sens). Ces différences de vocabulaire consistent également en des choix de mots empruntés tantôt au syriaque, tantôt au grec : $J 9,5$

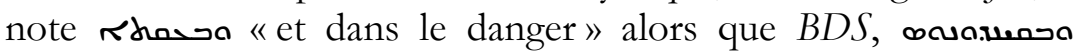

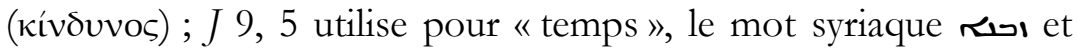

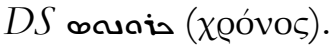

Les variantes morphologiques sont nombreuses. En voici quelques illustrations :

- 1, 7: dans $J$, טרשت participe passif peal m. p. et dans $B$, anm forme au $\mathrm{m}$. p. suivie de l'auxiliaire.

- 2, 2: anm raxo dans $J$ et cosidiro au etpaal dans $B S$; anm s sis, part. afel m. p. suivi de l'auxiliaire dans J et widir au etpeel dans $B D S$.

328 De son côté $D$ omet régulièrement les lettres quiescentes de la $3^{\mathrm{e}} \mathrm{p} . \mathrm{m}$.

${ }^{329}$ Les références des exemples cités mentionnent le numéro du chapitre de l'édition et le numéro de la ligne. 
- 3,8: arsosh au peal ("ils furent étonnés ») dans J, arssdidir au etpaal dans $D$ (« ils s'étonnèrent »).

- $8,3:$ : 3 ir parfait afel 3 m. p. dans $J$; @ i parfait peal à la même personne dans $D$.

- 16, 28 : 甘a dans J et 甘adu dans BDS.

Les variantes morphologiques peuvent également impliquer des variantes d'un point de vue de la syntaxe, par exemple dans $J$ 1, 6: anm art (" et ils sacrifiaient») participe pael m. p. avec auxiliaire pour exprimer l'imparfait en français ; $B$, ר. parfait pael dans une proposition circonstantielle de but ("pour qu'ils sacrifient »).

\section{Les variantes majeures}

\section{- Omissions dans J}

Quatre passages ne se retrouvent pas dans $J$ contre $B D S$ : les tortures infligées aux chrétiens sont plus développées en $B D S: 3$, 3 (cf. traduction, note 115) ; $B D S$ mentionnent explicitement que les jeunes gens sont attachés au service du palais : 3, 28 (cf. traduction, note 129) ; en $B D S$, Jamblique se rend en ville non seulement pour s'informer des événements mais également pour distribuer des aumônes : 6, 17 (cf. traduction, note 163) ; le travail des ouvriers qui ouvrent la caverne est décrit avec davantage de précision en $B D S: 12,11$ (cf. traduction, note 205).

\section{- Omission et ajout communs à J et D}

On trouve dans $B$ et $S$ une description des jeunes gens avant leur découverte par la population sous Théodose (17, 26 cf. traduction, note 270). Ce passage ne se retrouve ni dans $J$ ni dans $D$. De plus, $D$ et $J$ sont les seuls témoins qui mentionnent les jeunes gens dans la fournaise : ז.w. (17,20-21) : "que la force qui est descendue avec les trois jeunes gens dans la fournaise de Babylone entre avec nous devant le roi ».

\section{Ajouts et omissions communs à J, B et $D$}

$J$ rejoint $B$ et $D$ contre $S$ en trois endroits :

- celui de la description des tortures infligées aux fidèles

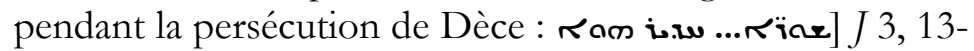
19. Cependant, ce passage présente des variantes par rapport à $B D$. On observe : a) des variantes lexicales : on a

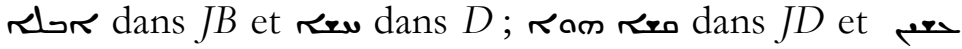
rom dans $B$. Ce sont des différences de vocabulaire mais 
les mots sont synonymes; b) deux omissions dans $D$ : une

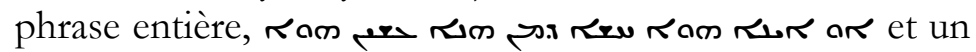
mot, , م ; c) deux omissions dans BD : rad aux lignes 17 et 18 ; c) un ajout dans $B$ : le pronom démonstratif 3 . m. p. حس ; d) une variante morphologique dans $B$ : ticipe pael au lieu du participe etpaal joint $D, J$ rejoint $B$, et tantôt encore $J$ rejoint $D$. C'est le seul passage commun à $B D J$ qui ne se retrouve pas dans $S$.

- là où on a deux ajouts dans $S$, on a deux omissions dans $B D J$; une prière avant qu'on ne dénonce les jeunes gens à l'empereur: 3, 28 (cf. traduction, note 133) et un monologue de Jamblique sur le trajet entre le marché et l'église : 16, 13 (cf. traduction, note 256).

\section{- $\quad$ Ajout commun à J, $B$ et $S$}

$J$ rejoint $B$ et $S$ à la fin du texte (cf. 19, 14-25). Cette conclusion ne se trouve pas dans $D$. On relève des variantes de différents types : a) variantes lexicales : là où $J$ rejoint $B, S$ diffère d'un point de vue du vocabulaire: : גastans $J B$ ("des croyants») et (《des confesseurs ») dans $S$; b) des variantes lexicales et syntaxiques dont ambosmos dans $J$ ("par leur témoignage ») et arshuiur dans $S$ («car par leur vision»); c) une variante morphologique : lin dans $S$, cum; d) six omissions dans $S$; e) un ajout dans $B$ :

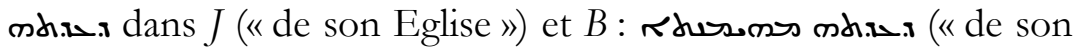

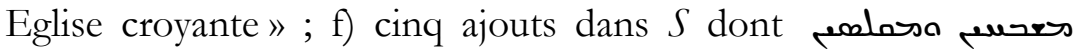
ה:Moso ("en glorifiant, en célébrant et en louant») ou encore Rhosios mhambal ("à sa divinité élevée "). J se rapproche ici davantage de $B, S$ présentant de nombreuses omissions, des variantes lexicales et morphologiques, ainsi que des ajouts.

\section{Conclusion}

Par rapport à $B, D$ et $S$, on constate que $J$ présente de nombreuses substitutions lexicales, des substitutions morphologiques, des différences de vocabulaire et des différences de formulation. Il présente certes des ajouts et des omissions communs avec les trois témoins, mais même dans ces cas-là, il s'en éloigne le plus souvent. Le groupe $S P$ reste la version la plus longue. L'examen systématique des variantes de $B, D$, et $S$ montre que $B F$ est proche de $D C L$ et que ces deux groupes rejoignent $S P$ en certains endroits. Sans doute est-il important de signaler que Peeters faisait remarquer que la totalité des leçons propres à $S$ se rencontrent dans une famille de manuscrits grecs, ce qui selon lui s'expliquerait « par la contamination de variantes propres à la tra- 
dition byzantine $»^{330}$. Les variantes de $J$ peuvent-elles s'expliquer par la traduction à partir du grec ? Cette question reste ouverte car l'intention ici était de situer le manuscrit $J$ à l'intérieur de la tradition manuscrite syriaque. Au terme de la comparaison, les nombreuses variantes (significatives et majeures) propres au ms Cambridge Syr. Add. 2020 laissent supposer que ce nouveau témoin représente une tradition distincte de l'histoire des Dormants.

\section{Abréviations bibliographiques}

$A B=$ Analecta Bollandiana, Bruxelles.

AMSS = Acta Martyrum et Sanctorum syriacae, 7 vols., Leipzig/Paris, 1890-1897.

Archiv SSL $=$ Archiv für das Studium der neueren Sprachen und Literaturen, Berlin.

Assemanus, Bibliotheca orientalis Clementino-vaticana $=\mathrm{J} . \mathrm{S}$. Assemanus, Bibliotheca orientalis Clementino-vaticana, 3 vols., Rome, 1719-1728.

Assfalg, Syrische Handschriften = J. Assfalg, Syrische Handschriften : syrische, karšnuische, christlich-palästinische, neusyrische und mandäische Handschriften, Wiesbaden, 1963.

BAILLY = A. BAILLY, Dictionnaire grec-français, Paris, 1980.

BHG = F. HALKIN, Bibliotheca hagiographica graeca, 3 vols., Bruxelles, 1957.

BHO = P. PEETERS, Bibliotheca hagiographica orientalis, Bruxelles, 1954.

BRIQUEL-CHATONNET, Manuscrits syriaques = F. BRIQUELCHAtonnet, Manuscrits syriaques de la Bibliothèque nationale de France (Nos 356-435, entrés depuis 1911), de la bibliothèque Méjanes d'Aix-en-Provence, de la bibliothèque municipale de Lyon et de la Bibliothèque nationale et universitaire de Strasbourg, Paris, 1997.

Chantraine $=$ P. Chantraine, Dictionnaire étymologique de la langue grecque : histoire des mots, 5 vols., Paris, 1968-1980.

COSTAZ = L. COSTAZ, Dictionnaire syriaque-français, Beyrouth, 1986.

CSCO = Corpus Scriptorum Christianorum Orientalium, Paris / Louvain.

$D A C L=$ Dictionnaire d'Archéologie chrétienne et de Liturgie.

$D A G R=$ Dictionnaire des antiquités grecques et romaines .

DHGE =Dictionnaire d'Histoire et de Géographie ecclésiastiques.

DTC = Dictionnaire de Théologie chrétienne.

330 P. PEETERs, «Bulletin des publications hagiographiques », dans $A B 39$ (1921), p. 176-179. 
HUBER $=$ M. HUBER, Die Wanderlegende von der Siebenschläfern: eine literargeschichtliche Untersuchung, Leipzig, 1910.

$O C=$ Oriens Christianus, Wiesbaden.

PAYNe-Smith = R. PAYNe-Smith, Thesaurus Syriacus, 2 vols., Oxford, 1879-1901.

PG = J.-P. Migne, Patrologiae cursus completus... Series Graeca..., 161 vols., Paris, 1857-1866.

$P O=$ Patrologia Orientalis, Paris.

ProsMByz = R.-J. LILIE (éd.), Prosopographie der mittelbyzantinischen Zeit. Erste Ableitung (641-867), Berlin/New York, 1999.

SACHAU, Verzeichnis der syrischen Handschriften = E. SACHAU, Die Handschriften-verzeichnisse der Königlichen Bibliothek zu Berlin, 23. Band. Verzeichnis der syrischen Handschriften, Berlin, 1899.

Sokoloff $=$ M. Sokoloff, A Syriac Lexicon. A Translation from the Latin, Correction, Expansion, and Update of C. Brockelmann's Lexicon Syriacum, Winona Lake/Piscataway, 2009.

Wright, Catalogue = W. Wright, Catalogue of Syriac Manuscripts in the British Museum acquired since the Year 1838, 3 vols., London, 1870-72.

ZDMG $=$ Zeitschrift der Deutschen Morgenländischen Gesellschaft, Berlin. 


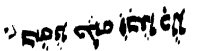

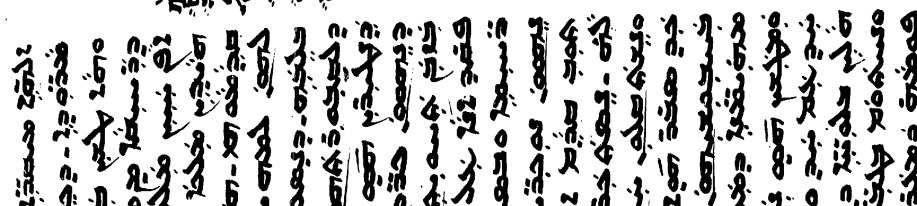

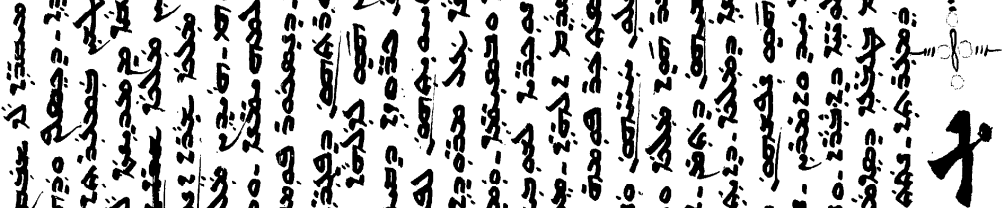
$40^{2}$

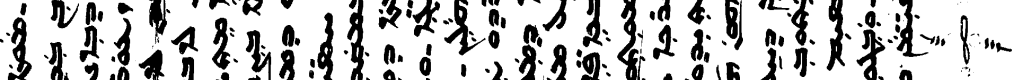

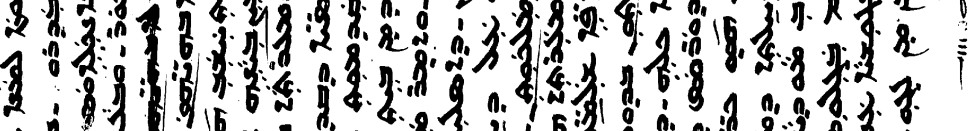
201000

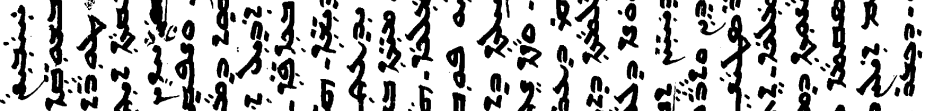

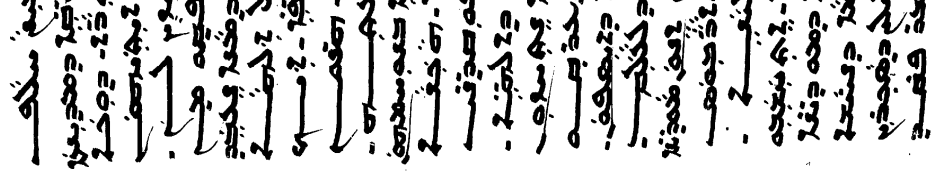

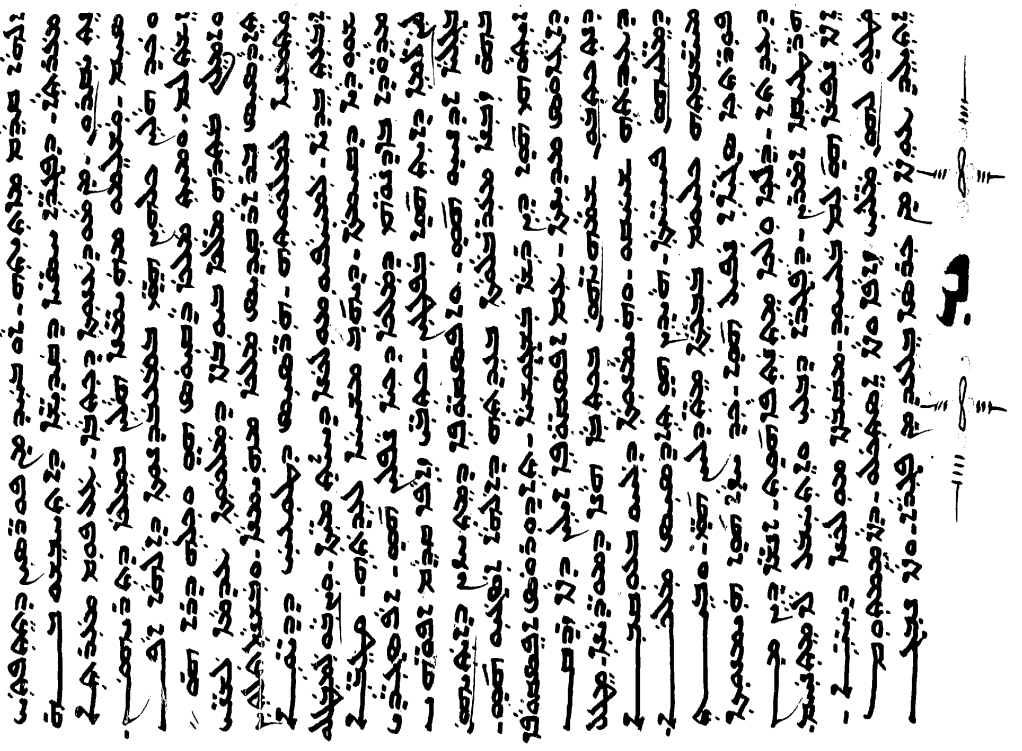

Cambridge Syr. Add. 2020 fol. $124^{\mathrm{b}}-125^{\mathrm{a}}$ 